\title{
Athletes' Perceptions of Performance
}

\author{
Brianna Elizabeth Ellis \\ Otago Polytechnic \\ Institute of Sport, Exercise and Health \\ Submitted in partial requirements for the fulfilment of \\ Master of Applied Science
}

November 1, 2021 
Form MAS8:

Declaration of Thesis Being Own Work

\section{Otago Polytechnic}

Declaration concerning Thesis presented for the degree of Master of Applied Science

I, Brianna Ellis

Of

Solemnly and sincerely declare, in relation to the thesis entitled:

Athletes' Perceptions of Performance

a. that the work was done by me personally

and

b. that the material has not previously been accepted in whole, or in part, for any other degree or diploma

Signature:

Date: 1 November 2021 


\begin{abstract}
Performance analysis is a growing field, with the aim of improving sporting performance through the examination of technical, tactical, physical, and psychological skills. With research and practice beginning to move away from the traditional approach of performance indicators, a greater understanding of athletes' perceptions is important to ensure the statistical needs of the athletes and coaching staff are still being met. This thesis aimed to explore athletes' perceptions of performance, the factors that influence performance and discuss the implications of these findings in performance analysis. A systematic review of the current literature highlighted a complex and dynamic system of sporting performance and a gap in knowledge around athletes' perceptions of performance-influencing variables. The review also revealed a lack of understanding of how athletes perceive performance analysis as a tool to improve performance. The main study of this thesis is a prospective cohort study with a focus on semi-elite netballers perceptions of their own performance. The results indicated that players experiences, and frequency of skill within a match can affect the degree in which an athlete can perceive their performance. Results from this thesis reinforces that sport is multifaceted, with multiple performance influencing factors. Further research is needed to improve the practice and evidence around performance analysis in netball.
\end{abstract}




\section{Acknowledgements}

As I am at the end of this chapter, it feels fitting to acknowledge all those who led me here and all those who have been involved.

Firstly, to my parents, accepting my lengthy period of academic study, pushing me to keep writing this 'book' as I began to fondly call it. For consistently trying to understand what it is I do, and for cheering me on always. I am eternally grateful for you.

To my partner, for putting up with my study for this long. For staying by my side and supporting me as I worked into the evenings and forgot to make dinner, and over the last 7 years in general. You are the best person to do life with.

To my friends for somehow always knowing how to support me, always encouraging, always hyping me up and never bringing me down. The ones who always replied to my messages of frustration with, "I'm proud of you" or "You got this". I appreciate you all.

And to my Supervisors. Hayden Croft, I thank you for your guidance in both this research and my career so far, giving me opportunities as an analyst and for being an expert I can always come to for advice. And Dr. Codi Ramsey, thank you for everything. For encouraging, complimenting, supporting, giving feedback, and being the calm, knowledgeable person that you are. Your unwavering faith in this project from the beginning, and consistent reassurance throughout has been a big contributor in getting me over the line.

So, thank you, thank you, thank you. To everyone who has got me here to this moment. 


\section{List of Tables}

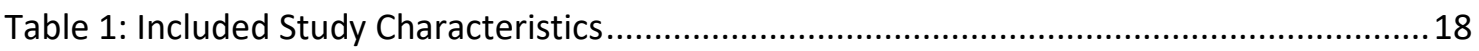

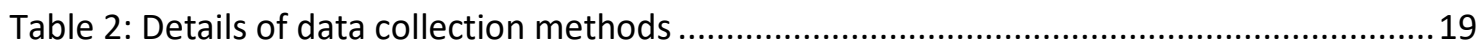

Table 3: Reported perception variables and the perceived impact on performance ..................21

Table 4: Perceived influence of the seven categories and the sub-variables on performance .23

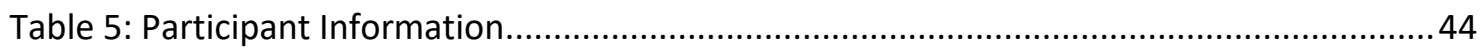

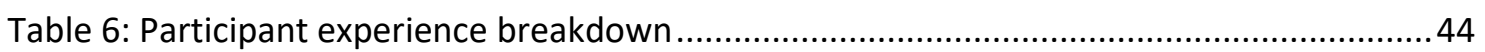

Table 7: Mean perceptions of skill difficulty prior to season commencement ........................... 45

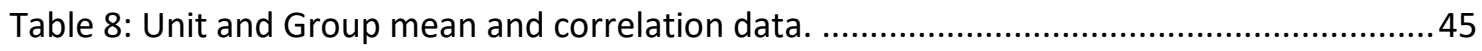

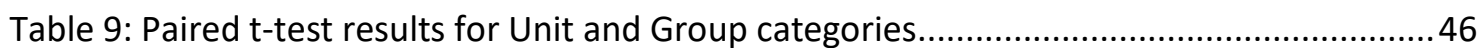




\section{List of Figures}

Figure 1: The analysis process of transforming data into knowledge .......................................4

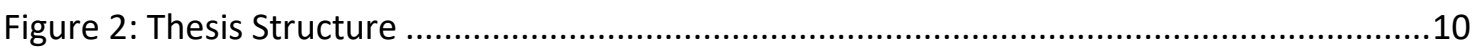

Figure 3: PRISMA flow diagram of included and excluded studies.........................................16

Figure 4: Flow chart of participant inclusion and Questionnaire completion ............................43

Figure 5: Forest plot showing the $95 \%$ confidence intervals and mean differences between perceived performance and the normalised statistic of each skill, contextualised by the mean

difference of the entire study population.

Figure 6: Forest plot showing the 95\% confidence intervals and mean differences between perceived performance and the normalised statistic by result, contextualised by the mean difference of the entire study population.

Figure 7: Forest plot showing the $95 \%$ confidence intervals and mean differences between perceived performance and the normalised statistic of each positional unit, contextualised by the mean difference of the entire study population.

Figure 8: Forest plot showing the $95 \%$ confidence intervals and mean differences between perceived performance and the normalised statistic of each experience group, contextualised by the mean difference of the entire study population

Figure 9: Venn diagram outlining the similarities and differences between findings in Chapter Two and Three .58

Figure 10: Proposed use of statistics across difference levels of experience............................61 


\section{Contents}

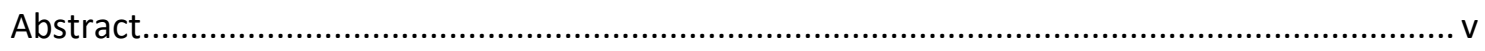

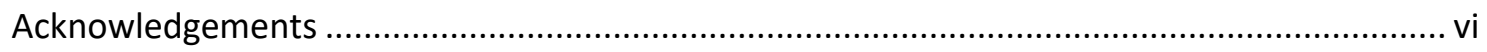

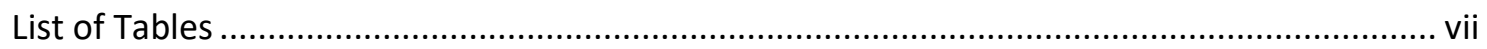

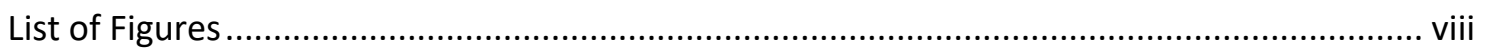

Chapter One : Introduction..................................................................................... 1

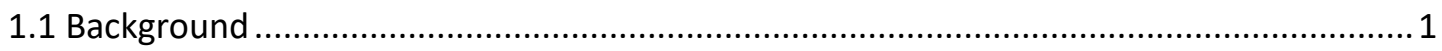

1.1.1 Netball................................................................................................ 1

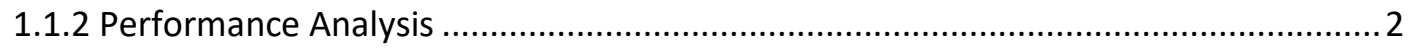

1.1.3 Research in Netball ............................................................................. 7

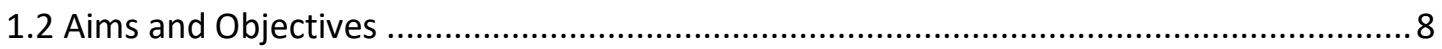

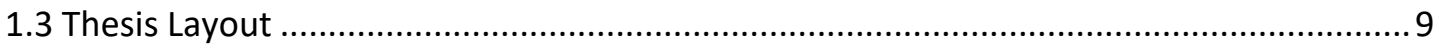

1.4 Implications of Covid-19 ............................................................................. 10

1.5 In the next chapter ..................................................................................... 11

Chapter Two : Systematic Review .......................................................................... 12

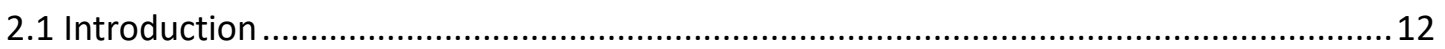

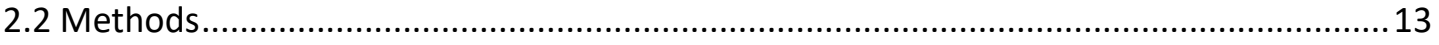

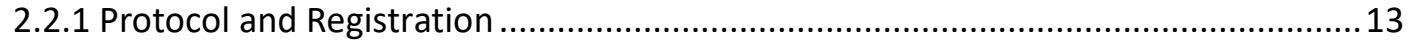

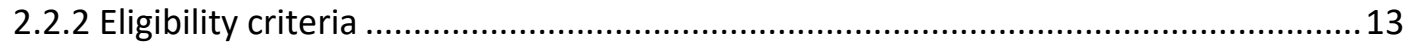

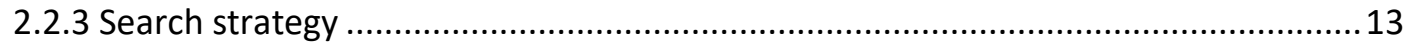

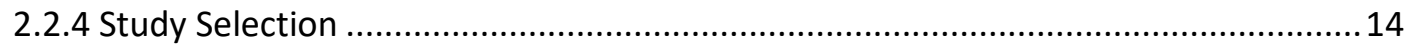

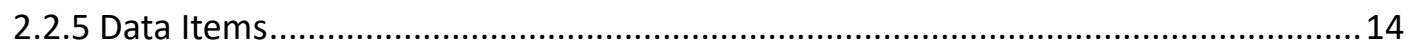

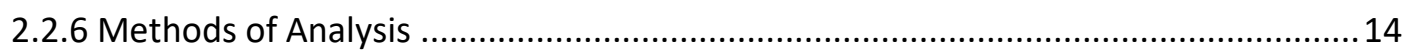

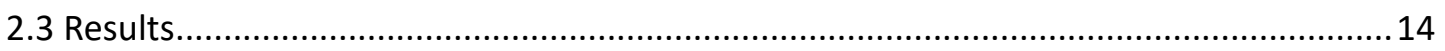

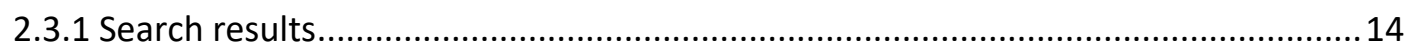

2.3.2 Perception measurement methods......................................................... 15

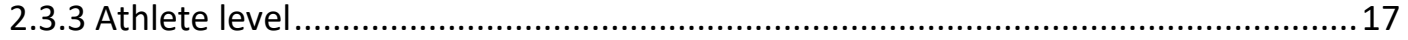

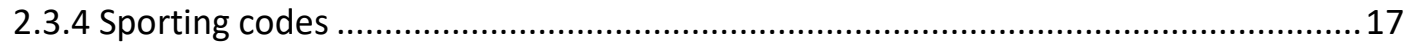

2.3.5 Perceptions of performance variables.......................................................... 19

2.3.6 Direction of impact on performance .......................................................... 19

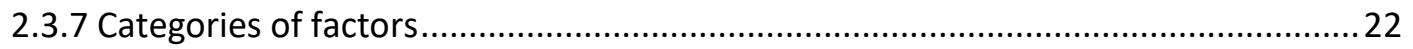

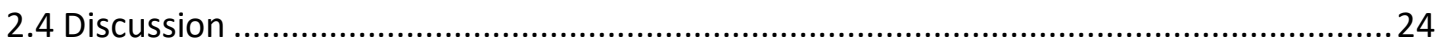

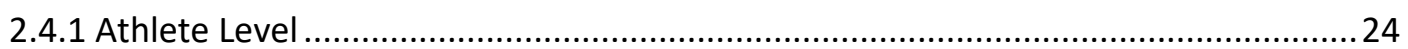


2.4.2 Sporting Codes .................................................................................... 24

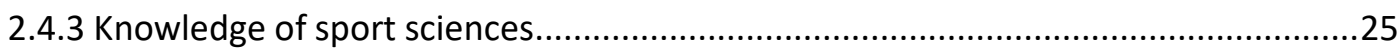

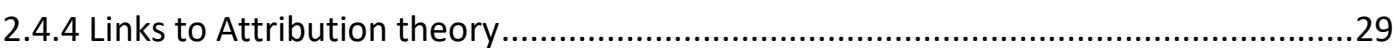

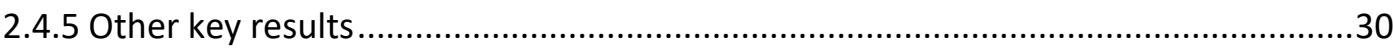

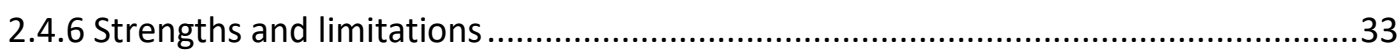

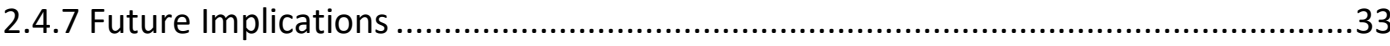

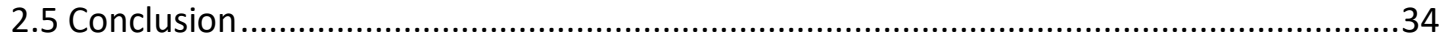

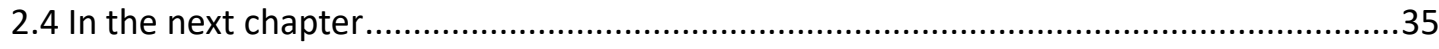

Chapter Three : Exploring Semi-Elite Netball Players Perceptions of Individual Performance

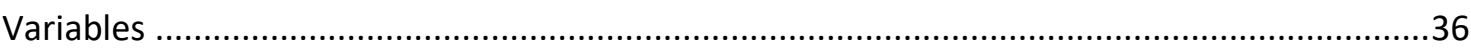

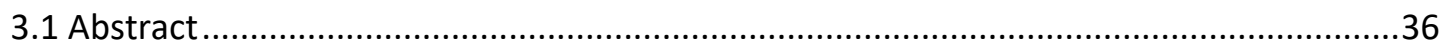

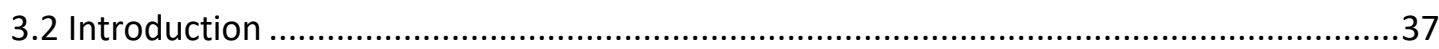

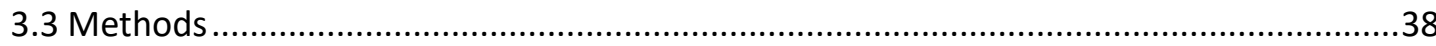

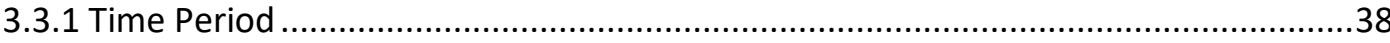

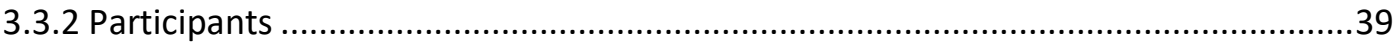

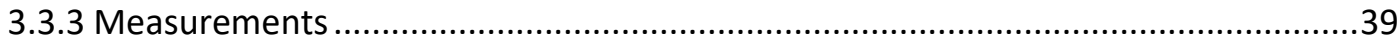

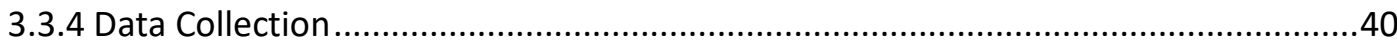

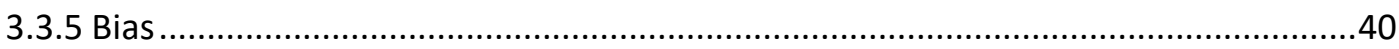

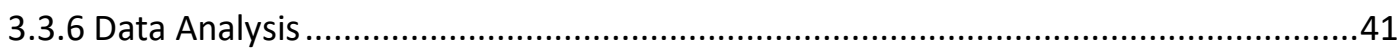

3.3.7 Perception of Performance...................................................................... 42

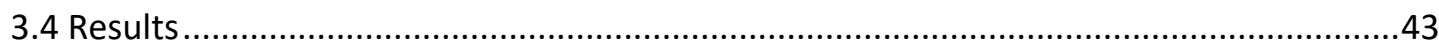

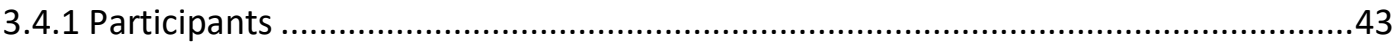

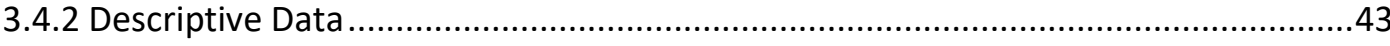

3.4.3 Perceived Skill Difficulty ........................................................................ 44

3.4.4 Perceptions of Performance ......................................................................45

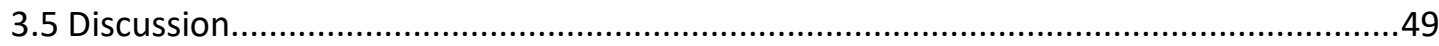

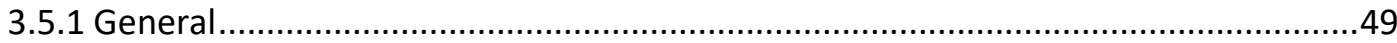

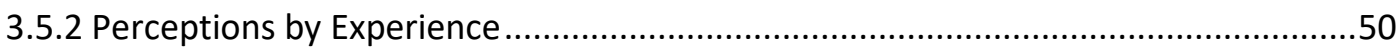

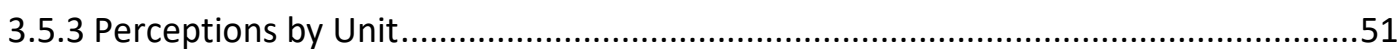

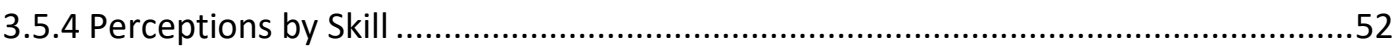

3.5.5 Athlete's perceptions of performance ........................................................ 53

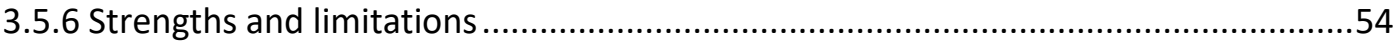

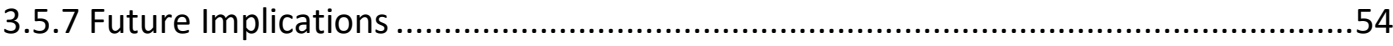

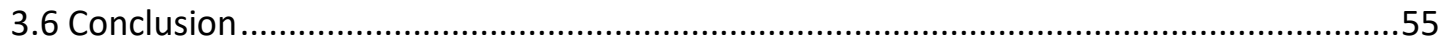


3.7 In the next chapter

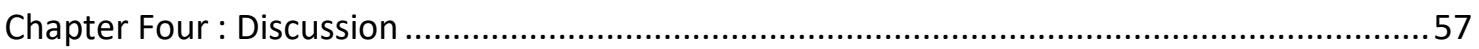

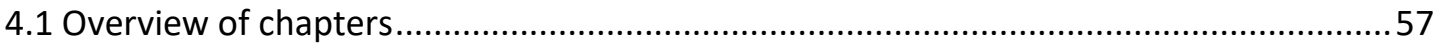

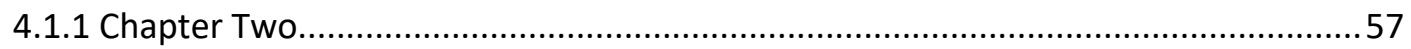

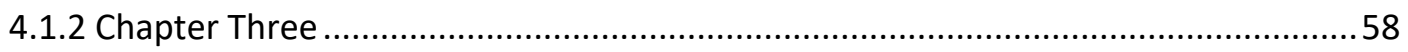

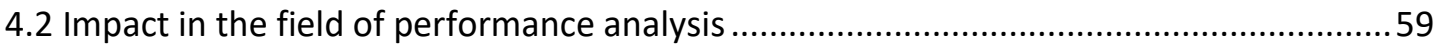

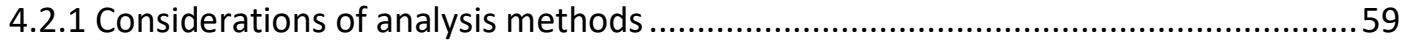

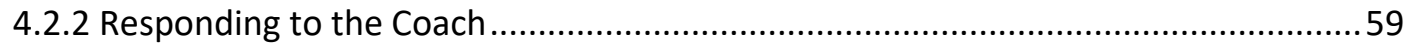

4.2.3 Consideration of experience in feedback ............................................................6 60

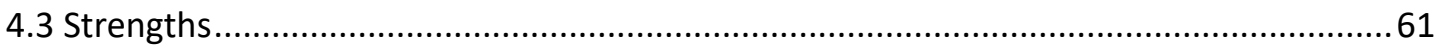

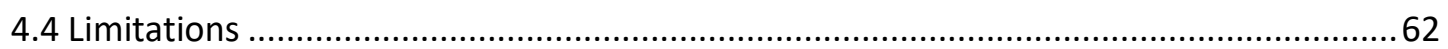

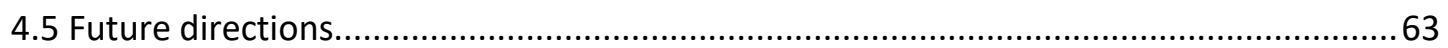

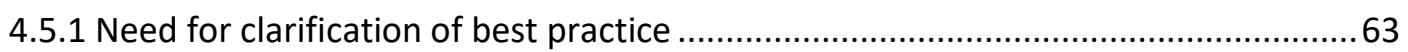

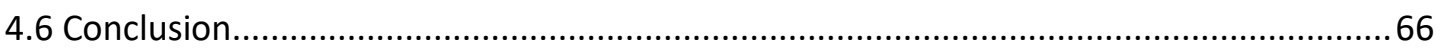

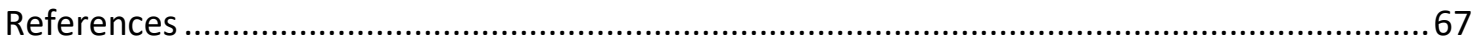

Appendices ……

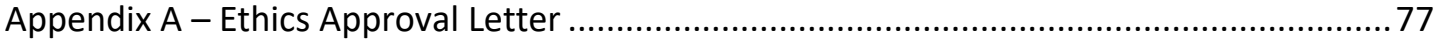

Appendix B - Player Information - Qualtrics Survey Flow ................................................... 78

Appendix C - Match Perceptions - Qualtrics Survey Flow..................................................91

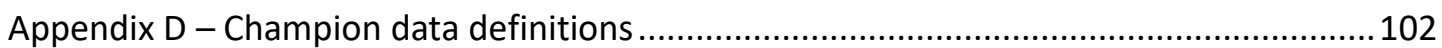

Appendix E - Email chain detailing permission from Champion Data for reproduction and

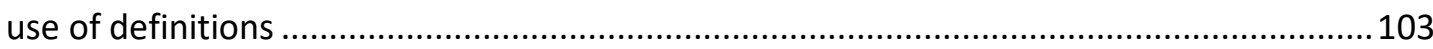




\section{Chapter One: Introduction}

\subsection{Background}

\subsubsection{Netball}

Netball is one of the most popular female team sports in the world, with the involvement of over 80 countries, and more than 20 million people from the Commonwealth and beyond (Chandler et al., 2014; Mclean et al., 2019; Steele, 1990). The inception in 1895, has led to steady growth throughout the $20^{\text {th }}$ century, with over 145,000 affiliated players within New Zealand alone (Chandler et al., 2014; Delextrat \& Goss-Sampson, 2010; McKenzie et al., 2020). A netball World Championship was created in 1963 and has since been played every four years (Netball New Zealand, 2018a). It was first featured as a demonstration sport within the Commonwealth games in 1990 and has included a medal contest since 1998 (Netball New Zealand, 2018b). The sport is largely populated by female athletes, due to the first iteration of the game for women, as a derivative of basketball (Young et al., 2016), however the male game is growing steadily and increasing in exposure, especially in the New Zealand context.

The sport of netball is played on a court, $30.5 \times 15.25$ metres, divided into thirds which subsequently constrains movement of the court residing players (Chandler et al., 2014; Cormack et al., 2014; McKenzie et al., 2020). Within the game there are seven positions which carry their own responsibilities on court and require different sets of skills (Fox et al., 2013), including shooting positions; goal shoot [GS] and goal attack [GA], midcourt positions; centre [C], wing attack [WA], and wing defence [WD], and defence positions; goal keep [GK] and goal defence [GD] (McKenzie et al., 2020; Young et al., 2016). Each position's movements are limited differently by the lines of the court (Bruce et al., 2018; Cormack et al., 2014). 
Netball has similar movement pattern to basketball (Chandler et al., 2014), however there are some key rule differences which change the integral structure of the game. These include the inability to dribble, therefore the player in possession of the ball cannot move more than one and half steps (Bruce et al., 2018; Cormack et al., 2014; Croft et al., 2017; Steele, 1990). Individual possession is time controlled lasting three seconds (Bruce et al., 2018; Cormack et al., 2014), and player movement is restricted, with only two players allowed to attempt to shoot a goal, of which there is no backboard (Croft et al., 2017).

\subsubsection{Professional Netball in New Zealand}

The singular professional domestic netball league in New Zealand, the ANZ premiership, was established in 2017 after the dissolution of the ANZ Championship held between Australia and New Zealand from 2008 through to 2016 (Bruce et al., 2018). The newer, New Zealand only format is generally played between March and June each year. The competition is comprised of six teams, from five regional areas across New Zealand. Each team has 10 contracted players and a minimum of three training partners with rules allowing one international import from each team. This league is an integral part of scouting for the New Zealand national team, the Silver Ferns, and development squad rosters for the next international match calendar.

\subsubsection{Performance Analysis}

Performance is a word that has multiple meanings across various fields and holds a wide definition within the field of sport. It can vary between a singular event or a series of multiple events (Butterworth et al., 2013). Skill execution, although microscopic, can also be viewed as a performance, with broader terms relating to games and competitions (Butterworth et al., 2013). The field of performance analysis is capable of evaluating all types of performance. 


\subsubsection{What is Performance Analysis?}

Performance Analysis is an independent subdivision of sport science, that is the conceptual integration of notational analysis and biomechanics, and can also include physiological and psychological factors (Glazier, 2010). The multifaceted practice includes recording, processing and interpreting events within sporting trainings and competitions, as a way of objectively quantifying and assessing performance (Drust, 2010; Laird \& Waters, 2008; Middlemas et al., 2018; Mooney et al., 2016). The practice of performance analysis can be a unique blend of data, with the use of both qualitative and quantitative measures to capture and analyse performance, before, during, and after the competition, as well as throughout the training period/season with an overarching goal of increasing performance output and results.

Biomechanical and notational analysis are the two key areas in performance analysis. Biomechanical analysis is often found within individual performance pursuits and injury prevention and is grounded in anatomy and movement mechanics. This area looks at the fine motor skills and movement technique, with strong links to movement efficiency and injury prevention and rehabilitation (M. Hughes \& Franks, 2015; Stuelcken et al., 2016). Notational analysis is an area that uses a larger gross view of movement and patterns within performance with sporting links to strategy and structure of a group playing against an opposition and performance statistics (M. Hughes \& Franks, 2015). Both forms of analysis have the same purpose - to improve sports performance with analysis processes - and can be integrated into the same analysis environment to varying degrees.

\subsubsection{Role of the performance analyst}

The role of the performance analyst is multifaceted with various responsibilities that are dependent on the working environment. An overarching theme of the role of a performance analyst includes collaboration with the coaching staff and other sport scientists to drive the analysis process. Performance analysts collect and collate data before analysing it to create 
information that is transformed into knowledge (Figure 1). Coaches and athletes then use this knowledge to understand performance, and make informed coaching and playing decisions (Light et al., 2005; Sykes, 2017).

Figure 1

The analysis process of transforming data into knowledge

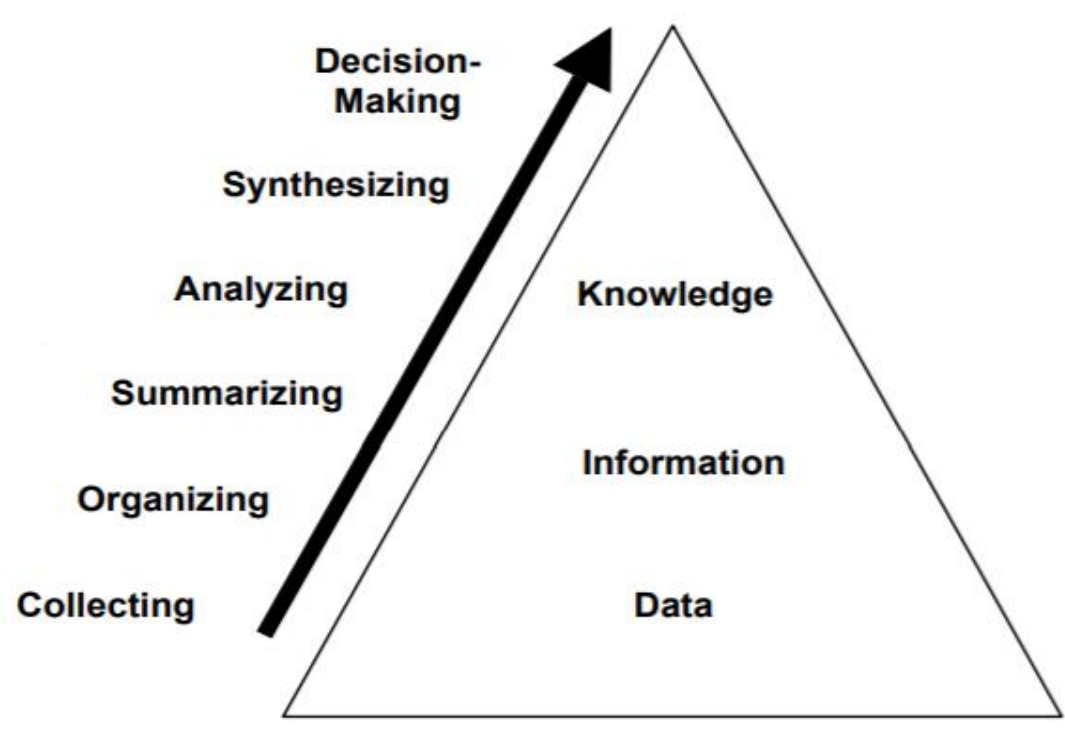

Note. Adapted from "Keeping teachers in the center: A framework for data-driven decisionmaking", by D. Light, D. Wexler and J. Heinze, 2005, Proceedings of Society for Information Technology \& Teacher Education International Conference, 128-133. Adapted with permission.

\subsubsection{Application of performance analysis in sport}

The analysis discipline is crucial in understanding the needs of athletes, and their strengths and weaknesses, while providing objective and accurate feedback (Drust, 2010; Laird \& Waters, 2008). Areas of improvement within individual sports often relate to the small changes and adaptions to make improvements as small as one percent. These marginal gains are more prevalent in individual pursuits and often relate to changes in technology, equipment, and technique cited as key in sports such as track cycling, athletics and motor 
racing (Hall et al., 2012). This relies on a multidisciplinary approach to performance analysis and the collaboration between multiple sport science fields. Team sports have also credited success to these "one percenters", or "critical non-essentials", such as mindset, nutrition and hydration and recovery processes (Hall et al., 2012). These gradual improvements over a period of time can create an accumulated effect of marginal gains, therefore aiding in performance improvements (Mooney et al., 2015).

Analysis within team sport environments is considerably different to that which occurs with an individual context. With various moving parts, teams are a collection of interacting individuals working towards the same goal. Therefore, the application of performance analysis is vastly different. The current application within team sports is largely through the use of video analysis and statistical data, with the use of key performance indicators to track and assess performance through the season (Croft et al., 2020; M. D. Hughes \& Bartlett, 2002; Mooney et al., 2016).

Video is an important tool in performance analysis as it provides an objective record of the events that occurred (Mooney et al., 2015). The use of video allows for both qualitative and quantitative analysis, with the ability to look at technique and also measure key performance indicators while providing context to the events that occurred (Mooney et al., 2015). It is also widely used within opposition analysis and tactical development, studying the behaviour of the opposition before and after competition, and team structures and set pieces, but is also used for skill acquisition and movement technique (García-González et al., 2013; Mooney et al., 2015).

\subsubsection{Performance analysis as a coaching and feedback tool}

Coaches and the field of coaching are linked to performance analysis through the evaluation of the technical, tactical and physical and psychological components of performance (Drust, 
2010; Garhammer \& Newton, 2013; Mclean et al., 2019). The primary purpose of this evaluation is to assist in decision making practices of both the coaches and athletes (O'Donoghue, 2006). Accurate and unbiased feedback can be communicated through postperformance review processes, and then implemented to increase performance outcomes (Drust, 2010; Laird \& Waters, 2008; Middlemas et al., 2018; Mooney et al., 2016; Nicholls et al., 2018). Research in event-recall has shown that football coaches can only remember 42 $59 \%$ of the important or critical events within a game (Franks \& Miller, 1986; Laird \& Waters, 2008). With post-match performance analysis and the use of video-based feedback, errors in event recall can be minimised and a more complete picture of a match can be maintained (Middlemas et al., 2018).

Feedback and modelling are two pedagogical techniques used widely in the coaching profession (O'Donoghue, 2006; Otte et al., 2020; Potrac et al., 2000). Performance analysis is a strong contributor to these techniques, with the ability to capture and analyse various forms of data including statistics and video. Use of video feedback and video modelling has also been shown to be more effective in increasing performance than verbal feedback alone in multiple skills across a variety of sports, including golf (Guadagnoli et al., 2002), gymnastics (Boyer et al., 2009), weightlifting (Garhammer \& Newton, 2013) and tennis (García-González et al., 2013).

\subsubsection{Performance analysis research}

Some codes, such as football (soccer), have been widely studied over the last few decades, therefore the athletes technical, tactical, physical and psychological needs within these sports are widely known (Mackenzie \& Cushion, 2013; McLean et al., 2017).

Some of the technical needs in football include: dribbling, passing, tackling, goal keeping, shooting and variations of these skills (Barnes et al., 2014; Bradley et al., 2013; Kelly et al., 
2020; Kubayi, 2021). Studies on the evolution of these factors, and their use in talent development are useful in understand how performance has changed over time and how vital these skills are in performance (Barnes et al., 2014; Kelly et al., 2020). Physical needs have been well studied across football, with the use of global positioning systems to understand the demands of players across different positions and levels, as well as the physical metrics within a game such as accelerations, deceleration, changes in direction (Abbott et al., 2018; Barnes et al., 2014; Bloomfield et al., 2007; Bradley et al., 2013; Jara et al., 2019; Ortega et al., 2016). These aid sport science teams, including the performance analyst, strength and conditioning coach and the coaching team in creating a physical profile of an athlete and the team. Psychological needs within football include but are not limited to mental skills such as imagery and visualisation, self-talk, attentional control and coping strategies (Burton et al., 2011; Campos et al., 2016; Diment, 2014; Monteiro et al., 2018; Norouzi et al., 2019; Shigeno et al., 2019; Wood et al., 2015). The tactical needs previously explored in football include player positioning and structures, as well as methods of tactical analysis (Bueno et al., 2021; Goes et al., 2021; Jara et al., 2019; Ortega et al., 2016; Rein \& Memmert, 2016; Rey et al., 2015). These studies assist us in understanding player coordination and dynamics, as well as team strategies, strengths and weaknesses.

\subsubsection{Research in Netball}

When comparing performance analysis research in netball to other sporting codes, one can find a large contrast in the base of knowledge. Research within netball has been building since the professionalisation of the game, with various studies looking at physical demands of performance (Chandler et al., 2014; Cormack et al., 2014; Fox et al., 2013; Gasston \& Simpson, 2004; O'Donoghue et al., 2008; Stoker et al., 2017; Young et al., 2016), biomechanical aspects of skills and game play (Delextrat \& Goss-Sampson, 2010; Steele, 1990), and anthropometric characteristics (Thomas et al., 2019). . More recent research has explored the themes and 
content of coach communication during a match (Croft et al., 2020), the use of machine learning and computer vision to monitor and identify players, their location, and then automatically identify player movements and pathways (Smith \& Bedford, 2020).

\subsubsection{Performance analysis research in netball}

The majority of performance analysis research focuses on isolated descriptions of performance variables rather than the complexities and integrated facets that influence it (Mclean et al., 2019). This has created a lack of understanding in elite netball as a whole as the complexities within the system are far less documented (Croft et al., 2017; Mclean et al., 2019). A recent study that looked at the relationship between match outcome and performance indicators highlighted the complexity of sport and the issues with the current methods of analysis (Smith \& Bedford, 2020). Results suggested that simple predictors and indicators of player and team performance may not be optimal measures of performance, as the outcomes are more complex in nature, with multiple layers, than the predictor itself (Smith \& Bedford, 2020). This study, alongside Mclean's work domain analysis (2019) suggests that the direction forward in performance analysis research within the netball space, is working with complex relationships and understanding performance and as a sum of multiple moving parts. However, the transition in use between key performance indicators and singular isolated predictors to a complex systems-based approach raises many questions around what we carry through from the previous and current performance analysis practice into the developing gold standard of a complex systems-based approach. This thesis seeks to explore one facet of this problem - the athletes and their perceptions.

\subsection{Aims and Objectives}

The aim of this project is to explore athletes' perceptions of performance, the numerous factors that influence performance and discuss the implications of these findings in the 
performance analysis environment. To fulfil this aim, two studies have been completed. A literature review (Chapter Two) evaluates the current literature on athletes' perceptions of various factors and how they affect performance. A prospective cohort study (Chapter Three) explores athletes' perceptions of their own performance, and the implications in performance analysis within netball. The discussion (Chapter Four) aims to synthesize and discuss the previous chapters, with the overall results holding the ability to improve the efficiency of coaching staff and analysts.

\subsection{Thesis Layout}

This thesis is presented in four chapters (Figure 1). This introductory chapter is followed by a systematic literature review, which explores how athletes perceive different factors within performance, in order to understand the current knowledge around athlete perceptions and to identify potential gaps within the literature. Chapter three is a prospective cohort study design to explore the perceptions of semi-elite netballers regarding their individual match performance. This study explores the differences between athletes' perceptions of their performance and the true performance, by comparing the perception with a match statistic. Chapter four discusses and concludes the outcomes of chapter two and three by examining the strengths, weaknesses, and limitations of this master's project in its entirety. The implications of this research and further recommendations regarding future research in this area and within the adjacent fields are made and presented in this concluding chapter. 


\section{Chapter One - Introduction}

Chapter Two -

Literature Review
Chapter Three -

Main Study

\section{Chapter Four - Discussion}

\subsection{Implications of Covid-19}

With the arrival of the COVID-19 pandemic, a large majority of research presented within this thesis was delayed for a period of three months. Data collection for Chapter Three was scheduled to begin in the third round of the ANZ Premiership beginning the $28^{\text {th }}$ of March 2020. The New Zealand government response to the global pandemic resulted in the season being suspended until it was reinstated on the $19^{\text {th }}$ of June. This suspension forced the creation of multiple back up plans to continue with the research project, however the reinstatement and new timeline was feasible and therefore no major changes were required to complete this project. Changes were made to the season structure, including centralisation of the games, the removal of crowds, and limits on travelling personnel within each team environment which limited my ability as a researcher, and the team's performance analyst to travel and collect data. The resurgence of COVID-19, and the subsequent local lockdown of Auckland on the $11^{\text {th }}$ of August, resulted in the cancelation of the final two rounds of competition and therefore the early conclusion of the data collection process. 
1.5 In the next chapter

The next chapter is a literature review which explores athletes' perceptions of various factors within and around sport, and their perceived influence on performance. 


\section{Chapter Two: Systematic Review}

\subsection{Introduction}

Sport is a multifaceted and complex system with multiple interrelated parts (Balague et al., 2013; Bruce et al., 2018; Mclean et al., 2019). This is well indicated by a work domain analysis, which provides a functional framework to evaluate factors usefulness within an environment (Mclean et al., 2019; Naikar \& Sanderson, 1999). A work domain analysis is a hierarchical model that explores the interactions between physical objects, object related process, purpose-related functions, values and priority measures and the overall functional purpose (Mclean et al., 2019; Naikar \& Sanderson, 1999). This web of interacting parts includes the technical, tactical, physical and psychological factors often associated with the sport science fields of strength and conditioning, sport psychology, coaching and performance analysis. With these dynamic relationships within the performance environment, it is important to consider how these may impact the athlete or team working in these environments. A deeper insight into athletes' perceptions can help understand the factors that create and influence sporting performance.

Athletes are an important source of ecologically valid information within sport due to being the vessel of performance. The combination of their technical, tactical, physical, and psychological skills and their knowledge creates a performance profile and is the foundation of the growing performance analysis field (Mclean et al., 2019; O’Donoghue, 2008). The acknowledgement of the performers perceptions is important when trying to understand performance, however the current literature surrounding this theme is limited. Performance analysis, or the study of performance in order to increase output, is a key coaching discourse within sports performance, and can include notational, tactical, technical and biomechanical analysis. In order for exercise science practitioners and performance analysts to make informed decisions to improve performance, this review was conducted. 
This literature review aimed to explore the current literature and investigate

athletes' perceptions of various factors and how they affect performance, with the intention to find the limits of, and to evaluate our current knowledge - exposing potential gaps within the literature.

\subsection{Methods}

\subsubsection{Protocol and Registration}

The Preferred Reporting Items for Systematic Reviews and Meta-Analysis (PRISMA) has been used to report this review (Liberati et al., 2009; Page et al., 2021).

\subsubsection{Eligibility criteria}

Qualitative and quantitative studies, published in English and involving collegiate through to elite level athletes, were included within this review. Studies which assessed athlete perceptions of different factors and their impact on either sport training or performance were included. Studies which focused on the perceptions of coaches, management, spectators, or other sports personnel were excluded. Studies were also excluded if participants were categorised as youth, children, adolescent, or elderly. Validation studies and systematic reviews were also excluded.

\subsubsection{Search strategy}

An electronic search strategy was developed to aid in systematically identifying relevant articles. Three online databases (Sport Discus, ProQuest Central and Taylor and Francis) were searched with the following search terms: Athlete*; Player*; Perception; Performance, with a date limit from 1 January 2010 to the day of search, $28^{\text {th }}$ May 2020. The searches were also limited to the English language and academic journals. 


\subsubsection{Study Selection}

Titles and abstracts were screened according to the inclusion criteria, after the removal of duplicates. A second reviewer was consulted when inclusion could not be determined. Full texts were then screened and relevant literature that met the inclusion criteria were included.

\subsubsection{Data Items}

Information was extracted from each included article on: (1) athlete level (2) the studied sporting code (3) type of research tool used to measure perceptions; (4) perception of performance variables (5) the impact the performance variable was found to or perceived to have on performance.

\subsubsection{Methods of Analysis}

In order to analyse the results of the systematic data collection detailed above, content analysis was planned, to collate, categorise and therefore simplify the findings from the current literature (Elo \& Kyngäs, 2008). To examine the variables in which athletes perceive to have an influence on their performance, the factors were grouped into seven categories: psychological factors, physical performance factors, personal factors, factors regarding the coaching and management group, health and wellbeing factors, and factors regarding both the playing and training environments.

\subsection{Results}

\subsubsection{Search results}

A total of 14 studies were included in this review (Figure 3). Six of the studies were conducted in France, Spain, the Netherlands and the United Kingdom. A further six studies were completed within the United States of America, and the final two, from Pakistan and Australia. 
Of the included articles three were cross-sectional (Armour et al., 2020; Boyd et al., 2017;

Gouttebarge et al., 2019) and three were qualitative (Jaeschke et al., 2016; Jones et al., 2014;

Solomon \& Kausar, 2017). Two were prospective (Nicolas et al., 2011; Reed et al., 2017) and a further two were retrospective (Adams et al., 2016; Ruiz-Tendero \& Martín, 2012). There were two mixed method approaches (López-Fernández et al., 2018; Readdy et al., 2014), one cross over trial (Cook \& Beaven, 2013) and one observational study (Fryer et al., 2018).

Of the 14 evaluated studies, four focused only on male perceptions (Cook \& Beaven, 2013; Gouttebarge et al., 2019; Readdy et al., 2014; Solomon \& Kausar, 2017), two solely on female perceptions (Armour et al., 2020; López-Fernández et al., 2018) and eight examined both genders (Adams et al., 2016; Boyd et al., 2017; Fryer et al., 2018; Jaeschke et al., 2016; Jones et al., 2014; Nicolas et al., 2011; Reed et al., 2017; Ruiz-Tendero \& Martín, 2012).

\subsubsection{Perception measurement methods}

The 14 included studies used various methodologies to measure athlete perceptions (Table 3). There were six studies that utilised questionnaires in their data collection process in order to examine athlete perceptions (Adams et al., 2016; Armour et al., 2020; López-Fernández et al., 2018; Nicolas et al., 2011; Reed et al., 2017; Ruiz-Tendero \& Martín, 2012). Four studies used surveys (Boyd et al., 2017; Cook \& Beaven, 2013; Fryer et al., 2018; Gouttebarge et al., 2019), two utilised semi-structured interviews (Jaeschke et al., 2016; Jones et al., 2014), and a further two used a mixed-method approach with interviews and questionnaires as well as interviews and focus groups, respectively (Readdy et al., 2014; Solomon \& Kausar, 2017).

\subsubsection{Validated Questionnaires}

Out of the 14 studies examined, seven used questionnaires for data collection purposes (Table 2). Of these seven, four used validated inventories and tools (Adams et al., 2016; Nicolas et al., 
2011; Readdy et al., 2014; Reed et al., 2017), whereas three were unvalidated, with two created under guidance of experts or experienced researchers (Armour et al., 2020; RuizTendero \& Martín, 2012), and one adapted from previous research (López-Fernández et al., 2018).

Figure 3

\section{PRISMA flow diagram of included and excluded studies}

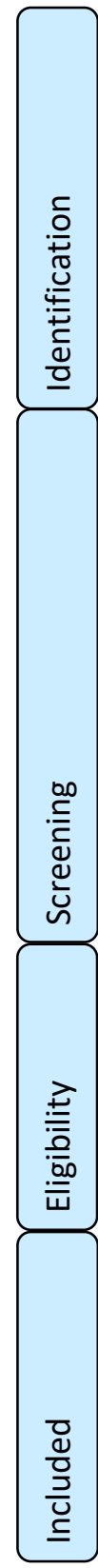

Records identified through database searching

Proquest Central $(n=1115)$

Taylor and Francis $(\mathrm{n}=315)$

Sport Discus $(n=594)$

Total $(n=2024)$

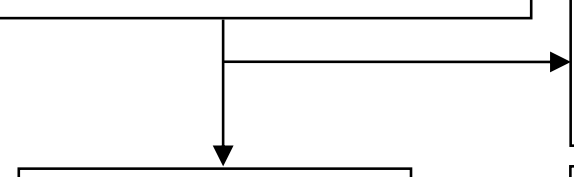

Duplicates removed

( $n=137)$

Titles screened

( $n=1887)$

Titles excluded

$(n=1806)$

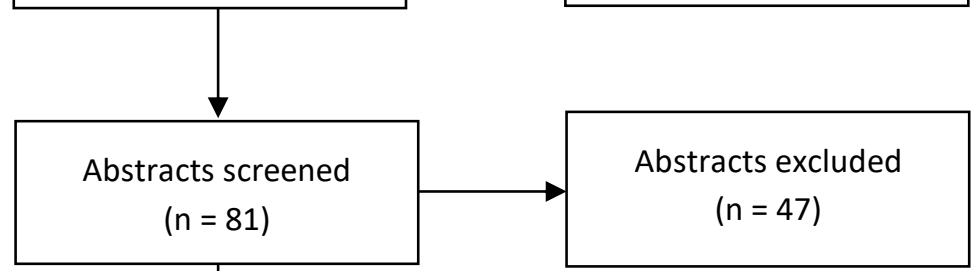

Studies included in

qualitative synthesis $(n=14)$ 


\subsubsection{Athlete level}

The level of athletes studied varied from senior club to elite. Five studies examined the perceptions of collegiate or university athletes (Adams et al., 2016; Boyd et al., 2017; Fryer et al., 2018; Readdy et al., 2014; Reed et al., 2017), three studies looked at elite athletes (Gouttebarge et al., 2019; Ruiz-Tendero \& Martín, 2012; Solomon \& Kausar, 2017), two at subelite (Cook \& Beaven, 2013; López-Fernández et al., 2018) and four examined mixed level athletes (Armour et al., 2020; Jaeschke et al., 2016; Jones et al., 2014; Nicolas et al., 2011).

\subsubsection{Sporting codes}

A total of 30 sporting codes were studied within the 14 included texts, with 24 directly reported (Table 1). Seven of the examined studies included athletes who participated in Football (Soccer), (Adams et al., 2016; Armour et al., 2020; Boyd et al., 2017; Gouttebarge et al., 2019; Jones et al., 2014; López-Fernández et al., 2018; Reed et al., 2017). Other notable sporting inclusions, include four examinations of track and field (Adams et al., 2016; Armour et al., 2020; Boyd et al., 2017; Nicolas et al., 2011), as well as basketball (Adams et al., 2016; Fryer et al., 2018; Jones et al., 2014) and tennis (Adams et al., 2016; Boyd et al., 2017; Reed et al., 2017) which were both included three times. 
Table 1

Included Study Characteristics

\begin{tabular}{|c|c|c|c|c|c|c|c|}
\hline Reference & Country & Study Design & $\begin{array}{l}\text { \# Of } \\
\text { Participants }\end{array}$ & Athlete Level & Age & Sex & Sport \\
\hline (Adams et al., 2016) & USA & Retrospective & 155 & Collegiate & $\geq 18$ Years & Both & $\begin{array}{l}\text { Baseball } \\
\text { Basketball } \\
\text { Cheerleading } \\
\text { Cross country } \\
\text { Track and field } \\
\text { American } \\
\text { Football } \\
\text { Golf } \\
\text { Soccer } \\
\text { Softball } \\
\text { Tennis } \\
\text { Volleyball }\end{array}$ \\
\hline (Armour et al., 2020) & Australia & Cross Sectional & 143 & Club or above & $29 \pm 7.3$ & Female & $\begin{array}{l}\text { Cricket } \\
\text { Australian Rules } \\
\text { Athletics } \\
\text { Netball } \\
\text { Rowing } \\
\text { Soccer } \\
\text { Water Polo }\end{array}$ \\
\hline (Boyd et al., 2017) & USA & Cross Sectional & 123 & Collegiate & $\geq 18$ years & Both & $\begin{array}{l}\text { Baseball } \\
\text { Softball } \\
\text { Soccer } \\
\text { Tennis } \\
\text { Track and Field }\end{array}$ \\
\hline (Cook \& Beaven, 2013) & $\begin{array}{l}\text { United } \\
\text { Kingdom }\end{array}$ & Cross Over & 12 & Sub-Elite & $23.3 \pm 1.4$ & Male & Rugby Union \\
\hline (Fryer et al., 2018) & USA & Observational & 53 & Collegiate & $21.09 \pm 3.26$ & Both & Basketball \\
\hline $\begin{array}{l}\text { (Gouttebarge et al., } \\
\text { 2019) }\end{array}$ & Netherlands & Cross Sectional & 543 & Elite & $26 \pm 6$ & Male & Soccer \\
\hline (Jaeschke et al., 2016) & USA & Qualitative & 12 & $\begin{array}{l}\text { Collegiate, } \\
\text { Elite }\end{array}$ & $\geq 18$ Years & Both & Ultra-Marathon \\
\hline (Jones et al., 2014) & $\begin{array}{l}\text { United } \\
\text { Kingdom }\end{array}$ & Qualitative & 20 & $\begin{array}{l}\text { Collegiate, } \\
\text { Elite }\end{array}$ & 23 & Both & $\begin{array}{l}\text { Basketball } \\
\text { Soccer } \\
\text { Rugby Union } \\
\text { Netball } \\
\text { Hockey }\end{array}$ \\
\hline $\begin{array}{l}\text { (López-Fernández et al., } \\
\text { 2018) }\end{array}$ & Spain & $\begin{array}{l}\text { Mixed } \\
\text { methods }\end{array}$ & 16 & Sub-Elite & $19.56 \pm 1.97$ & Female & Soccer \\
\hline (Nicolas et al., 2011) & France & Prospective & 80 & Mixed & $18.46 \pm 2.71$ & Both & $\begin{array}{l}\text { Gymnastics } \\
\text { Cycling } \\
\text { Combat Sports } \\
\text { Track and Field } \\
\text { Racquet Sports } \\
+6 \text { more }\end{array}$ \\
\hline (Readdy et al., 2014) & USA & $\begin{array}{l}\text { Mixed } \\
\text { methods }\end{array}$ & 60 & Collegiate & 20.3 & Male & $\begin{array}{l}\text { American } \\
\text { Football }\end{array}$ \\
\hline (Reed et al., 2017) & USA & Prospective & 75 & Collegiate & DNR & Both & $\begin{array}{l}\text { Soccer } \\
\text { Tennis } \\
\text { Volleyball }\end{array}$ \\
\hline $\begin{array}{l}\text { (Ruiz-Tendero \& Martín, } \\
\text { 2012) }\end{array}$ & Spain & Retrospective & 48 & Elite & $37.4 \pm 7.3$ & Both & Triathletes \\
\hline $\begin{array}{l}\text { (Solomon \& Kausar, } \\
\text { 2017) }\end{array}$ & Pakistan & Qualitative & 11 & Elite & $\begin{array}{l}\text { U19 }(17.67 \pm \\
2.49) \\
\text { Senior }(25.88 \pm \\
2.03)\end{array}$ & Male & Cricket \\
\hline
\end{tabular}


Table 2

Details of data collection methods

\begin{tabular}{|c|c|c|}
\hline Reference & Study Design & Collection details \\
\hline (Adams et al., 2016) & Questionnaire & $\begin{array}{l}\text { Female Athlete Screening Tool; Eating Disorder Examination } \\
\text { Questionnaire; Eating Disorder Inventory }\end{array}$ \\
\hline (Armour et al., 2020) & Questionnaire & \\
\hline (Boyd et al., 2017) & Survey & Training Information Survey \\
\hline (Cook \& Beaven, 2013) & Survey & 5-point Likert Scale; Like very much - dislike very much \\
\hline (Fryer et al., 2018) & Survey & 9-point Likert Scale; Very Minor - Very Substantial \\
\hline $\begin{array}{l}\text { (Gouttebarge et al., } \\
\text { 2019) }\end{array}$ & Survey & 4-point Likert Scale; Totally Agree - Totally Disagree \\
\hline (Jaeschke et al., 2016) & Qualitative & Semi-structured interviews \\
\hline (Jones et al., 2014) & Qualitative & Semi-structured interviews \\
\hline $\begin{array}{l}\text { (López-Fernández et } \\
\text { al., 2018) }\end{array}$ & Questionnaire & $100 \mathrm{~mm}$ Visual Analogue Scales \\
\hline (Nicolas et al., 2011) & Questionnaire & $\begin{array}{l}\text { Coaching Behaviour Scale for Sport; Coping Inventory for Competitive } \\
\text { Sport; Attainment of Sport Achievement Goal Scale }\end{array}$ \\
\hline (Readdy et al., 2014) & $\begin{array}{l}\text { Questionnaire; } \\
\text { Qualitative }\end{array}$ & Sport Motivation Scale; Basic Need Satisfaction at Work Scale; Interview \\
\hline (Reed et al., 2017) & Questionnaire & Modified Elite Athlete Self-Description Questionnaire \\
\hline $\begin{array}{l}\text { (Ruiz-Tendero \& } \\
\text { Martín, 2012) }\end{array}$ & Questionnaire & 5-Point Likert Scale; No Influence - Very Influential \\
\hline $\begin{array}{l}\text { (Solomon \& Kausar, } \\
\text { 2017) }\end{array}$ & Qualitative & Interview; Focus Groups \\
\hline
\end{tabular}

\subsubsection{Perceptions of performance variables}

Perceptions of 49 different performance variables, found within the 14 included studies, were examined and these variables were then separated into three groups: intrinsic factors, extrinsic factors and a combination of both intrinsic and extrinsic factors. The use of intrinsic factors within the included studies was equal to that of the extrinsic factors, both making up $36 \%$ of the review. The studies which examined both intrinsic and extrinsic factors made up the remaining $28 \%$ of the review. The sub variables were largely extracted from the four studies that contained both intrinsic and extrinsic factors, with the next largest amount from the extrinsic studies, and lastly the intrinsic based studies (

Table 3).

\subsubsection{Direction of impact on performance}

Within the 14 studies examined in this review, performance was found to be impacted in four directions: positive, negative, neutral or no effect, and simultaneously both positive and negative. Three studies exploring athletes perceptions on recovery interventions, mental 
toughness and psychological skills to have a positive influence on performance (Cook \& Beaven, 2013; Jaeschke et al., 2016; Solomon \& Kausar, 2017), and five studies found that the presence of menstrual symptoms, the effects of choking, the international match calendar, social loafing and differences in playing surface have a negative influence on performance (Armour et al., 2020; Fryer et al., 2018; Gouttebarge et al., 2019; Jones et al., 2014; LópezFernández et al., 2018). Three studies which analysed athletes perceptions on body weight and nutrition, the psycho-social factors associated within sport and strength training found both positive and negative effects on performance (Adams et al., 2016; Boyd et al., 2017; RuizTendero \& Martín, 2012) and one study found that athletes perceived extrinsic rewards had a neutral effect on performance (Readdy et al., 2014). Two studies found athlete monitoring, coaching behaviours and coping strategies have both a positive and neutral effect on performance (Nicolas et al., 2011; Reed et al., 2017).

Of the 49 variables found within this review, $37 \%(n=18)$ were perceived by athletes to be positive influences on performance. Of these 18 , six were intrinsic factors, 11 were extrinsic and one had both intrinsic and extrinsic links (Table 5). Proportionately this means there is no clear difference between the impact of intrinsic or extrinsic factors on performance, both with $35 \%$ and $36 \%$ positive factors, respectively

Positive influences on performance include supportive behaviour, scientific and technological interventions, nutritional supplementation, recovery and medical interventions, monitoring of athletes' overall performance, power, and strength, having a strong training environment and the inclusion of training partners. Whereas pressure from, and a lack of understanding with the coach, the demands of international sport (a high number of matches, short recovery time and long-haul flights) different playing surfaces, increases in weight, menstrual symptoms, and the presence of injuries were perceived as negative. Unsupportive coach behaviour was found to be neutral in its impact on performance, along with the monitoring of the athlete's skill, 
anaerobic and aerobic capacity, and speed. Strength training was perceived as both a positive and negative influence on performance (Error! Reference source not found.Table 4).

Table 3

Reported perception variables and the perceived impact on performance

\begin{tabular}{|c|c|c|c|c|}
\hline Reference & $\begin{array}{l}\text { Variable } \\
\text { Type }\end{array}$ & Perception Variable & Sub-Variable & $\begin{array}{l}\text { Impact on } \\
\text { Performance }\end{array}$ \\
\hline \multirow[t]{2}{*}{ (Adams et al., 2016) } & Both & Body Weight and Nutrition & Supplements & + \\
\hline & & & Increased Weight & - \\
\hline (Armour et al., 2020) & & Symptoms & & \\
\hline (Boyd et al., 2017) & Extrinsic & Strength Training & - & + and- \\
\hline (Fryer et al., 2018) & & & Lack of Concentration & - \\
\hline \multirow[t]{4}{*}{ (Gouttebarge et al., 2019) } & Extrinsic & The International Match & Number of Matches & - \\
\hline & & Calendar & & \\
\hline & & & Limited Recovery Time & - \\
\hline & & & Long Haul Flights & - \\
\hline \multirow{2}{*}{ (Nicolas et al., 2011) } & & & Unsupportive behaviour & Neutral \\
\hline & & Coping & - & + \\
\hline (Readdy et al., 2014) & Extrinsic & Extrinsic Rewards & - & Neutral \\
\hline \multirow[t]{7}{*}{ (Reed et al., 2017) } & Extrinsic & Athlete Monitoring & Overall Performance & + \\
\hline & & & Skill & Neutral \\
\hline & & & Anaerobic & Neutral \\
\hline & & & Aerobic & Neutral \\
\hline & & & Power & + \\
\hline & & & Speed & Neutral \\
\hline & & & Strength & + \\
\hline \multirow[t]{18}{*}{ (Ruiz-Tendero \& Martín, 2012) } & Both & Psycho-Social Factors & Dedication/Engagement & + \\
\hline & & & Economic Incentives & + \\
\hline & & & Family Issues & - \\
\hline & & & Financial Constraints & - \\
\hline & & & Injuries & - \\
\hline & & & Institutional Support & + \\
\hline & & & Lack of Self-Confidence & - \\
\hline & & & Lack of Support from Relatives & - \\
\hline & & & Lack of Understanding with & - \\
\hline & & & Coach & \\
\hline & & & Medical Support & + \\
\hline & & & Parents Pressure & - \\
\hline & & & Plateau of Performance & - \\
\hline & & & Scientific Technological & + \\
\hline & & & Sport-Studies Conflicts & - \\
\hline & & & Sport-Work Conflicts & - \\
\hline & & & Training Environments & + \\
\hline & & & Training Partners & + \\
\hline (Solomon \& Kausar, 2017) & Intrinsic & Psychological Skills & - & + \\
\hline
\end{tabular}




\subsubsection{Categories of factors}

The variables determined in this review were organised into seven categories relating to the performance environment. Psychological factors were found to be the most studied at $31 \%$ (n $=15)$ of the variables, many relating to the possession of mental skills and the behaviours associated. Of these factors six were perceived to have a positive impact on performance, while seven where perceived to be negative. Factors relating to the training environment contributed to $21 \%$ ( $n=10)$, with five factors perceived as having a positive impact on performance. The personal factors contributed to $14 \%(n=7)$ of the perception variables, six of which were perceived as negative while factors regarding the coaching and management group contribute to $12 \%(n=6)$ of the variables within this review, with three positive influences and two negative. Health and Wellbeing factors also contributed to $12 \%(n=6)$ of the variables, with perceptions evenly spread across both positive and negative. The factors relating to the playing environment contribute to $8 \%(n=4)$ of the 49 variables and lastly physical performance factors contributed to $2 \%(n=1)$ of the variables, with a plateau of performance perceived as a negative influence on performance (Table 4). 
Table 4

Perceived influence of the seven categories and the sub-variables on performance

\begin{tabular}{|c|c|c|c|c|c|}
\hline & & & Perceived influence on performance & & \\
\hline & & + & - & + and - & Neutral \\
\hline Psychological & $\begin{array}{l}\mathrm{n}=15 \\
31 \%\end{array}$ & $\begin{array}{l}\text { - } \quad \text { Mental toughness (Jaeschke et al., 2016) } \\
\text { - } \quad \text { Coping (Nicolas et al., 2011) } \\
\text { - } \quad \text { Ecompetitive Success; Dedication/Engagement; } \\
\quad \text { Martín, 2012) } \\
\text { - } \quad \text { Psychological skills (Solomon \& Kausar, 2017) }\end{array}$ & $\begin{array}{ll}\text { - } & \text { Choking - Time pressure; Lack of concentration (Fryer } \\
\text { et al., 2018) } \\
\text { - } \quad \text { Social loafing (Jones et al., 2014) } \\
\text { - Boredom/Lack of motivation; Competitive Anxiety; } \\
\text { Competitive Pressure; Lack of Self-Confidence (Ruiz- } \\
\text { Tendero \& Martín, 2012) }\end{array}$ & $\begin{array}{l}\text { Competitive Failure } \\
\text { (Ruiz-Tendero \& } \\
\text { Martín, 2012) }\end{array}$ & $\begin{array}{ll}- & \text { Extrinsic rewards (Readdy } \\
& \text { et al., 2014) }\end{array}$ \\
\hline $\begin{array}{l}\text { Training } \\
\text { Environment }\end{array}$ & $\begin{array}{l}n=10 \\
21 \%\end{array}$ & $\begin{array}{l}\text { - Monitoring of: Overall Performance; Power; } \\
\text { Strength (Reed et al., 2017) } \\
\text { - Training environment; Training Partners (Ruiz- } \\
\text { Tendero \& Martín, 2012) }\end{array}$ & & $\begin{array}{l}\text { - } \quad \text { Strength Training } \\
\text { (Boyd et al., 2017) }\end{array}$ & $\begin{array}{l}\text { - } \quad \text { Monitoring of: Skill; } \\
\text { Anaerobic; Aerobic; Speed } \\
\text { (Reed et al., 2017) }\end{array}$ \\
\hline Personal & $\begin{array}{l}\mathrm{n}=7, \\
14 \%\end{array}$ & $\begin{array}{l}\text { - Institutional support (Ruiz-Tendero \& Martín, } \\
\text { 2012) }\end{array}$ & $\begin{array}{l}\text { Family issues; Financial constraints; Lack of support } \\
\text { from relatives; Parental Pressure; Sport/Study } \\
\text { conflict; Sport/work conflict (Ruiz-Tendero \& Martín, } \\
\text { 2012) }\end{array}$ & & \\
\hline $\begin{array}{l}\text { Coaching and } \\
\text { Management }\end{array}$ & $\begin{array}{l}n=6, \\
12 \%\end{array}$ & $\begin{array}{l}\text { - } \quad \text { Supportive behaviour (Nicolas et al., 2011) } \\
\text { - Coach; Scientific/Technological (Ruiz-Tendero } \\
\text { \& Martín, 2012) }\end{array}$ & $\begin{array}{l}\text { - Coaches Pressure; Lack of understanding with Coach } \\
\text { (Ruiz-Tendero \& Martín, 2012) }\end{array}$ & & $\begin{array}{l}\text { - Unsupportive behaviour } \\
\text { (Nicolas et al., 2011) }\end{array}$ \\
\hline $\begin{array}{l}\text { Health and } \\
\text { Wellbeing }\end{array}$ & $\begin{array}{l}n=6 \\
12 \%\end{array}$ & $\begin{array}{l}\text { - } \quad \text { Supplements (Adams et al., 2016) } \\
\text { - } \quad \text { Recovery interventions (Cook \& Beaven, 2013) } \\
\text { - Medical Support (Ruiz-Tendero \& Martín, } \\
\text { 2012) }\end{array}$ & $\begin{array}{ll}\text { - } & \text { Increased weight (Adams et al., 2016) } \\
\text { - } & \text { Menstrual symptoms (Armour et al., 2020) } \\
\text { - } & \text { Injuries (Ruiz-Tendero \& Martín, 2012) }\end{array}$ & & \\
\hline $\begin{array}{l}\text { Playing } \\
\text { Environment }\end{array}$ & $\begin{array}{l}n=4, \\
8 \%\end{array}$ & & $\begin{array}{l}\text { - Number of matches; Limited recovery time; Long } \\
\text { haul flights (Gouttebarge et al., 2019) } \\
\text { - } \quad \text { Playing surface (López-Fernández et al., 2018) }\end{array}$ & & \\
\hline Physical Factors & $\begin{array}{l}n=1 \\
2 \%\end{array}$ & & $\begin{array}{l}\text { - Plateau of performance (Ruiz-Tendero \& Martín, } \\
\text { 2012) }\end{array}$ & & \\
\hline
\end{tabular}




\subsection{Discussion}

The purpose of this literature review was to explore athletes' perceptions of various factors and how they affect performance. There were 49 factors identified within the 14 studies that were categorised into three groups: intrinsic, extrinsic and both intrinsic and extrinsic. These factors were further categorised by the direction in which they impacted performance and into groups of similarities. This review highlights that the current literature lends a strong focus to athletes' perceptions of different psychological factors and their effect on performance, with the lesser studied categories spanning performance factors, physical factors, the coaching and management staff, health and wellbeing, training, and performance environments.

\subsubsection{Athlete Level}

The range of athlete levels gives insight into perceptions of factors influencing sporting performance across both senior and high-level amateur, as well as professional athletes. This is beneficial in creating an accurate picture of the how perceptions of performance can be impacted across multiple levels of the performance pathway allowing adequate support to those progressing through the pathway and ensuring that athletes performance needs are met as they change with movement through the sporting landscape.

\subsubsection{Sporting Codes}

The results of this literature review show that many sporting codes have been included in studies previously. There is a large emphasis on football within the research which is to be expected due to the world-wide following that football holds as the most popular sport in the world, as well as due to the high distribution of studies based in Europe. The large distribution of sporting codes is a promising sign, with this scope allowing us to understand the 
perceptions of a wide variety athletes across multiple sporting codes, and the similarities and differences across them.

The distribution of sporting participation varies across different continents and generally align with the key sporting codes within the studies country of origin. Two of the key sporting codes within New Zealand, Rugby Union (Cook \& Beaven, 2013; Jones et al., 2014) and Netball (Armour et al., 2020; Jones et al., 2014), were present within this review. However with only one article from within Oceania (Armour et al., 2020) the results have limited ability to reflect upon the athletes perceptions of performance environments within New Zealand. Due to world-leading status of New Zealand in both Rugby and Netball, athletes' perceptions within the New Zealand high-performance sporting environment, may be variable to the findings within this review.

\subsubsection{Knowledge of sport sciences}

Within this review there is discussion around a multitude of disciplines with sport and the sport sciences, including strength and conditioning, sports psychology, sports coaching and management, sports technology, and sports nutrition. However, there is no direct inclusion of performance analysis - a growing field within a large variety of sports, which has a strong focus in finding trends, improving, and maintaining performance across season (M. D. Hughes \& Bartlett, 2002; Mooney et al., 2016). Performance analysis has strong ties to many of the sport sciences due to the analysis of the physical, technical, tactical and psychological areas of sport (Drust, 2010; Mclean et al., 2019). The results of this literature review show research within these areas that could link to performance analysis practices, including strength and conditioning, and the use of technology. Athlete monitoring techniques in strength and conditioning practices may include the use of fitness testing and global positioning systems (GPS), which are important aids in the measurement of player load, capacity to perform and 
their effectiveness within a game (Theodoropoulos et al., 2020), however a direct mention of performance analysis was found to be limited.

\subsubsection{Performance Analysis and its relationship with Strength and Conditioning}

Results indicate that we have information surrounding how athletes perceive the monitoring of various strength and conditioning factors, but not how the goals and outcomes of strength and conditioning are perceived by athletes in relationship to their performance output. With strength and conditioning coaches considered to be integral parts of sports teams since the early 1970's (Massey et al., 2004), it is surprising that there is limited research in how factors such as strength, power, and endurance are perceived by athletes to influence their performance output. Strength training was perceived by athletes to have both a positive and negative impact on performance. Therefore, these results could be due to the perceived transferability of the strength training to the performance. If athletes cannot see the transferability between the two, they may deem strength training as a negative influence on performance. The aforementioned factors of strength, power and endurance, can also sit within the bracket of performance analysis, with links to biomechanical and technique based analysis as well as the potential to aid in tactical analysis, especially through individual sports, such as cycling, and athletics (Hall et al., 2012). Greater muscular strength is often consider beneficial to performance as it improves force-time characteristics (Suchomel et al., 2016). The use of athlete monitoring practices, and monitoring of overall performance, strength and power by a strength and conditioning coach could be a perceived as a positive influence on performance. Especially for athletes that have a strong sense of intrinsic motivation, and want to improve on their own performance, setting and achieving personal bests. This would all be considered in biomechanical analysis and links to the physical aspects of performance. 


\subsubsection{Performance Analysis and its relationship with Sport Psychology}

The largest proportion of factors within this review belonged to the psychological category, which could be caused by the spike in popularity after the 2008 Beijing Olympic games, where it was determined that performance differences across placings were minimal, with $1.34 \%$ differences for men and 1.03\% for women (Birrer \& Morgan, 2010). The positive psychological factors extracted from the literature show that athletes perceive general psychological skills are performance enhancing, and the development of mental toughness and coping skills are key. This perception can be supported by a recent systematic review on mental toughness in sport, which found that $88 \%$ of the included studies showed mental toughness to be a key contributor to success within sport (Cowden, 2017). It could be suggested that without the mental toughness attribute, athletes may be performing at a lower level, achieving less and producing less successful performances. A lack of psychological skills was perceived to be detrimental to performance with an inability to cope with performance anxiety, and being unable to regulate arousal, leading to losses of concentration and, sometimes, a choking effect in performance (Birrer \& Morgan, 2010).

\subsubsection{Performance Analysis and its relationship with Coaching and Management}

The field of performance analysis is placed within and alongside coaching practices, with a large link to informing decisions, about the player, team and opposition, and providing forms of feedback, all whilst aiming to improve performance output. The current literature suggests that athletes believe supportive coaching behaviours, and the use of scientific and technological knowledge are positive contributors to performance. A supportive coach-athlete relationship is one of the main contributing factors in how athletes experience sport (Davis et al., 2018; Davis \& Jowett, 2014) and high levels of performance from athletes are unlikely to occur with limited support from coaches (Hampson \& Jowett, 2014; Helliwell \& Huang, 2011). Having a strong relationship and mutual trust, allows for a more comfortable and satisfying 
work environment (Helliwell \& Huang, 2011). Studies have shown that increased trust in management can improve workplace satisfaction to a similar degree of a $30 \%$ pay rise (Helliwell \& Huang, 2011). In the sporting context, this trust extends to technical, tactical, and physical decisions surrounding the athlete to aid in performance improvement - the fundamental aim of performance analysis. A negative player-coach relationship, increased pressure, and a lack of understanding between the athlete and coach was perceived to have a negative effect on performance, contributing to a disconnection, and a lack of trust regarding the important performance decisions a coach makes.

\subsubsection{Performance Analysis and its relationship to Sports Technology}

The literature does not elaborate on the definition of scientific and technological knowledge within the coaching field; but it could link to a variety of sports science including sports technology and performance analysis. It could link to clothing and equipment advances, similar to the Speedo LZR Racer swimsuit of which over 130 world records were broken with the first 17 months of release and before it was subsequently banned (MacDonald, 2017). Advances such as these may be perceived as positive influences on performance and link to the marginal gains approach. This approach became more prominent after the 2012 London Olympic games, and is defined by the aggregation of multiple small changes in order to improve performance (Hall et al., 2012). The marginal gains approach has strong links to technical and biomechanical analysis, with increases effectiveness across data collection methods, small changes in technology and equipment that can reduce drag and change the weight balance of gear (Hall et al., 2012).

\subsubsection{Suggestions of Performance Analysis in the research}

This study shows that a plateau of performance is perceived by athletes to have a negative effect on performance. The definition of plateau suggests no change or little progress which 
effectively halts performance. Elite athletes have an intrinsic desire to always improve and get better (Ruiz-Tendero \& Martín, 2012), therefore a plateau is an obvious negative influence of most athlete's performance goals. With the primary aim of performance analysis being to improve performance outputs, you would assume while following this logic that athletes' perceptions of performance analysis and its impact on performance would be positive. However, as this review has identified that performance analysis is not present within the current research, we cannot know for certain whether athletes believe performance analysis is a helpful tool in guiding their performance and influencing improvements.

\subsubsection{Links to Attribution theory}

There is a body of psychological research within sport which helps us understand how an athlete responds to various factors within sport, and how one attributes different stimuli to explain causation and evaluate event outcomes. It is also suggested that these attributes can affect future motivation, as well as how one prepares and makes decisions in the future (Gill et al., 2017). Attribution theory, originally compiled by Fritz Heider (1958), is a perceptionbased theory comprised of the combination of stability and the locus of causality and the locus of control, where various factors either permanent or unstable, internal or external to the person, and whether the factor is controllable by the person, are perceived differently in terms of their influence on performance (Gill et al., 2017). Attributes aid in determining much of our understanding of our environment and assist in the formation of our reactions (Heider, 1958).

The current literature surrounding athletes' perceptions of various factors that impact performance, suggests the intrinsic and extrinsic factors are associated to performance to a similar degree. Having a balance between these two categories within the research is ideal, as performance is affected by both types of factors, and we therefore have a greater understanding of how an athlete attributes success and failure. However, this review found 
extrinsic sub-variables are represented in current literature to a greater degree $(n=31)$, than intrinsic sub-variables ( $n=16)$. Having a greater proportion of information regarding the extrinsic factors means we are less aware of how athletes perceive intrinsic factors in relation to performance outcomes and how they attribute the result.

Sport Scientists can adapt and change various factors external to the athlete, such as the training environment and surfaces, as well as assist the athlete in creating internal changes, therefore understanding how athletes perceive both intrinsic and extrinsic factors is vital in sport science. These intrinsic and extrinsic factors can link where the athlete attributes the result to - either internally or externally - as well as the level of controllability. Internal attribution and therefore the intrinsic factors found within this study have a greater degree of controllability stemming from the direct connection between the person and the intrinsic factor, as well as the human ability to change and direct our attention. External attribution, and the related extrinsic factors within the study, have lower controllability as they are outside of ourselves, often within the environment or regarding other people's actions which act upon us. However, there is a self-serving bias within attribution theory where people often attribute success internally and failure externally, to preserve pride and motivation (Gill et al., 2017). Therefore, there is reason to believe that intrinsic factors are more likely to be perceived as positive influencers in performance whereas external factors would be perceived as negative.

\subsubsection{Other key results}

\subsubsection{Personal factors}

Athletes perceive multiple factors as negative influences on performance, including family issues, lack of relative support and parental pressure, constrained finances and conflicts between sport and work and study (Ruiz-Tendero \& Martín, 2012). These personal factors are 
external to the athlete's performance environment, any issues or constraints within this area of the athlete's life could affect their focus on the performance.

Social support has been recognised as a key factor in athlete wellbeing and has been found to be linked to greater recovery, self-confidence and overall performance (Freeman et al., 2011; McCormack et al., 2015). Research in the health sector and with cancer patients supports this notion, with perceived social support has been found to increase the feeling of belonging, and acts as a barrier against high levels of stress therefore aiding in recovery and greater health (Hale et al., 2005; Usta, 2012).Perceived support can lead to athletes believing they have more resources available to them to aid in coping, thereby reducing the stressfulness of performance situations and potentially leading to increased performance (Freeman \& Rees, 2009). With a lack of support from the various institutions and people within the athlete's life, athletes may have increased pressure within their environment. This coupled with a potential lack of coping skills, as discussed under the psychological factors above, may result in a choking effect, minimising the performance outcomes (Fryer et al., 2018).

\subsubsection{Health and Wellbeing}

For many athletes, sporting performance is a fulltime job which requires the mind and body to be in peak physical condition. Therefore, it is understandable that correct nutrition, recovery interventions and the support of medical staff are perceived as positive as they ensure the body is functioning effectively and efficiently in order to perform the skills required in performance. Their sport is often their career or livelihood, with their body as their tool to complete the work within their contract. Without an effectively functioning body and mind they will be unable to perform to the best of their ability, reducing their performance output, which if ongoing can result in the loss of a contract. 
Injuries, and presence of menstrual symptoms can result in a decrease in performance, as they disrupt the balance of the body, and could also affect the athlete's attention and concentration, removing it from the task at hand and reducing the performance output. Previous research shows that attending to an injury, or individual body part, with an internal narrow focus, results in a lesser movement outcome, and lower task performance than having an external focus on the movement environment and the goal (Yamada \& Raisbeck, 2021). There are multiple potential reasons for an athletes attention to change to an internal narrow focus when carrying an injury that may therefore reduce performance (Gray, 2015). The pain of the injury and rehabilitation feedback language may draw focus toward the body part and away from the movement or task at hand, potentially with the focus on technique (Gray, 2015). Athletes may also fear re-injury, and therefore the internal narrow focus may act as a protective factor, to limit over exertion and avoid pain (Ardern et al., 2013; Gray, 2015). Gray (2015) found that expert baseball batters, recovering from injury and with an internal narrow focus on attentional, return to sport with significantly lower performance outcomes.

\subsubsection{Playing environment}

The current literature included within this review explored only negatively perceived variables within the performance environment including long-haul flights, short game turnarounds, and limited recovery time, as well as different playing surfaces. The stressors relating to the international match calendar put strain on the body and can affect the performance output of the athletes involved. Long haul flights can induce the loss of synchronicity in the body's circadian rhythm, commonly known as jet lag (Chapman et al., 2012; Zubac et al., 2020). This can affect sleep, core temperature, gastrointestinal function, and hydration status (Zubac et al., 2020), as well as concentration and motivation, which can impair both mental and physical performance with detrimental effects on jump performance for the first 48 hours after travel found by Chapman (2012). These effects on performance need to be managed well in order 
for athletes to be well prepared for quick match turnaround times, and small recovery periods.

\subsubsection{Strengths and limitations}

This review included 14 studies of various study designs and is the first review of our knowledge that systematically looks at athletes' perceptions of the various influencing factors on performance. The Preferred Reporting Items for Systematic Reviews and Meta-Analyses (PRISMA) checklist allowed a focused reporting of athlete's perceptions of the various factors which may have an influence on performance. This systematic method is a strength in literature-based research. However, due to the heterogeneity between studies, we were unable to assess the methodological quality or complete a meta-analysis.

\subsubsection{Future Implications}

This review has highlighted multiple gaps within the current literature around athlete's perceptions in performance, especially regarding the athletes within New Zealand. With limited current literature describing the perceptions of athletes within Oceania and specifically New Zealand, we are required to apply findings from other countries of which have different levels of support, varying performance and pay structures, different key sporting codes, and contrasting physical and performance environments.

The key sporting codes within New Zealand, Rugby and Netball are mentioned twice each, in the current literature, which cannot allow us a big picture look at these sport specific athletes. Where in comparison, football (soccer) was reported seven times, creating a more complete picture of the factors within football and the athletes within it. The studies in Rugby discuss the perceptions of recovery interventions and social loafing, only providing insight into very 
small dimensions of performance. Comparatively netball is only discussed in terms of athlete's perceptions on the presence on menstrual symptoms and social loafing.

This review discusses the how literature currently has information around the other sport science disciplines, such as strength and conditioning, sport psychology, coaching and management and sports technology. However, performance analysis is not directly reported, despite its growth across sport, and its focus on performance improvement (M. D. Hughes \& Bartlett, 2002; Mooney et al., 2016). Therefore, we do not know how athletes perceive the influence of various analysis processes. For such a growing field, it may be informative to know how athletes may feel about different methods of analysis and whether this impacts their performance in a positive or negative way, especially as one of the goals within the field of performance analysis is to increase the performance outcomes. Despite the connections between most sport sciences fields with the four of the key facets of performance analysis technical, tactical, physical, and psychological - we do not see the presence of notational analysis within this review. The use of statistics and performance indicators is currently heavy within the performance analysis field however the current landscape is shifting away from the traditional performance indicator approach to a complex systems-based approach. Knowing how athletes perceive personal individual statistics influence on performance is important before the potential removal or reduction from the analysis process occurs. To get to this knowledge we first need to examine how athletes perceive their performance and what factors may influence these perceptions.

\subsection{Conclusion}

Athletes' perceptions of various factors and their influence on performance are vast and varied showing a complex web of interrelating parts. We are aware that psychological factors are well studied and are perceived to have a large influence on performance, whether that be 
positive or negative, closely followed by aspects of the training environment including strength and conditioning practices. Gaps were also evident in research surrounding the various sport sciences, with limited knowledge on how athletes perceive performance analysis practices such as the use of statistics, and video. Within the current literature there are gaps in which the relevancy to the New Zealand athlete cohort is limited. With little knowledge on how New Zealand athletes perceive various factors, and a small percentage of literature in this area linked to the national sports of New Zealand, we remain unaware of how factors within the performance environment are perceived across our high-performance environments.

\subsection{In the next chapter}

The next chapter is a prospective cohort study in form of a manuscript, which seeks to fill some of the identified gaps in chapter two. A key take away from the systematic review was the complex nature of performance, with a large number of interrelating parts that are both internal and external to the athlete. With the practice of performance analysis moving away from the use of isolated performance indicators, the next chapter seeks to explore how athletes perceive their performance in an environment without the use of individual performance statistics, and the implications this may on performance analysis practices in netball. Due to the loose manuscript structure, some sections and information may be repeated. 


\section{Chapter Three: Exploring Semi-Elite Netball Players}

\section{Perceptions of Individual Performance Variables}

\subsection{Abstract}

Within netball, a large focus of research has included isolated performance indicators, however a growing body of research suggests that a complex systems-based approach is necessary in understanding sport as a whole. We are unaware of how athletes perceive their individual performance in comparison to their actual performance. This prospective cohort study explored semi-elite athletes' perceptions of individual performance variables and how these relate to their true performance, to aid in our understanding of how performance analysis can be best applied. Nine semi-elite female netball players completed post-match questionnaires across the 2020 ANZ Premiership season, recording their self-perceptions of their individual performances. Athletes significantly perceived their performance to be worse than their true performance $(p<0.001)$. Player's perceptions are influenced by the match result, with a positive result $(p=0.588)$ influencing more closely related performance and perceptions compared to a loss $(p<0.001)$. The frequency of the performed skill and the athlete's exposure to different performance environments also influenced athlete perceptions, with greater exposure resulting in a lower mean difference $(p<0.001)$ than those with lesser exposure $(p<0.001)$. These results suggested that different levels of experience may require various levels of statistical feedback, with national squads requiring less individual feedback than premiership and championship teams.

Keywords: performance analysis; performance perceptions; netball; feedback; key performance indicators 


\subsection{Introduction}

Netball is a sport most commonly played within the Commonwealth and is one of New Zealand's largest female-based sporting code (Chandler et al., 2014; Steele, 1990). Played on a court measuring $30.5 \times 15.25 \mathrm{~m}$ and divided into thirds, players aim to gain and maintain possession while working to the constraints of the court and the rules (Chandler et al., 2014). The game is played by two teams of seven, with seven different positions, including two shooting positions; goal shoot [GS] and goal attack [GA], three midcourt positions; centre $[C]$, wing attack [WA], and wing defence [WD], and two defence positions; goal keep [GK] and goal defence [GD] (McKenzie et al., 2020; Young et al., 2016). Each position has a different role on court, requiring a different skill set and are limited in movement by varying degrees by the lines of the court (Bruce et al., 2018; Cormack et al., 2014; Fox et al., 2013).

Sport can be observed as a complex system (Bruce et al., 2009) with multiple interacting human and non-human parts, which constantly adapt and change with various emerging constraints (Balague et al., 2013; Mclean et al., 2019). McLean and colleagues (2019) work domain analysis (WDA) in netball has helped determine the composition of, and interactions between, the components of netball performance, finding 80 contributing factors to performance. Through this WDA, it is acknowledged that performance analysis is a functional process within the netball environment that can assist in reaching the desired goal. However, there is limited research on perceptions in a netball environment or research detailing how athletes perceive the various components of performance analysis.

Recent research within the netball environment by Croft et al. (2020) has explored the themes and content of coach communication within netball in New Zealand. Results from this study show five dimensions of which the communication during a match fell under including, movement (35.7\%), actions (23.4\%), positioning (16.1\%), strategy (15.7\%) and possession outcomes (9.1\%). Coaches are focused on the player directions, structures, and movement 
patterns, whereas a large amount of research in netball is focused on performance indicators and isolated factors of performance (Croft et al., 2017; Mclean et al., 2019). Coaches are less likely to discuss possession outcomes and the related statistics during a game compared to structural and tactical success, and even less likely to discuss individual player statistics (Croft et al., 2020). Croft et al. (2020) have provided an ecologically valid understanding of communication and feedback during the game from the coach, but we are still unaware of the conversation and feedback from the coach after the conclusion of the game, as well as how players assess their own performance using performance analysis processes, such as the use of individual statistics. The question remains that if coaches are not using individualised statistics in-game to inform player-based decisions, then what relevance are they post-match? Do players require these statistics to inform them of their performance or are they aware of their performance level by intrinsic processes, self-reflection of video footage and other forms of feedback?

To understand how athletes use and perceive the various performance analysis components, we first need to explore how athletes perceive their performance in a broad sense and discover the potential factors that influence these perceptions. This study aimed to explore athletes' perceptions of performance in a netball environment where individual statistics are not reported by coaching personnel, as well as the scope of potential implications these perceptions may have on performance analysis within netball.

\subsection{Methods}

\subsubsection{Time Period}

This prospective cohort study analysed athletes who were contracted with the ANZ Premiership netball competition ( $n=15$ games) which was initially set to run from March through to June 2020 ( $n=16$ rounds). Due to the COVID-19 pandemic the competition was 
delayed until June 2020 and shortened. The modified competition included 15 games, each 48 minutes long, instead of the original 60, and took place over 10 rounds (From June 19 to August 23, 2020).

\subsubsection{Participants}

Ten elite New Zealand-based female Netball players were recruited to participate in this study. Participants were approached as a group through management staff before the season recommencement. The Otago Polytechnic Research Ethics Committee (reference number 850) approved this study and participants provided informed written consent via Qualtrics (Provo, UT).

\subsubsection{Measurements}

\subsubsection{Demographic}

A demographic survey collected self-reported participant information including age, height, and weight prior to study commencement. Additional information was collected on experience level, year of highest experience and the time spent within a high-performance netball environment such as the ANZ Premiership or an equivalent (Appendix B).

\subsubsection{Athlete Perception}

Questionnaires which measured athlete perceptions of individual performance for unitspecific skills (Croft \& Spencer, 2020) were to be completed within 60 minutes post-match via Qualtrics (Provo, UT). The variables of performance included in this study were selected due to their use within the New Zealand netball environment for individual athlete performance monitoring (Croft \& Spencer, 2020). These variables were divided into position-based units (i.e. attack, mid-court, and defence). Prior to data collection participants were also asked to 
rate the difficulty level of their unit specific skills on a 7-point scale ranging from Extremely Easy (1) to Extremely Difficult (7).

\subsubsection{Performance Analysis}

Objective statistical performance data for each participant was obtained through Champion Data (Southbank Victoria, Aus. 2019). Each perception variable is directly related to a performance statistic which are measured live at each venue and displayed online. This data was supplied to each team's analyst and was publicly available via web forum. Appendix $E$ breaks down the variables and their working definitions.

\subsubsection{Data Collection}

Qualtrics (Provo, UT) was used to collect demographic information, consent, and athlete perception data after each game across the 10-week season. Familiarisation of the survey occurred via video conference, prior to the study commencement to reduce the potential learning effect and explain the survey instructions. The survey consists of perception-based questions rated on a Likert scale of $0-100$. Completion of the survey was requested to be within 60 minutes of each games final whistle if they had played for a minimum of 12 minutes (a quarter of the match time). Due to the COVID-19 restrictions on venue numbers and the centralised location of the games away from the home venue, participants were responsible for completing their surveys in a reasonable time frame. Reminders were distributed by management staff and the lead researcher by WhatsApp and email after the final whistle.

\subsubsection{Bias}

Participants were asked to refrain from viewing or discussing any match statistics before the completion of the performance perception survey, and any pre-survey consumption of statistics was to be reported. If statistics had been consumed, perceptions were not collected, 
and the survey was complete. To minimize the effect of recall bias, perception surveys were to be completed at least 30 minutes, and no later than an hour, post-game. Awareness of the match outcome also has potential to create bias within the data, this was tested for at the completion of data collection.

\subsubsection{Data Analysis}

Prior to data analysis, perception data was linked with personal data, anonymised by number, collated, and cleaned. Missing values were removed prior to the analysis process.

\subsubsection{Perceived difficulty}

Perceived skill difficulty was analysed by assigning numeric values to the Likert scale with $1=$ extremely easy, and 7 = extremely difficult. Values were analysed in ranges of Very Easy (11.9), Moderately easy, (2-3.4) Neutral (3.5-4.5), Moderately difficult (4.6-6), and very difficult (6.1-7). These values provide context and may help to explain any differences in skill perceptions and skill performance.

\subsubsection{Normalisation}

To directly compare athlete perceptions to the performance of the athlete, both variables were required to have the same scale. For this reason, minimum-maximum normalisation of each athlete's match statistics collected from Champion Data (Southbank Victoria, Aus. 2019) was completed. This process included finding a range of performance, ranging from poor to excellent as per the perception scale. Data from all athletes involved within the previous three years of the ANZ Premiership was analysed, finding a range (Mean \pm 2 SD) in which $95 \%$ of performances would fit. Statistics were adjusted to 48 minutes of playing time for direct comparison in match time, which was changed from 60 minutes to aid in athlete load management in the condensed post-COVID-19 season. Each match statistic within this study 
was normalised into these ranges to create a value from 0-100, therefore making it directly comparable with the perception values collected, and throughout this paper will be defined as the 'normalised statistic'.

\subsubsection{Analysis Software}

Data was analysed through IBM SPSS Statistics (Version 26). Paired t-tests were used to compare the means between the athlete's perceptions of their performance and their normalised performance statistic. Correlations were categorised as negligible (0-0.1), weak (0.1-0.39), moderate (0.4-0.6.9), strong (0.7-0.89) and very strong (0.9-1.0) (Schober \& Schwarte, 2018). Significance was assessed under the threshold of $p<0.05$, and confidence intervals were set to the threshold of $95 \%$.

\subsubsection{Perception of Performance}

The participants, and therefore the analysis, within this study can be categorised in three ways: 1) group, 2) unit, and 3) experience level. The group category was separated into subcategories to examine each skill in question, and by match result (win/loss). For this study the order of experience level starting with the lowest is as follows: ANZ Premiership participation, National Age Group (i.e. NZ Under 21's), National Development Squad and National team. All players were contracted to an ANZ Premiership team, therefore experience groupings were dictated by the additional team environments. Under this definition the classification of National Age group representation was considered more experienced that the ANZ Premiership despite not all players within these teams being contracted to a franchise. 


\subsection{Results}

\subsubsection{Participants}

Nine elite female netball players were included within this study. One participant was excluded due to poor adherence and prior viewing of statistics. Two participants had season ending injuries however their pre-injury data was included in the analysis of this study (Figure 4). Each participant completed between one and ten match perception surveys ( $M=5.4 \pm$ 3.1). The average response time was 91 seconds and was completed at an average of 52 minutes post-match $(S D=24)$.

Figure 4

Flow chart of participant inclusion and Questionnaire completion

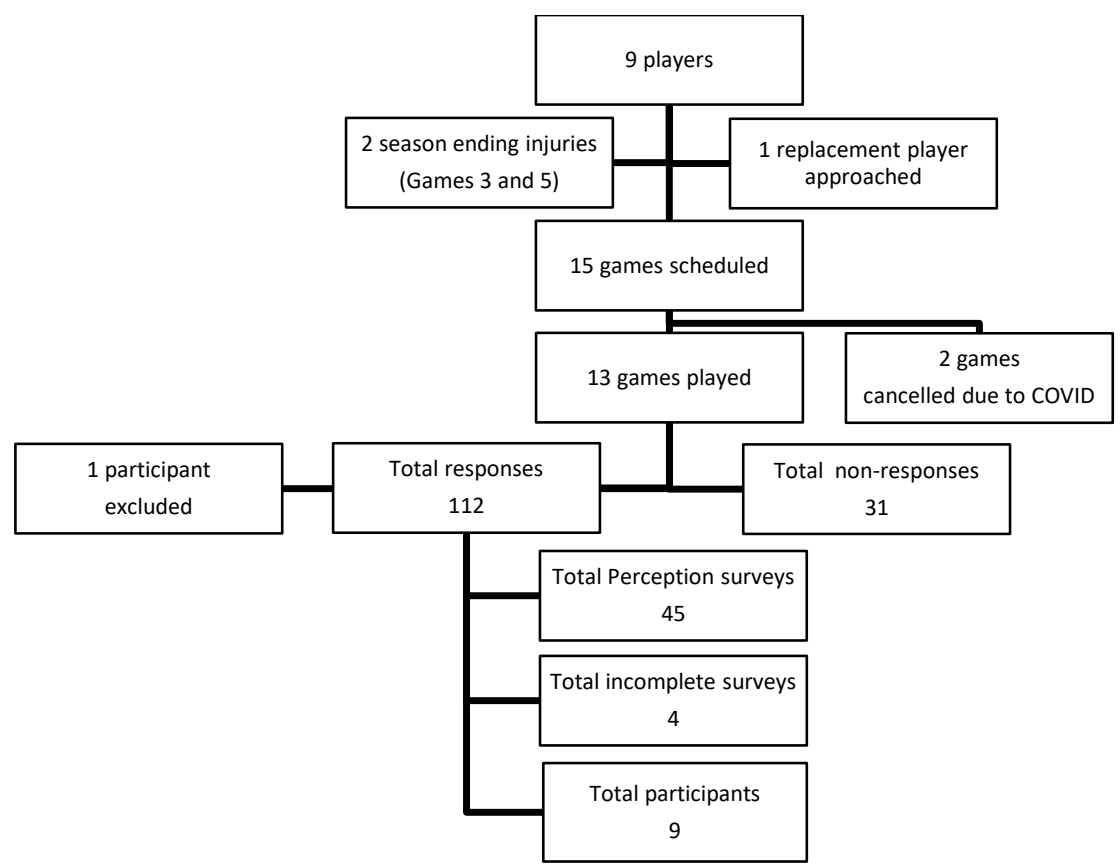

\subsubsection{Descriptive Data}

The participants mean age was 23 years $(S D=3.54)$. The mean height was $181.22 \mathrm{~cm}(S D=$ 5.36) with a mean weight of $78.3 \mathrm{~kg}(S D=9.63)$ (Table 5). Athletes who have previously represented their nation at various levels, contribute to $77 \%$ of participants, with a third of 
the participants having previously competed for their countries at an elite international level (Table 6). Participants had an average court time of 39.26 minutes, over the 13 games played, each 48 minutes long (Table 5). The average number of games where participants were eligible to participate in this study (i.e., played 12 minutes or more) was 8.89 games (SD = 5.16) (Table 5). Five participants played all 13 games, with the lowest number of eligible games being one. There are 22 missing data values, equating to $5.7 \%$ of all data collected.

Table 5

Participant Information

\begin{tabular}{ccccc}
\hline & $\begin{array}{c}\text { Attack } \\
(\mathbf{n}=\mathbf{4}) \\
\text { Mean (SD) }\end{array}$ & $\begin{array}{c}\text { Mid-Court } \\
(\mathbf{n}=\mathbf{3}) \\
\text { Mean (SD) }\end{array}$ & $\begin{array}{c}\text { Defence } \\
(\mathbf{n}=\mathbf{2}) \\
\text { Mean (SD) }\end{array}$ & $\begin{array}{c}\text { Total } \\
(\mathbf{n}=\mathbf{9}) \\
\text { Mean (SD) }\end{array}$ \\
\hline Age (years) & $22(1.83)$ & $25.66(4.93)$ & $21(2.83)$ & $23(3.54)$ \\
Height (cm) & $183.25(6.55)$ & $177.33(3.51)$ & $183(2.83)$ & $181.22(5.36)$ \\
Weight (kg) & $80.25(12.34)$ & $71(1.73)$ & $85.5(0.71)$ & $78.3(9.63)$ \\
Minutes played per game & $36.83(15.07)$ & $45.5(6.50)$ & $28(11.50)$ & $39.26(12.63)$ \\
Games played & $5.25(5.44)$ & $13(0)$ & $10(4.24)$ & $8.89(5.16)$ \\
\hline
\end{tabular}

Table 6

Participant experience breakdown

\begin{tabular}{lccccc}
\hline Experience level & Attack & Mid-Court & Defence & \multicolumn{2}{c}{ Total } \\
\cline { 5 - 6 } & & & & $\mathbf{n}$ & $\%$ \\
\hline National Squad & 1 & 2 & & 3 & $33 \%$ \\
National Development & 1 & 1 & & 2 & $22 \%$ \\
National Age Group Squad & & & 2 & 2 & $22 \%$ \\
ANZ Premiership & 2 & & & 2 & $22 \%$ \\
\hline
\end{tabular}

\subsubsection{Perceived Skill Difficulty}

Prior to the season commencing players perceived intercepting to be the hardest skill, with a mean rating of 6.2(au) $(\mathrm{SD}=0.84)$ or 'Very difficult' (Table 7). Retaining possession of the ball was deemed 'neutral' $(M=4.44, S D=1.24)$ and deflecting the ball out of its path of flight was perceived to be 'moderately difficult' with a mean of $5.4(\mathrm{au})(\mathrm{SD}=1.14)$. All skills were collectively perceived between 'Neutral' and 'Very Difficult'. The attacking unit deemed 
rebounding as 'moderately difficult', whereas the defensive unit rated this skill as 'neutral', with means of $5.75(S D=0.96)$ and $4(S D=1.41)$ respectively.

Table 7

Mean perceptions of skill difficulty prior to season commencement

\begin{tabular}{ccccc}
\hline & $\begin{array}{c}\text { Attack } \\
\text { Mean (SD) }\end{array}$ & $\begin{array}{c}\text { Mid } \\
\text { Mean (SD) }\end{array}$ & $\begin{array}{c}\text { Defence } \\
\text { Mean (SD) }\end{array}$ & $\begin{array}{c}\text { Total } \\
\text { Mean (SD) }\end{array}$ \\
\hline Shooting & $4.75(2.06)$ & & & \\
Rebounding & $5.75(0.96)$ & & $4(1.41)$ & $5.16(1.33)$ \\
Feeding & $4.25(2.22)$ & $5(1)$ & & $4.57(1.72)$ \\
Ball Retention & $4.75(1.71)$ & $4.33(1.15)$ & $4(0)$ & $4.44(1.24)$ \\
Centre Pass Receives & & $5.66(0.58)$ & & \\
Gains & & $6.33(1.15)$ & $5(0)$ & $5.8(1.09)$ \\
Intercepts & $6.33(1.15)$ & $6(0)$ & $6.2(0.84)$ \\
Pick Ups & & $4.66(1.53)$ & $5.5(0.71)$ & $5(1.22)$ \\
Deflection with Gain & & $5.66(1.53)$ & $5(0)$ & $5.4(1.14)$ \\
Deflection no Gain & & $5(1.73)$ & $3.5(0.71)$ & $4.4(1.52)$ \\
\hline
\end{tabular}

\subsubsection{Perceptions of Performance}

\subsubsection{Perceptions by Group.}

Athletes perceived their performance to be lower than their normalised statistic $(p<0.001)$.

The group of athletes studied had a mean perception of $22.29(\mathrm{SD}=23.55)$ and a mean normalised statistic of $31.25(S D=31.04)$, which results in a mean difference of -8.97 (Table 9). These two variables have a statistically significant moderate to high correlation of 0.424 with a p-value of $<0.001$ (Table 8 ). The paired t-test shows the mean difference, and $95 \% \mathrm{Cl}[-$ $12.08,-5.85$ ] to be statistically significant $t(357)=-5.66$ and $p<0.001$, therefore as a group, athletes' perceptions of their performance are below their actual performance (Table 9).

Table 8

Unit and Group mean and correlation data.

\begin{tabular}{cccc}
\hline Unit & \multicolumn{2}{c}{ M(SD) } & Correlation(p) \\
\hline \multicolumn{3}{c}{ Perception Value } & Normalised Value \\
\hline Attack & $13.67(19.45)$ & $30.14(23.96)$ & $0.509(<0.001)$ \\
Mid & $29.56(25.12)$ & $32.21(32.65)$ & $0.503(<0.001)$ \\
Defence & $16.07(19.36)$ & $30.43(33.19)$ & $0.255(0.01)$ \\
Total & $22.29(23.55)$ & $31.25(31.04)$ & $0.424(<0.001)$ \\
\hline
\end{tabular}


Table 9

Paired t-test results for Unit and Group categories

\begin{tabular}{cccccc}
\hline Unit & Mean difference (SD) & Std. Error of Mean & $\mathbf{9 5 \% ~ C l}$ & $\boldsymbol{t}$ & $\boldsymbol{p}$ \\
\hline Attack & $-16.47(21.87)$ & 2.46 & $-21.37,-11.57$ & -6.692 & $<0.001$ \\
Defence & $-14.36(33.89)$ & 3.39 & $-21.08,-7.64$ & -4.237 & $<0.001$ \\
Mid & $-2.65(29.53)$ & 2.21 & $-7.00,1.71$ & -1.200 & 0.232 \\
Total & $-8.97(29.98)$ & 1.58 & $-12.08,-5.85$ & -5.662 & $<0.001$ \\
\hline
\end{tabular}

\subsubsection{Perceptions by Skill.}

The mean differences between players perceptions and actual performance for Deflections with No Gain (-5.84), Gains (-2.06), Intercepts (-0.71), Possession Loss (-5.47) and Rebounds (1.83) are all within 0 (no difference) and the group mean (-8.97), showing that these variables are well perceived by athletes (Figure 5). Ball retention is a clear outlier with players less successful at acknowledging their actual performance of this skill. Pick-ups, deflections to gain and obstruction penalties were all over-perceived, with positive mean difference (Figure 5). Players perceived their pick-up performance to be greater than their normalised statistic resulting in a difference of, 9.48 (Figure 5). The shooting related data shows statistically significant negative mean differences (Figure 5). Players with the ability to shoot, perceived their number of attempts at goal to be lower than their normalised statistic. Perceptions of goals scored were also lower than the normalised statistics.

\subsubsection{Perceptions by Match Result.}

After a loss, players perceived their performance to be significantly worse $(M=19.51, S E=$ 1.31) than the normalised measure of performance $(M=30.65, S E=1.82)$. However, when the game resulted in a win, players perceived their performance higher $(M=31.21, S E=2.95)$ than their normalised performance $(M=33.26, \mathrm{SE}=3.68)$. (Figure 6$)$ 
Figure 5

Forest plot showing the 95\% confidence intervals and mean differences between perceived performance and the normalised statistic of each skill, contextualised by the mean difference of the entire study population.

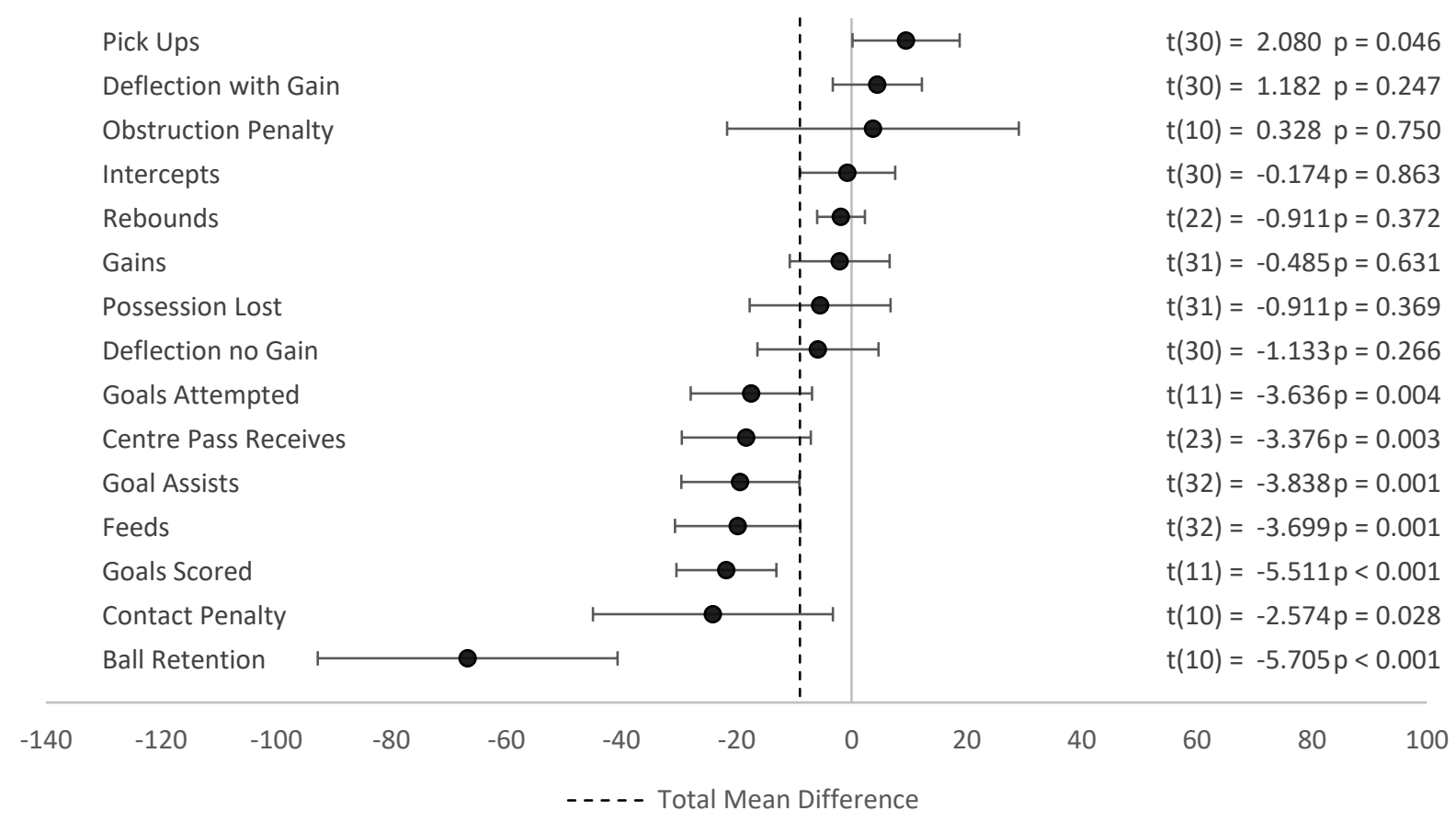

\subsubsection{Perceptions by Positional Unit.}

Of the three unit groups, the attacking unit has the largest mean difference followed closely by the defensive unit (Table 9). The associated confidence interval shows the largest distribution across the three units; however, it is deemed statistically significant $(p<0.001)$ (Figure 7). The mid-court unit has a significantly smaller mean difference in comparison (-2.65) and is closer to zero than the total mean difference of the group (Figure 7).

\section{Figure 6}

Forest plot showing the 95\% confidence intervals and mean differences between perceived performance and the normalised statistic by result, contextualised by the mean difference of the entire study population.

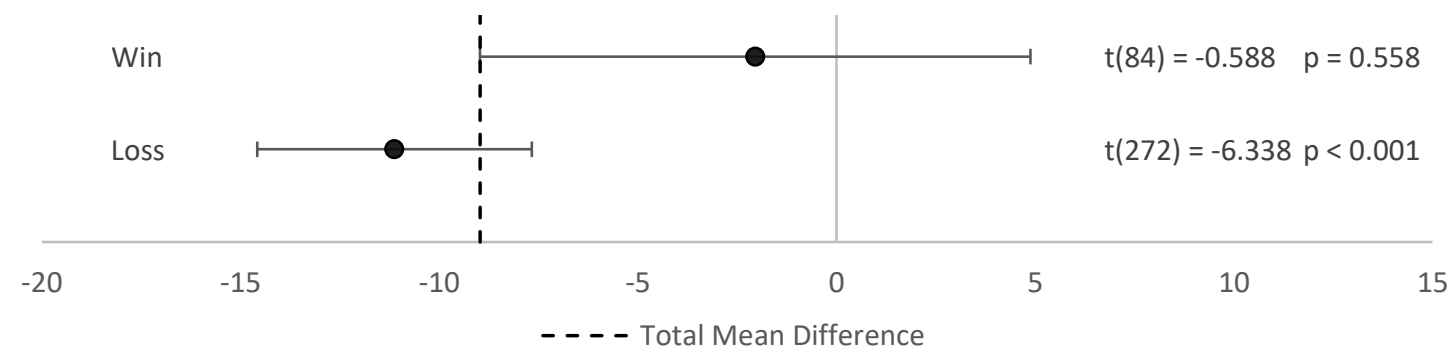


Figure 7

Forest plot showing the 95\% confidence intervals and mean differences between perceived performance and the normalised statistic of each positional unit, contextualised by the mean difference of the entire study population.

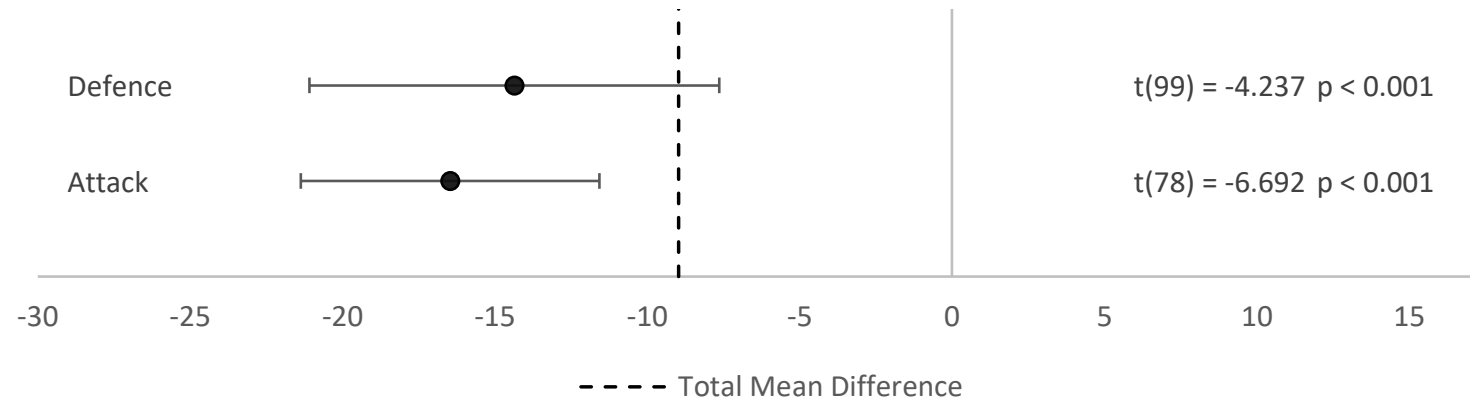

\subsubsection{Perceptions by Experience.}

Players who have experience within national development squads seem to consistently overevaluate their performance (Figure 8). These development athletes' perceptions of their performance $(M=41.10, S E=2.77)$ were higher than their normalised statistic $(M=30.05, S E$ $=3.85$ ), resulting in a mean difference of 11.05 (Figure 8 ). The players who have participated within national teams have the smallest mean difference (Figure 8). This group of players perceptions $(M=21.66, S E=1.79)$ were less than their normalised statistic $(M=32.69, S E=$ 2.33) to a lesser extent than other experience groups, with a mean difference of -10.73 . Players who have only participated in their highest netball within the domestic level and within the ANZ Premiership, have a greater difference in their perception $(M=1.76, S E=0.29)$ and performance $(M=26.71, S E=5.57)($ Figure 8$)$.

\section{Figure 8}

Forest plot showing the 95\% confidence intervals and mean differences between perceived performance and the normalised statistic of each experience group, contextualised by the mean difference of the entire study population

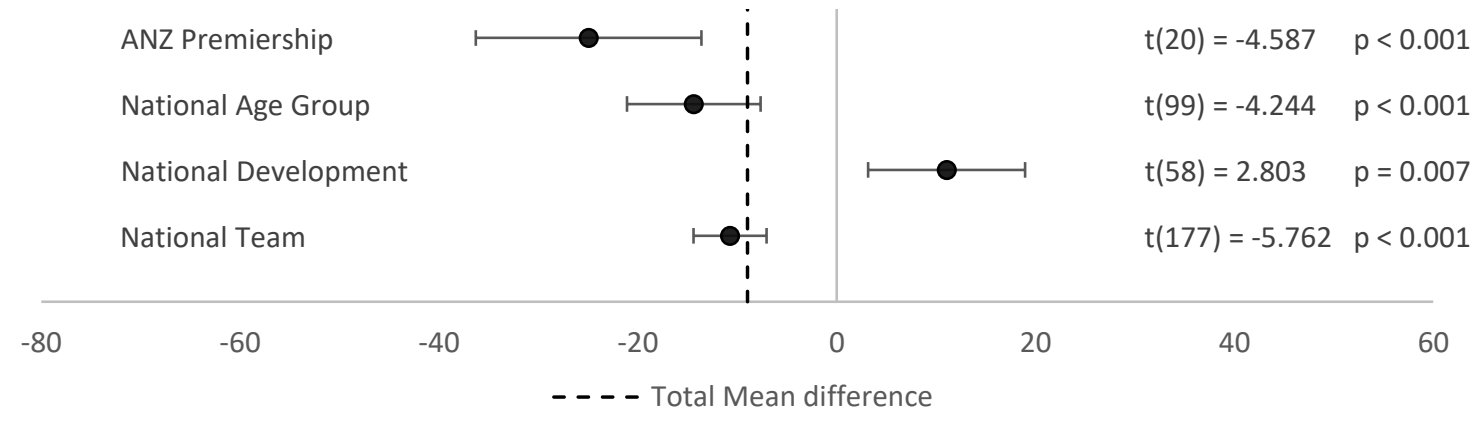




\subsection{Discussion}

The purpose of this study was to explore the semi-elite netball players perceptions of their performance in an environment where individual statistics are not reported, and the potential factors that may be of influence. Results from this study show that athletes perceive their performance to be less than their statistics show. However, these performance perceptions were found to be variable and are influenced by the match result, the level of experience and their exposure to different performance environments. We have also shown that not all performance skills are perceived by athletes to the same degree, with more difficult and less frequent skills being perceived more closely to their performance, compared to less difficult and more common skills.

\subsubsection{General}

Within the Performance analysis profession, the results of this study act as a starting point to understand how and when statistics may be used within the netball team environment. The evidence suggests that within teams of mixed experience such as in the ANZ Premiership, statistics may be a necessary step in the analysis workflow, as the levels of perception, and the knowledge of their individual performances are varied. In these instances, contextualisation of the statistics is important to have meaningful discussions around what 'good' performance is, what the expectations are at each level and in terms of goal setting and player development. However, in teams where experience level is high, or in high-performance teams such as a national squad, statistics may be irrelevant in the review process of these athletes, instead focussing solely on tactical strategy and complete performance, may be more valid and beneficial to the athletes and team.

Athlete's low perceptions of performance could be motivating to that athlete to play/train harder and avoid settling in their performance. The effect of the low perception on 
performance, may be influenced by differences in motivation, and how they attribute success and failure. We therefore do not know how the ongoing development of the complex athlete and their performance may be affected.

\subsubsection{Perceptions by Experience}

Athletes with greater levels of experience and exposure to higher performance environments, will generally have better perceptions than players with less experience. It is accepted that experience is an influential factor among a variety of sports, especially regarding pattern recall, anticipation of play and decision making (Bruce et al., 2009). Bruce et al (2009) explains that this is due to the increased exposure of various critical events within a match, increasing their knowledge on the potential outcomes.

Players within the development pathway over-perceive their performance. The lowest experience group were found to have the lowest perceptions and as experience increased into the development group, perceptions also increased, but the players over perceived their performance, believing they played better than their statistics show. When experience increased further to the national squad, the perceptions of their performance dropped to be closer to, but below their actual performance. These results can be compared to findings within the psychological field, in particular the Dunnings-Kruger effect.

The Dunnings-Kruger effect is often used to explain low skilled, or incompetent people overestimating their true ability compared with more skilled peers (Coutinho et al., 2020; Kruger \& Dunning, 1999; Sullivan et al., 2018). When we analyse our results grouped by experience, we can see that our lower competence athletes do not fit the Dunnings-Kruger model, however our highest level of experience does. One explanation for this could be that although the less experienced athletes are not complete novices, they may perceive themselves to be in this environment. Therefore, they are aware that they are less able than 
the more experienced players, reversing the potential bias, which may skew their perceptions to be lower than their performance. Whereas athletes with greater levels of experience tend to underestimate their ability and performance (Kruger \& Dunning, 1999), perhaps due to a false-consensus effect. This is described in Kruger and Dunning (1999) as participants assuming because they are performing well that their team must be performing at a similar level, regardless of their actual performance, leading them to underestimate their level of performance.

The results from the national development group show an average over perception of their performance. This result could indicate a Dunnings-Kruger effect, as they are working largely in the same environment as the National Squad, however they are less experienced and may be over-confident in their ability due to their elevation into the National Development pathway. As time within this environment increases, we would expect their perceptions of performance to lower slightly, becoming more similar to, or below those of the National squad. This theory is supported by results from Kruger and Dunning (1999) which show that when the incompetent become the expert, their perception becomes more closer to their true score, this change in skill could be due to training or time in the environment. Upon elevation into the national squad, perceptions would be expected to be slightly to be more in tune with their actual performance, yet still below their objective level (Sullivan et al., 2018). These athletes are also often considered as the top players in their national franchise team environment, elevating their perception of their skill, so that when introduced into the national side, their inflated ego creates an over-perception of their performance level.

\subsubsection{Perceptions by Unit}

The mid court unit is the most experienced unit with two out of three participants being of international level. As this study has shown that experience is an important consideration 
when looking at perception, we cannot conclude that position of play is a factor in the perceptions of performance.

\subsubsection{Perceptions by Skill}

The best perceived skills are actions that occur less frequently within the match. Intercepts, rebounds and gains are three of the best perceived skills, yet the frequency these occur within a game is low, reiterating that perhaps skills that lead to a turnover are more important and therefore the perceptions of the performance of these skills, and the ability for athletes to recall these critical events is greater.

Athletes may also be better at perceiving their performance in skills deemed harder, as they could be seen as more important in relation to the game, i.e., they lead to positive possession changes and therefore an increase in the score difference. The results support this theory as Intercepts are perceived as the hardest skill to perform in a game, yet it is one of the best perceived skills. The rules within netball, dictate that each centre pass is alternate, therefore a positive increase in goal difference relies in a turnover from the opposition losing possession, or the team gaining possession via an Intercepts or Deflections to Gain (Appendix A). In the absence of turnovers, the number of possessions would be equal, thus turnovers can be deemed critical in relation to the match outcome. Parallels could be drawn with the aforementioned research which found that football coaches could only remember the $42-59 \%$ of the important or critical events within a game depending on experience (Franks \& Miller, 1986; Laird \& Waters, 2008).

The number of general play turnovers for an athlete can be summated and referred to as possession lost (Appendix A). This tells us how many times a player loses possession of the ball in a match, and therefore calculating the inverse of this statistic creates a measure of ball retention. It was assumed that due to being the derivative of possession lost, ball retention 
would have a comparable level of perception to possession lost. Possession loss was well perceived by each athlete; however, ball retention was a clear outlier in the athletes' perceptions. As this variable is a predicted compound measure, rather than a complete count of the number of possessions retained, athletes may have found this harder to perceive. This was a similar thought process to expectations regarding the perceptions of Gains, which is defined by the sum of Intercepts, Deflections to gain, toss ups won and Defensive Rebounds (Appendix A). However, Gains were well perceived by the athletes, which may show that the nature of compound statistics is less concerning and perhaps the critical nature of an event is more important.

\subsubsection{Athlete's perceptions of performance}

Both sport and the individuals involved with the game are complex therefore there are various factors that could be influential in the formation of their perceptions. Results from the literature review (Chapter two) show that athletes perceive performance to be impacted by many intrinsic and extrinsic factors. These results are supported by the work domain analysis (WDA) chart of netball by McLean and colleagues (2019) which shows the numerous factors that attribute to the team and sporting system. Both Chapter two and the WDA (Mclean et al., 2019) highlight the complex process that is sport, and the interactions of different components which make up performance. We know from McLean and colleagues (2019) that the performance environment is ever changing and complex, with many interacting parts. However, performance analysts are often focused on isolated factors that contribute to the result and can forget that organised sport is the sum of the actions form various people (Mclean et al., 2019). Analysing performance via a complex systems approach allows us to view the coordination and behaviours of the players in relation to time and space, as well the self-organisation that occurs in response to changes in the system (Bruce et al., 2018; Davidson \& Trewartha, 2008; Delextrat \& Goss-Sampson, 2010; Mclean et al., 2019). For a 
performance analyst it increasingly important to consider the performance environment in a broader manner, looking at team coordination, the interactions between players on and off the court (coupling), and the synergy that exists within the system (Silva et al., 2015).

\subsubsection{Strengths and limitations}

A strength of this study is its novelty, allowing it to guide future performance analysis research within the netball environment. It may also inform the analysis process throughout various sports and guide the direction of statistical feedback in sport.

The questionnaire used in this study was based on previously valid and reliable tools (Marsh et al., 2010; Perry \& Marsh, 2003). However, the modified version of the questionnaire used in this study was not validated. To counter this limitation, questionnaire familiarisation was built into the study methodology. Data was self-collected due to the interruption of the season and the reworking of the draw to allow the season to continue post-COVID-19 lockdown. Travel and contact time with the team was therefore reduced significantly, and all correspondence was through video, email or WhatsApp messenger. Participant adherence was also a limitation, which was a result of the reduced contact time with the team.

The number of people within the experience groups is small, and a larger study of the entire competition would give a clearer understanding of how experience influences athletes perceptions. With a larger sample size, the effect of position and unit on perceptions could be explored without the confounding factor of experience.

\subsubsection{Future Implications}

The current study cannot suggest when statistics should be presented within the analysis environment, only that in some netball environments statistics may be less necessary in the review process due to differences in experience and game exposure. It may be that statistics 
may not be required throughout the season in its entirety, instead it is possible that different phases in the season may require a different analysis approach and therefore statistics may be best utilised when taken in and out of the environment across the season. For progression of development athletes, statistics may be most beneficial within the preseason cycle, and then intermittently throughout the season as a monitoring tool, and for progression and goal setting. Further investigation in this direction, could be beneficial for both teams and performance analysts in order to find an approach that is beneficial to all parties.

Athlete perceptions of their performance during a losing a match are significantly worse than when the team is winning. These results were expected due to the nature of the outcome creation in sport, where the work the team puts out on the court, or the performance, is an influential factor in the result. However further exploration of this result is needed to establish whether positive skills in which possession is gained, or a goal is scored, are better perceived in a win compared to a loss, and vice versa. To decrease the effect of expertise on the athlete's perceptions, a study looking directly at certain areas of experience, i.e., the national side or development group, may also be useful.

\subsection{Conclusion}

This study explored how athletes perceive their performance and the factors that may influence them. The results show that the match result and player experience is a large contributing factor to performance perceptions. Skills that occur less frequently within a match are perceived to a greater degree than the variables that occur with higher frequencies. More research within this area may be beneficial in the field of performance analysis and aid in creating discussion around what the players know and what we as analysts may need to provide, to help develop valid feedback systems and greater reflective skills in our athletes. 


\subsection{In the next chapter}

The next chapter aims to summarize the findings from Chapter Two and Three, and evaluate the strengths and weakness of this project, in order to make recommendations for future work and highlight the implications of this research. 


\section{Chapter Four: Discussion}

Athlete's perceptions are an important source of ecologically valid information in sport performance, and therefore understanding these perceptions is key to understanding performance outcomes. The overall aim of this thesis was to explore athletes' perceptions of performance, examine the factors that influence performance, and discuss the implications of these findings in the performance analysis environment. To fulfil this aim, a systematic review (Chapter Two) evaluated the literature about athletes' perceptions of various factors within sport and their effect on performance. A prospective cohort study (Chapter Three) surveyed nine semi-elite netball players' perceptions of their own performance, in a netball environment where individual performance statistics were not reported.

This final chapter discusses the outcomes of Chapter Two and Three (Figure 9) and provides a critical analysis of the strengths, and limitations of the project in its entirety. The implications of this research and further recommendations regarding future research in this area are also discussed.

\subsection{Overview of chapters}

\subsubsection{Chapter Two}

Chapter Two is a literature review exploring current research on athletes' perceptions of various factors and how they affect performance. This review included 14 studies of various methodologies, across 30 sporting codes from a senior to elite level. Findings from this review showed a lack of understanding surrounding athletes' perceptions of performance analysis, as well the physical factors in performance and the growing areas of sport science. There is also limited understanding of athlete perceptions within the New Zealand sport environments and national sports, such as rugby union and netball. 


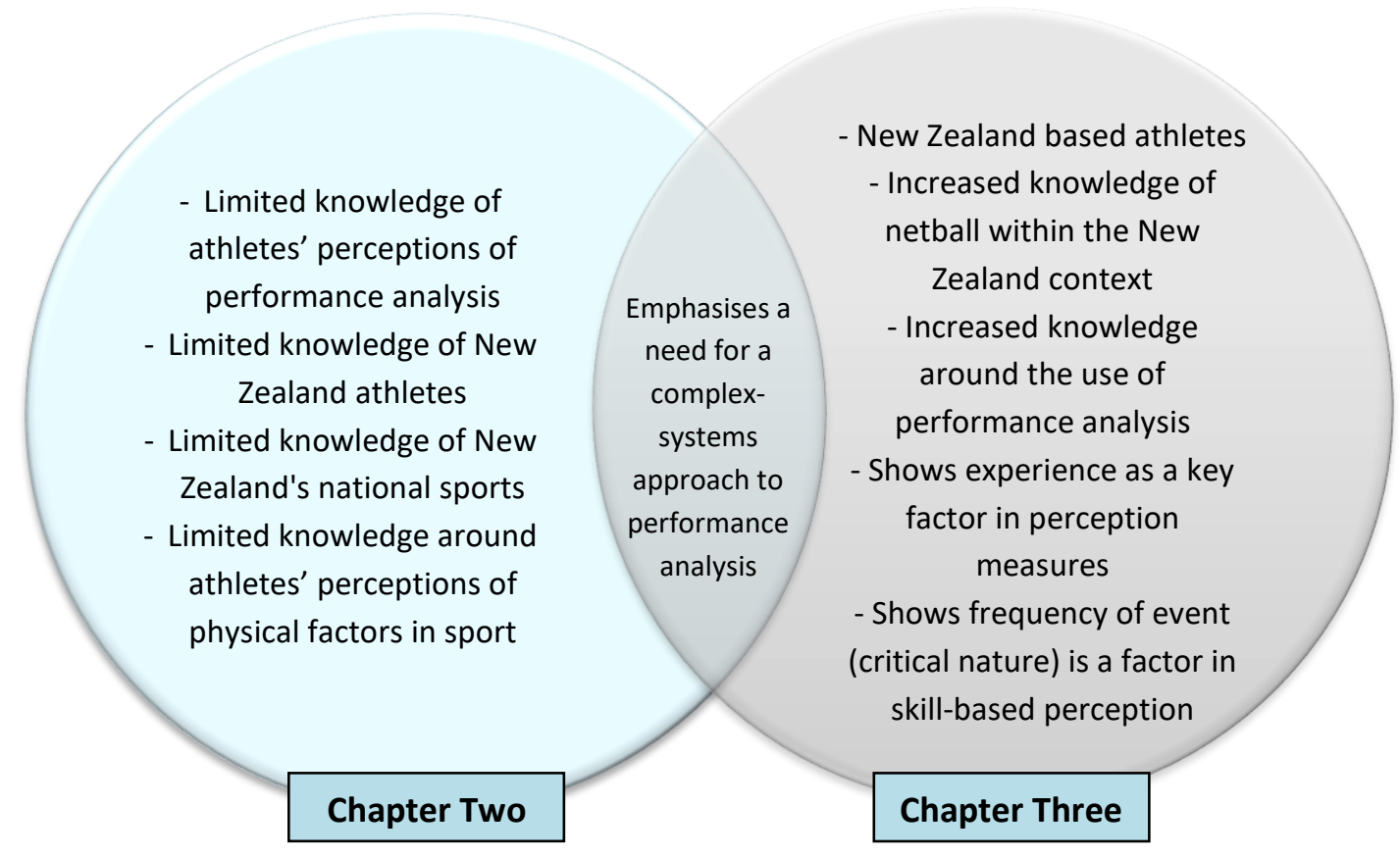

\subsubsection{Chapter Three}

Chapter Three is a prospective cohort study exploring nine semi-elite netball players'

perceptions of their individual performance variables without receiving statistical feedback.

Results showed that athletes perceive their performance to be lesser than what their match

statistics present. These performance perceptions varied across different match results,

performed skills, and the level of training exposure (i.e. Semi-elite franchise to Elite National representation). Athletes had greater perceptions of their performance after a winning match, and when having previous and ongoing experience within the national netball environment. Skills that could be perceived as critical moments within a match, were better perceived than skills that occur more frequently. 


\subsection{Impact in the field of performance analysis}

The results of this thesis show that performance analysts need to consider the complex and dynamic nature of performance, the needs of the coach, and how each person and their performance experiences lead to different needs. These research impacts are explained further below.

\subsubsection{Considerations of analysis methods}

Research from this thesis has shown that there are multiple factors to consider within performance (i.e. psychological, physical, environmental, personal, health, coaching, and management, as seen in Chapter Two) (Figure 9). Through this lens we can infer that performance analysis methods, as well as other sport science practices, need to reflect the complexity in sport to create a well-rounded and accurate picture of performance (Hulme et al., 2019; Mclean et al., 2019). With this in mind, it is important to examine each individual sport, as has been done with netball within the current thesis and decipher the unique complexities within a single sporting code and apply tailored performance analysis techniques to provide players with the most effective form of feedback.

\subsubsection{Responding to the Coach}

Recent research examining the comments coaches made throughout a netball game, showed a high use of movement related comments (35.7\%), followed by actions ( $23.4 \%)$, positioning (16.1\%), strategy (15.7\%) and possession outcomes (9.1\%) (Croft et al., 2020). Key performance indicators in netball, such as centre pass completion, turnover completion and shooting percentage, sit squarely within the possession outcome dimension - the least common dimension found within the coaches' comments. These results show that key performance indicators are only a small portion of the coaches in-match discussion, yet they are currently dominating the performance analysis practice within netball, especially in New 
Zealand. This ecologically valid insight into what coaches discuss during a match, should be our starting point in what we as analysts collect live during a match. It reinforces that although key performance indicators are valid in post-match processes and giving athletes feedback, they do not show the full story, nor do they fully meet the coaches needs during the game. Although the aforementioned study, mostly discusses team performance indicators (Croft et al., 2020), the results support the findings of this thesis, in which performance indicators and complex systems-based approaches need to work in tandem to create the most effective performance analysis environment that attempts to understand the dynamic nature of performance in all sporting codes, especially netball.

\subsubsection{Consideration of experience in feedback}

Results in Chapter Three show that statistical feedback may be a more necessary tool at certain stages of the performance pathway, with more experienced players having a greater understanding and perception of their performance than their less experienced counterparts, which was significantly demonstrated within Chapter Three (Figure 10). Players new to the semi-elite netball league in New Zealand were found to have lower perceptions compared to their true performance as based on their statistics. This shows that perhaps we need higher, more consistent use of individual statistics within the beginning of the performance pathway, to allow athletes to have a greater understanding of what "good" performance is and how changes in various performance statistics may relate to their performance perceptions. Using tailored feedback within different experience contexts could help athletes become more intrinsically aware of their performance output- building a connection between what feels good and what is statistically considered a good performance. However, athletes within the national squad may not require the same level of individual statistics, with results showing there is the potential to minimise their usage to specific timeframes or checkpoints, with limited to no effect on perceived performance outcomes. 
Figure 10

Proposed use of statistics across difference levels of experience

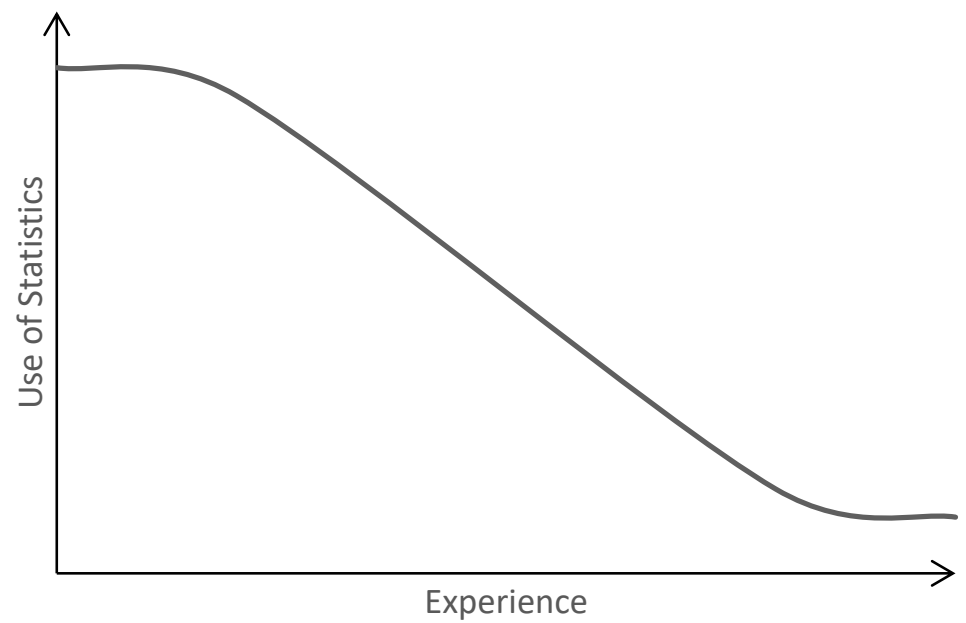

\subsection{Strengths}

This thesis questions the current practice and knowledge within the performance analysis field. With the large majority of performance analysis practice relying on isolated performance factors, this thesis explored the athletes' perception of these isolated factors, the need for and the best practice in the use of individual statistics within the performance analysis environment. Results suggest that the current practices within the field of performance analysis of using isolated performance indicators, may not align with the potential best practice, as such the transferability of research into the "real world" analysis environment is currently limiting (Mclean et al., 2019; McLean et al., 2017). Challenging the current practices allows us to explore possible new theories and practices and how these may enhance the future of this field. Individual performance indicators (e.g. number of mistakes, attempts at goal), do not complete the picture of sporting performance, they are just one piece of the complex puzzle that is sport (Mclean et al., 2019). Although performance indicators still contribute to an athlete and coaches understanding of a game, and are still valid within the performance analysis environment, examination of complex measures, such as player 
interactions, coordination, and external influencing factors, should also be used to provide athletes with well-rounded performance analysis.

The use of a practical, real-world environment in Chapter Three is also a strength within this thesis. With the nationwide COVID-19 lockdown occurring prior to data collection, and the potential for the ANZ Premiership season to be cancelled (as detailed in Chapter One), plans were discussed to use viewing of past matches video footage to simulate performance and collect perceptions of performance based on this. The use of a real time environment, collecting data directly after each competition match across the season is important to ensure athlete recall was fresh and unbiased, using their perceptions and "gut feeling" to complete the study questionnaire. This means that results hold greater validity, in that it measures perceptions of performance, directly after the performance occurs, as opposed to months later, with video as a recall stimulus.

\subsection{Limitations}

Due to the nature of this thesis, and its submission as a partial requirement for a Master's degree, a clear limitation is the singular perspective it holds. It includes a systematic review to synthesise the current literature and a prospective cohort study, which quantitatively explores athletes' perceptions of performance. It does not include a qualitative exploration which could have explained why athletes have certain perceptions about their performances, but this was beyond the scope of this thesis. For example, player interviews and focus groups that explored what performance is, and the direct factors that impacted performance, could have provided greater depth and rationale to the completed studies as well as provided a greater understanding of the specific environment this study was completed within. Future studies should consider including such methodologies to further the understanding performance analysis needs and effectiveness. 
The novelty of this thesis lends itself to be a limitation. Despite all efforts to find validated questionnaires within studies of a similar nature, this topic had yet to be explored in the same way, and therefore the questionnaire within Chapter Three is unvalidated. The creation of this questionnaire, through the adaption of previously validated questionnaires remains unvalidated as the scope of this research did not allow for the validation process to be completed.

The small sample size examined within Chapter Three of this thesis was a convenience sample and all part of the same team. Future studies should examine a larger sample across multiple teams to assess the effects different team environments may have on performance analysis needs and effectiveness.

\subsection{Future directions}

This Master's thesis has identified gaps in the current performance analysis literature, which have been discussed within both Chapters Two and Three. However, an overarching theme, is presented below.

\subsubsection{Need for clarification of best practice}

Further work in netball and around the perceptions of individual athletes, teams, and coaching staff, on the multiple facets of performance analysis as well as the field of performance analysis would be an important step in understanding the sport. Furthermore, the manipulation of the sports science environment within netball may enable us to better understand how different approaches effect outcomes and the environment. Ensuring performance analysis research can be transferred into the practice environment should be a key consideration in research moving forward to help consolidate what best practice is for each sporting code. 


\subsubsection{Ensure transferability of research into practice}

The current best practice within the field of performance analysis, and netball in particular, is not clear, with analysis in general, being further complicated by an increasing pool of information (Croft et al., 2020). The field is currently at a crossroad, between the use of individualised performance indicators and the use of statistics, and the growing approach of complex systems theory (Mclean et al., 2019). Practitioners are aware that sport is complex and requires a complex systems approach, however, the performance analysis field is limited by a lack of funding, technology and a potential lack of education around how to apply the research-based approach into the field-based setting. Further research surrounding the application of complex systems-based analysis in a real-time environment (i.e., live during a match), is important to aid in determining the feasibility and credibility of analysing the interactions and changing dynamics within an applied setting.

\subsubsection{Greater ecological understanding of the performance environment}

Performance analysis is a field that is intertwined with many skills, and therefore requires the analyst to understand different areas e.g., coaching, technique, game management and rules of the game. Various coaching styles and methods of feedback - both statistical and visual create a complex environment that an analyst must navigate. When combining these factors with the dynamic nature of the sport, an intricate set of problems and questions which require various combinations of skills to solve become prevalent. Without a clear understanding of the current best practice, problems can be difficult to solve, and may create a follow-on effect that could be detrimental to performance, results, or even the athletes and coaches involved. One of the shortcomings in sport science research, especially within football, is the failure to consult with real experts, of the subject matter, and methodology (McCall, 2021), which limits our ecological understanding. Therefore, more studies which examine athlete and coach 
perceptions of performance analysis methods, the various facets of the field, and the impact they have on performance improvements is necessary.

\subsubsection{Learning from other sporting codes}

As discussed in Chapter one, and later discussed in the systematic review (Chapter two), football is one of the most well-researched sporting codes, with a substantial base of research in the technical skills (Barnes et al., 2014; Bradley et al., 2013; Kelly et al., 2020; Kubayi, 2021), tactical (Burton et al., 2011; Campos et al., 2016; Diment, 2014; Monteiro et al., 2018; Norouzi et al., 2019; Shigeno et al., 2019; Wood et al., 2015), physical (Abbott et al., 2018; Barnes et al., 2014; Bloomfield et al., 2007; Bradley et al., 2013; Jara et al., 2019; Ortega et al., 2016) and psychological needs (Burton et al., 2011; Campos et al., 2016; Diment, 2014; Monteiro et al., 2018; Norouzi et al., 2019; Shigeno et al., 2019; Wood et al., 2015), which gives us a wide range of understanding (Mackenzie \& Cushion, 2013; McLean et al., 2017)

Multiple systematic reviews within football have explored these areas which allows us a summative understanding on specific areas of interest (Caicedo-Parada et al., 2020; Goes et al., 2021; Low et al., 2020; Sarmento et al., 2014, 2018; Whitehead et al., 2018). With less research completed in netball, there is less knowledge to be able to ascertain a summative understanding of performance and its relative parts, i.e., the technical, tactical, physical and psychological areas of the sport. We have a broad body of literature, but these results are not summarised and presented in a way to best aid decisions makers, therefore our picture is less accurate. Topics that have been studied and reviewed that hold benefit within football, such as the use of big data (Goes et al., 2021), micro-technologies (Whitehead et al., 2018) and tactical actions (Low et al., 2020) are yet to be thoroughly explored in netball. These topics may be ideal for further exploration and could aid in closing some of the gaps within the complete understanding of netball. 
Despite this greater understanding of performance analysis throughout the research, the transferability into practice has been minimal (McLean et al., 2017). A lack of standardised operational definitions, and a lack of match context, using questionable research practices and with a lack of expert consultation are just some of the challenges in transferring the evidence into practice within football (McCall, 2021; McLean et al., 2017). For these challenges to exist within the biggest sport in the world (i.e., football), it is expected that they will also be prevalent across other sports, including netball. However, drawing from research from larger and highly documented sports will ensure that analysis in netball can potentially bypass the issues that have plagued other sports in the past. Streamlining the performance analysis practice quicker and with less confounding research, ensuring a better picture of what netball performance is, and how an analyst can assist teams in improving it.

\subsection{Conclusion}

This Master's thesis explored athletes' perceptions of performance and the numerous factors that influence performance while discussing the implications within the performance analysis environment. The results within this thesis highlight that both athletes and performance are multifaceted, with many factors influencing performance-based perceptions. With a large emphasis on statistical feedback in practice and a complex systems-based approach in research, this thesis has taken a step forward in exploring athletes' perceptions and questioning the current practices in performance analysis. It suggests that there is no one size fits all approach, and individual statistical feedback still has a place within performance environments alongside a complex systems-based approach albeit its usefulness is likely athlete experience dependent. The two methods of analysis, working in tandem, allows an analyst to capture a more complete view of performance. 


\section{References}

Abbott, W., Brickley, G., \& Smeeton, N. J. (2018). Physical demands of playing position within English Premier League academy soccer. Journal of Human Sport and Exercise, 13(2), 285-295. https://doi.org/10.14198/jhse.2018.132.04

Adams, V. J., Goldufsky, T. M., \& Schlaff, R. A. (2016). Perceptions of body weight and nutritional practices among male and female National Collegiate Athletic Association Division II athletes. Journal of American College Health, 64(1), 19-24. http://search.ebscohost.com/login.aspx?direct=true\&db=s3h\&AN=111555013\&site=eho st-live

Ardern, C. L., Taylor, N. F., Feller, J. A., Whitehead, T. S., \& Webster, K. E. (2013). Psychological responses matter in returning to preinjury level of sport after anterior cruciate ligament reconstruction surgery. American Journal of Sports Medicine, 41(7), 1549-1558. https://doi.org/10.1177/0363546513489284

Armour, M., Parry, K. A., Steel, K., \& Smith, C. A. (2020). Australian female athlete perceptions of the challenges associated with training and competing when menstrual symptoms are present. International Journal of Sports Science \& Coaching, 15(3), 316-323.

http://search.ebscohost.com/login.aspx?direct=true\&db=s3h\&AN=143357919\&site=eho st-live

Bagatin, R., Padilha, M., Milheiro, A., Rodrigues, G., Tavares, F., \& Casanova, F. (2017). Perception and action in soccer: Performance comparison under different perceived effort intensities in Small-Sided and Conditioned Games. Revista Portuguesa de Ciências Do Desporto, 2017(S1A), 367-374. https://doi.org/10.5628/rpcd.17.s1a.367

Balague, N., Torrents, C., Hristovski, R., Davids, K., \& Araújo, D. (2013). Overview of complex systems in sport. Journal of Systems Science and Complexity, 26(1), 4-13. https://doi.org/10.1007/s11424-013-2285-0

Barnes, C., Archer, D. T., Hogg, B., Bush, M., \& Bradley, P. S. (2014). The Evolution of Physical and Technical Performance Parameters in the English Premier League. International Journal of Sports Medicine, 35(13), 1095-1100. https://doi.org/10.1055/s-0034-1375695

Birrer, D., \& Morgan, G. (2010). Psychological skills training as a way to enhance an athlete's performance in high-intensity sports. Scandinavian Journal of Medicine \& Science in Sports, 20(2), 78-87.

http://web.a.ebscohost.com.ergo.southwales.ac.uk/ehost/detail/detail?vid=0\&sid=fa55 e93e-c173-4814-82b5-

2acd8ccd4fb3\%40sessionmgr4008\&bdata=JnNpdGU9ZWhvc3QtbG|2ZQ\%3D\%3D\#AN=53 $474882 \& d b=a 9 h$

Bloomfield, J., Polman, R., \& O'Donoghue, P. (2007). Physical demands of different positions in FA Premier League soccer. Journal of Sports Science and Medicine, 6(1), 63-70.

Boyd, J. M., Andrews, A. M., Wojcik, J. R., \& Bowers, C. J. (2017). Perceptions of NCAA Division I Athletes on Strength Training. Sport Journal, 1.

http://search.ebscohost.com/login.aspx?direct=true \&db=s3h\&AN=123270052\&site=eho st-live

Boyer, E., Miltenberger, R. G., Batsche, C., Fogel, V., \& LeBlanc, L. (2009). Video Modeling By 
Experts With Video Feedback To Enhance Gymnastics Skills. Journal of Applied Behavior Analysis, 42(4), 855-860. https://doi.org/10.1901/jaba.2009.42-855

Bradley, P. S., Lago-Peñas, C., Rey, E., \& Gomez Diaz, A. (2013). The effect of high and low percentage ball possession on physical and technical profiles in English FA Premier League soccer matches. Journal of Sports Sciences, 31(12), 1261-1270. https://doi.org/10.1080/02640414.2013.786185

Bruce, L., Brooks, E. R., \& Woods, C. T. (2018). Team and seasonal performance indicator evolution in the ANZ Championship netball league. Journal of Sports Sciences, 36(24), 2771-2777. https://doi.org/10.1080/02640414.2018.1473099

Bruce, L., Farrow, D., Raynor, A., \& May, E. (2009). Notation analysis of skill expertise differences in netball. International Journal of Performance Analysis in Sport, 9(2), 245254. https://doi.org/10.1080/24748668.2009.11868481

Bueno, M. J. de O., Silva, M., Cunha, S. A., Torres, R. da S., \& Moura, F. A. (2021). Multiscale fractal dimension applied to tactical analysis in football: A novel approach to evaluate the shapes of team organization on the pitch. PLOS ONE, 16(9), 1-14. https://doi.org/10.1371/journal.pone.0256771

Burton, D., Gillham, A., \& Glenn, S. (2011). Motivational styles: Examining the impact of personality on the self-talk patterns of adolescent female soccer players. Journal of Applied Sport Psychology, 23(4), 413-428. https://doi.org/10.1080/10413200.2011.568469

Butterworth, A., O'Donoghue, P., \& Cropley, B. (2013). Performance profiling in sports coaching: A review. International Journal of Performance Analysis in Sport, 13(3), 572593. https://doi.org/10.1080/24748668.2013.11868672

Caicedo-Parada, S., Lago-Peñas, C., \& Ortega-Toro, E. (2020). Passing networks and tactical action in football: A systematic review. International Journal of Environmental Research and Public Health, 17(6649), 1-19. https://doi.org/10.3390/ijerph17186649

Campos, G. G., Valdivia-Moral, P., Zagalaz, J. C., \& Ortega, F. Z. (2016). Visualisation and goalsetting in footballers. Journal of Human Sport and Exercise, 11(2), 279-291. https://doi.org/10.14198/jhse.2016.112.01

Chandler, P. T., Pinder, S. J., Curran, J. D., \& Gabbett, T. J. (2014). Physical Demands of Training and Competition in Collegiate Netball Players. Journal of Strength \& Conditioning Research, 28(10), 2732-2737.

Chapman, D. W., Bullock, N., Ross, A., Rosemond, D., \& Martin, D. T. (2012). Detrimental effects of West to East transmeridian flight on jump performance. European Journal of Applied Physiology, 112(5), 1663-1669. https://doi.org/10.1007/s00421-011-2134-6

Cook, C. J., \& Beaven, C. M. (2013). Individual perception of recovery is related to subsequent sprint performance. British Journal of Sports Medicine, 47(11), 705. https://doi.org/http://dx.doi.org/10.1136/bjsports-2012-091647

Cormack, S. J., Smith, R. L., Mooney, M. M., Young, W. B., \& O’Brien, B. J. (2014). Accelerometer load as a measure of activity profile in different standards of netball match play. International Journal of Sports Physiology and Performance, 9(2), 283-291. https://doi.org/10.1123/IJSPP.2012-0216 
Coutinho, M. V. C., Thomas, J., Fredricks-Lowman, I., \& Bondaruk, M. V. (2020). The DunningKruger effect in Emirati college students: Evidence for Generalizability across cultures. International Journal of Psychology and Psychological Therapy, 20(1), 29-36.

Cowden, R. G. (2017). Mental Toughness and Success in Sport: A Review and Prospect. The Open Sports Sciences Journal, 10(1), 1-14. https://doi.org/10.2174/1875399x01710010001

Croft, H., \& Spencer, K. (2020). An evaluation of data sources in netball performance analysis. [Conference Presentation]. Sport and Exercise Science New Zealand, 28. https://sesnz.org.nz/wp-content/uploads/2020/11/SESNZ-2020-Booklet-V4.pdf

Croft, H., Spencer, K., \& Robertson, S. (2020). What tactical and technical comments do coaches make during netball matches ? A content analysis in netball. International Journal of Performance Analysis in Sport. https://doi.org/10.1080/24748668.2020.1846112

Croft, H., Willcox, B., \& Lamb, P. (2017). Using performance data to identify styles of play in netball: an alternative to performance indicators. International Journal of Performance Analysis in Sport, 17(6), 1034-1043. https://doi.org/10.1080/24748668.2017.1419408

Davidson, A., \& Trewartha, G. (2008). Understanding the Physiological Demands of Netball: a time-motion investigation. International Journal of Performance Analysis in Sport, 8(3), 1-17. https://doi.org/10.1080/24748668.2008.11868443

Davis, L., Appleby, R., Davis, P., Wetherell, M., \& Gustafsson, H. (2018). The role of coachathlete relationship quality in team sport athletes' psychophysiological exhaustion: implications for physical and cognitive performance. Journal of Sports Sciences, 36(17), 1985-1992. https://doi.org/10.1080/02640414.2018.1429176

Davis, L., \& Jowett, S. (2014). Coach-athlete attachment and the quality of the coach-athlete relationship: implications for athlete's well-being. Journal of Sports Sciences, 32(15), 1454-1464. https://doi.org/10.1080/02640414.2014.898183

Delextrat, A., \& Goss-Sampson, M. (2010). Kinematic analysis of netball goal shooting: A comparison of junior and senior players. Journal of Sports Sciences, 28(12), 1299-1307. https://doi.org/10.1080/02640414.2010.498482

Diment, G. M. (2014). Mental skills training in soccer: A drill-based approach. Journal of Sport Psychology in Action, 5(1), 14-27. https://doi.org/10.1080/21520704.2013.865005

Drust, B. (2010). Performance analysis research: Meeting the challenge. Journal of Sports Sciences, 28(9), 921-922. https://doi.org/10.1080/02640411003740769

Elo, S., \& Kyngäs, H. (2008). The qualitative content analysis process. Journal of Advanced Nursing, 62(1), 107-115. https://doi.org/10.1111/j.1365-2648.2007.04569.x

Fox, A., Spittle, M., Otago, L., \& Saunders, N. (2013). Activity profiles of the Australian female netball team players during international competition: Implications for training practice. Journal of Sports Sciences, 31(14), 1588-1595. https://doi.org/10.1080/02640414.2013.792943

Franks, I. M., \& Miller, G. (1986). Eyewitness Testimony in Sport. Journal of Sport Behavior, 9(1), 38-45. 
Freeman, P., Coffee, P., \& Rees, T. (2011). The PASS-Q: The perceived available support in sport questionnaire. Journal of Sport and Exercise Psychology, 33(1), 54-74. https://doi.org/10.1123/jsep.33.1.54

Freeman, P., \& Rees, T. (2009). How does perceived support lead to better performance? An examination of potential mechanisms. Journal of Applied Sport Psychology, 21(4), 429441. https://doi.org/10.1080/10413200903222913

Fryer, A. M., Tenenbaum, G., \& Chow, G. M. (2018). Linking performance decline to choking: players' perceptions in basketball. Journal of Sports Sciences, 36(3), 256-265. http://search.ebscohost.com/login.aspx?direct=true\&db=s3h\&AN=126098264\&site=eho st-live

García-González, L., Moreno, M. P., Moreno, A., Gil, A., \& Del Villar, F. (2013). Effectiveness of a video-feedback and questioning programme to develop cognitive expertise in sport. PLOS ONE, 8(12), 1-12. https://doi.org/10.1371/journal.pone.0082270

Garhammer, J., \& Newton, H. (2013). Applied Video Analysis For Coaches: Weightlifting Examples. International Journal of Sport Science \& Coaching, 8(3), 581-593. http://web.a.ebscohost.com.op.idm.oclc.org/ehost/pdfviewer/pdfviewer?vid=1\&sid=2b 68f51c-f9cd-4376-89e0-f822a91da25e\%40sdc-v-sessmgr01

Gasston, V., \& Simpson, C. (2004). A netball specific fitness test. International Journal of Performance Analysis in Sport, 4(2), 82-96. https://doi.org/10.1080/24748668.2004.11868307

Gill, D., Williams, L., \& Reifsteck, E. (2017). Psychological Dynamics of Sport and Exercise (4th ed.). Human Kinetics.

https://books.google.co.nz/books?hl=en\&lr=\&id=ePR6DwAAQBAJ\&oi=fnd\&pg=PR1\&dq= psychological+dynamics+of+sport+and+exercise\&ots=|BorjNeDTh\&sig=Vhuot7EWPoAkLf SNN8V-OqzRgGI\#v=onepage\&q=psychological dynamics of sport and exercise\&f=false

Glazier, P. S. (2010). Game, set and match? Substantive issues and future directions in performance analysis. Sports Medicine, 40(8), 625-634. https://doi.org/10.2165/11534970-000000000-00000

Goes, F. R., Meerhoff, L. A., Bueno, M. J. O., Rodrigues, D. M., Moura, F. A., Brink, M. S., Elferink-Gemser, M. T., Knobbe, A. J., Cunha, S. A., Torres, R. S., \& Lemmink, K. A. P. M. (2021). Unlocking the potential of big data to support tactical performance analysis in professional soccer: A systematic review. European Journal of Sport Science, 21(4), 481496. https://doi.org/10.1080/17461391.2020.1747552

Gouttebarge, V., Brink, M. S., \& Kerkhoffs, G. M. M. J. (2019). The perceptions of elite professional footballers on the International Match Calendar: a cross-sectional study. Science \& Medicine in Football, 3(4), 339-342. http://search.ebscohost.com/login.aspx?direct=true\&db=s3h\&AN=139364535\&site=eho st-live

Gray, R. (2015). Differences in attentional focus associated with recovery from sports injury: Does injury induce an internal focus? Journal of Sport and Exercise Psychology, 37(6), 607-616. https://doi.org/10.1123/jsep.2015-0156

Guadagnoli, M., Holcomb, W., \& Davis, M. (2002). The efficacy of video feedback for learning the golf swing. Journal of Sports Sciences, 20(8), 615-622. 
https://doi.org/10.1080/026404102320183176

Hale, C. J., Hannum, J. W., \& Espelage, D. L. (2005). Social support and physical health: The importance of belonging. Journal of American College Health, 53(6), 276-284. https://doi.org/10.3200/JACH.53.6.276-284

Hall, D., James, D., \& Marsden, N. (2012). Marginal gains: Olympic lessons in high performance for organisations. HR Bulletin: Research and Practice, 7(2), 9-13. http://eprints.port.ac.uk/10012/

Hampson, R., \& Jowett, S. (2014). Effects of coach leadership and coach-athlete relationship on collective efficacy. Scandinavian Journal of Medicine and Science in Sports, 24(2), 454-460. https://doi.org/10.1111/j.1600-0838.2012.01527.x

Heider, F. (1958). The Psychology of Interpersonal Trust. In The Psychology of Interpersonal Trust (pp. 1-19). Wiley. https://doi.org/10.4324/9781351035743

Helliwell, J. F., \& Huang, H. (2011). Well-Being and Trust in the Workplace. Journal of Happiness Studies, 12(5), 747-767. https://doi.org/10.1007/s10902-010-9225-7

Hughes, M. D., \& Bartlett, R. M. (2002). The use of performance indicators in performance analysis. Journal of Sports Sciences, 20(10), 739-754. https://doi.org/10.1080/026404102320675602

Hughes, M., \& Franks, I. M. (2015). Essentials of Performance Analysis in Sport: second edition (Second). Routledge.

https://books.google.co.nz/books?id=HfMjCQAAQBAJ\&printsec=frontcover\#v=onepage $\& q \& f=$ false

Hulme, A., McLean, S., Read, G. J. M., Dallat, C., Bedford, A., \& Salmon, P. M. (2019). Sports Organizations as Complex Systems: Using Cognitive Work Analysis to Identify the Factors Influencing Performance in an Elite Netball Organization. Frontiers in Sports and Active Living, 1(56), 1-12. https://doi.org/10.3389/fspor.2019.00056

Jaeschke, A. M. C., Sachs, M. L., \& Dieffenbach, K. D. (2016). Ultramarathon runners' perceptions of mental toughness: A qualitative inquiry. Sport Psychologist, 30(3), 242255. https://doi.org/10.1123/tsp.2014-0153

Jara, D., Ortega, E., Gómez-Ruano, M. Á., Weigelt, M., Nikolic, B., \& de Baranda, P. S. (2019). Physical and tactical demands of the goalkeeper in football in different small-sided games. Sensors (Switzerland), 19(16), 1-13. https://doi.org/10.3390/s19163605

Jones, G. W., Høigaard, R., \& Peters, D. M. (2014). "Just Going Through the Motions....": A Qualitative Exploration of Athlete Perceptions of Social Loafing in Training and Competition Contexts -- Implications for Team Sport Coaches. International Journal of Sports Science \& Coaching, 9(5), 1067-1082.

http://search.ebscohost.com/login.aspx?direct=true \&db=s3h\&AN=108776769\&site=eho st-live

Kelly, A., Wilson, M. R., Jackson, D. T., \& Williams, C. A. (2020). Technical testing and match analysis statistics as part of the talent development process in an English football academy. International Journal of Performance Analysis in Sport, 20(6), 1035-1051. https://doi.org/10.1080/24748668.2020.1824865

Kruger, J., \& Dunning, D. (1999). Unskilled and Unaware of It: How difficulties in Recognizing 
One's OWn Incompetence Lead to Inflated Self-Assessments. 77(6).

Kubayi, A. (2021). Technical demands of the various playing positions in the qualifying matches for the European football championship. International Journal of Performance Analysis in Sport, 21(3), 374-382. https://doi.org/10.1080/24748668.2021.1901436

Laird, P., \& Waters, L. (2008). Eyewitness Recollection of Sport Coaches. International Journal of Performance Analysis in Sport, 8(1), 76-84. https://doi.org/10.1080/24748668.2008.11868424

Liberati, A., Altman, D. G., Tetzlaff, J., Mulrow, C., Gøtzsche, P. C., loannidis, J. P. A., Clarke, M., Devereaux, P. J., Kleijnen, J., \& Moher, D. (2009). The PRISMA statement for reporting systematic reviews and meta-analyses of studies that evaluate healthcare interventions: explanation and elaboration. BMJ (Clinical Research Ed.), 339.

https://doi.org/10.1136/bmj.b2700

Light, D., Wexler, D. H., \& Heinze, J. (2005). Keeping teachers in the center: A framework for data-driven decision-making. Proceedings of Society for Information Technology \& Teacher Education International Conference 2005, 128-133. http://www.editlib.org/index.cfm?fuseaction=Reader.ViewAbstract\&paper_id=18964\&fr om=NEWDL

López-Fernández, J., Sánchez-Sánchez, J., Rodríguez-Cañamero, S., Ubago-Guisado, E., Colino, E., \& Gallardo, L. (2018). Physiological responses, fatigue and perception of female soccer players in small-sided games with different pitch size and sport surfaces. Biology of Sport, 35(3), 291-299.

http://search.ebscohost.com/login.aspx?direct=true\&db=s3h\&AN=131749017\&site=eho st-live

Low, B., Coutinho, D., Gonçalves, B., Rein, R., Memmert, D., \& Sampaio, J. (2020). A Systematic Review of Collective Tactical Behaviours in Football Using Positional Data. Sports Medicine, 50(1), 343-385. https://doi.org/10.5114/BIOLSPORT.2020.96321

MacDonald, R. (2017). "Doping on a hanger": Regulatory lessons from the FINA elimination of the polyurethane swimsuit applied to the International Anti-Doping paradigm. Columbia Journal of Law and Social Problems, 51(2), 275-314.

Mackenzie, R., \& Cushion, C. (2013). Performance analysis in football: A critical review and implications for future research. Journal of Sports Sciences, 31(6), 639-676.

https://doi.org/10.1080/02640414.2013.807352

Marsh, H. W., Martin, A. J., \& Jackson, S. (2010). Introducing a short version of the physical self description questionnaire: New strategies, short-form evaluative criteria, and applications of factor analyses. Journal of Sport and Exercise Psychology, 32(4), 438-482. https://doi.org/10.1123/jsep.32.4.438

Massey, C. D., Vincent, J., \& Maneval, M. (2004). Job Analysis of College Division I-A Football Strength and Conditioning Coaches. Journal of Strength and Conditioning Research, 18(1), 19-25.

McCall, A. (2021). Research in football: evolving and lessons we can learn from our mistakes. Science and Medicine in Football, 5(2), 87-89. https://doi.org/10.1080/24733938.2021.1899275

McCormack, H. M., Maclntyre, T. E., O’Shea, D., Campbell, M. J., \& Igou, E. R. (2015). Practicing 
what we preach: Investigating the role of social support in sport psychologists' wellbeing. Frontiers in Psychology, 6(DEC), 1-12. https://doi.org/10.3389/fpsyg.2015.01854

McKenzie, C. R., Whatman, C., \& Brughelli, M. (2020). Performane Profiling of Female Youth Netball Players. Journal of Strength and Conditioning Research, 34(11), 3275-3283. https://doi.org/10.31857/s0367676520010160

Mclean, S., Hulme, A., Mooney, M., Read, G. J. M., Bedford, A., \& Salmon, P. M. (2019). A systems approach to performance analysis in women's netball: Using work domain analysis to model elite netball performance. Frontiers in Psychology, 10(201), 1-13. https://doi.org/10.3389/fpsyg.2019.00201

McLean, S., Salmon, P. M., Gorman, A. D., Read, G. J. M., \& Solomon, C. (2017). What's in a game? A systems approach to enhancing performance analysis in football. PLOS ONE, 12(2), 1-16. https://doi.org/10.1371/journal.pone.0172565

Mears, S. A., Dickinson, K., Bergin-Taylor, K., Dee, R., Kay, J., \& James, L. J. (2018). Perception of Breakfast Ingestion Enhances High-Intensity Cycling Performance. International Journal of Sports Physiology \& Performance, 13(4), 504-509. http://search.ebscohost.com/login.aspx?direct=true\&db=s3h\&AN=129945783\&site=eho st-live

Middlemas, S. G., Croft, H. G., \& Watson, F. (2018). Behind closed doors: The role of debriefing and feedback in a professional rugby team. International Journal of Sports Science and Coaching, 13(2), 201-212. https://doi.org/10.1177/1747954117739548

Monteiro, D., Teixeira, D. S., Travassos, B., Duarte-Mendes, P., Moutão, J., Machado, S., \& Cid L. (2018). Perceived effort in football athletes: The role of achievement goal theory and self-determination theory. Frontiers in Psychology, 9(1575), 1-13. https://doi.org/10.3389/fpsyg.2018.01575

Mooney, R., Corley, G., Godfrey, A., Osborough, C., Newell, J., Quinlan, L. R., \& ÓLaighin, G. (2016). Analysis of swimming performance: perceptions and practices of US-based swimming coaches. Journal of Sports Sciences, 34(11), 997-1005. http://search.ebscohost.com/login.aspx?direct=true\&db=s3h\&AN=113738933\&site=eho st-live

Mooney, R., Corley, G., Godfrey, A., Osborough, C., Quinlan, L. R., \& ÓLaighin, G. (2015). Application of Video-Based Methods for Competitive Swimming Analysis: A Systematic Review. Sports and Exercise Medicine - Open Journal, 1(5), 133-150. https://doi.org/10.17140/semoj-1-121

Naikar, N., \& Sanderson, P. M. (1999). Work domain analysis for training-system definition and acquisition. International Journal of Aviation Psychology, 9(3), 271-290. https://doi.org/10.1207/s15327108ijap0903_5

Netball New Zealand. (2018a). History: 1960-1990. https://www.netballnz.co.nz/ourgame/history/1960-1990

Netball New Zealand. (2018b). History: 1990-1999. https://www.netballnz.co.nz/ourgame/history/1990-1999

Nicholls, S. B., James, N., Bryant, E., \& Wells, J. (2018). Elite coaches' use and engagement with performance analysis within Olympic and Paralympic sport. International Journal of Performance Analysis in Sport, 18(5), 764-779. 
https://doi.org/10.1080/24748668.2018.1517290

Nicolas, M., Gaudreau, P., \& Franche, V. (2011). Perception of Coaching Behaviors, Coping, and Achievement in a Sport Competition. Journal of Sport \& Exercise Psychology, 33(3), 460-468. http://search.ebscohost.com/login.aspx?direct=true \&db=s3h\&AN=62639968\&site=ehos t-live

Norouzi, E., Norouzi Seyed Hossini, R., Afroozeh, M. S., Vaezmosavi, M., Gerber, M., Puehse, U., \& Brand, S. (2019). Examining the effectiveness of a PETTLEP Imagery intervention on the football skill performance of novice athletes. Journal of Imagery Research in Sport and Physical Activity, 14(1), 30-36. https://doi.org/10.1515/jirspa-2018-0010

O'Donoghue, P. (2006). The use of feedback videos in sport. International Journal of Performance Analysis in Sport, 6(2), 1-14.

https://doi.org/10.1080/24748668.2006.11868368

O'Donoghue, P. (2008). Principal Components Analysis in the selection of Key Performance Indicators in Sport. International Journal of Performance Analysis in Sport, 8(3), 145-155. https://doi.org/10.1080/24748668.2008.11868456

O'Donoghue, P., Mayes, A., Edwards, K. M., \& Garland, J. (2008). Performance Norms for British National Super League Netball. International Journal of Sports Science \& Coaching, 3(4), 501-511. https://doi.org/10.1260/174795408787186486

Ortega, J. I., Evangelio, C., Clemente, F. M., Martins, F. M. L., \& González-Víllora, S. (2016). Analysis of physiological, technical, and tactical analysis during a friendly football match of elite u19. Sports, 4(35), 1-14. https://doi.org/10.3390/sports4020035

Otte, F. W., Davids, K., Millar, S. K., \& Klatt, S. (2020). When and How to Provide Feedback and Instructions to Athletes?-How Sport Psychology and Pedagogy Insights Can Improve Coaching Interventions to Enhance Self-Regulation in Training. Frontiers in Psychology, 11(1444). https://doi.org/10.3389/fpsyg.2020.01444

Page, M. J., Moher, D., Bossuyt, P. M., Boutron, I., Hoffmann, T. C., Mulrow, C. D., Shamseer, L., Tetzlaff, J. M., Akl, E. A., Brennan, S. E., Chou, R., Glanville, J., Grimshaw, J. M., Hróbjartsson, A., Lalu, M. M., Li, T., Loder, E. W., Mayo-Wilson, E., Mcdonald, S., ... Mckenzie, J. E. (2021). PRISMA 2020 explanation and elaboration: Updated guidance and exemplars for reporting systematic reviews. The BMJ, 372 .

https://doi.org/10.1136/bmj.n160

Perry, C., \& Marsh, H. W. (2003). Relations Between Elite Athlete Self-Concept And International Swimming Performance [Conference Presentation]. Joint AARE/NZARE Conference.

Potrac, P., Brewer, C., Jones, R., Armour, K., \& Hoff, J. (2000). Toward an holistic understanding of the coaching process. Quest, 52(2), 186-199. https://doi.org/10.1080/00336297.2000.10491709

Readdy, T., Raabe, J., \& Harding, J. S. (2014). Student-Athletes' Perceptions of an Extrinsic Reward Program: A Mixed-Methods Exploration of Self-Determination Theory in the Context of College Football. Journal of Applied Sport Psychology, 26(2), 157-171. https://doi.org/10.1080/10413200.2013.816801

Reed, J. P., Palmero, M., Sato, K., Hsieh, C.-T., \& Stone, M. (2017). Athlete Perceptions of a 
Monitoring and Strength and Conditioning Program. Sport Journal, 1.

http://search.ebscohost.com/login.aspx?direct=true \&db=s3h\&AN=122316313\&site=eho st-live

Rein, R., \& Memmert, D. (2016). Big data and tactical analysis in elite soccer: future challenges and opportunities for sports science. SpringerPlus, 5(1410). https://doi.org/10.1186/s40064-016-3108-2

Rey, E., Lago-Ballesteros, J., \& Padrón-Cabo, A. (2015). Timing and tactical analysis of player substitutions in the UEFA champions league. International Journal of Performance Analysis in Sport, 15(3), 840-850. https://doi.org/10.1080/24748668.2015.11868835

Ruiz-Tendero, G., \& Martín, J. J. S. (2012). Psycho-social factors determining success in high performance triathlon: Compared perception in the coach-athlete pair. Perceptual and Motor Skills, 115(3), 865-880. https://doi.org/10.2466/08.25.PMS.115.6.865-880

Sarmento, H., Clemente, F. M., Araújo, D., Davids, K., McRobert, A., \& Figueiredo, A. (2018). What Performance Analysts Need to Know About Research Trends in Association Football (2012-2016): A Systematic Review. Sports Medicine, 48(4), 799-836. https://doi.org/10.1007/s40279-017-0836-6

Sarmento, H., Rui, M., Anguera, M. T., Campaniço, J., Matos, N., \& Leitão, J. C. (2014). Match analysis in football: A systematic review. Journal of Spot Sciences, 32(20), 1831-1843. https://doi.org/10.26773/mjssm.190909

Schober, P., \& Schwarte, L. A. (2018). Correlation coefficients: Appropriate use and interpretation. Anesthesia and Analgesia, 126(5), 1763-1768. https://doi.org/10.1213/ANE.0000000000002864

Shigeno, T. C., Lauer, E. E., Wrisberg, C. A., DeLisio, D. C., \& Lin, P. C. (2019). Developing Attentional Control in High School Football: Two Case Studies. Journal of Sport Psychology in Action, 10(2), 82-93. https://doi.org/10.1080/21520704.2018.1518281

Silva, P., Chung, D., Carvalho, T., Cardoso, T., Davids, K., Araújo, D., \& Garganta, J. (2015). Practice effects on intra-team synergies in football teams. Human Movement Science, 46 , 39-51. https://doi.org/10.1016/j.humov.2015.11.017

Smith, P. D., \& Bedford, A. (2020). Automatic Classification of Locomotion in Sport: A Case Study from Elite Netball. International Journal of Computer Science in Sport, 19(2), 1-20. https://doi.org/10.2478/ijcss-2020-0007

Solomon, V., \& Kausar, R. (2017). Perception of Psychological Skills in Pakistani Cricketers: An Exploratory Study. Journal of Behavioural Sciences, 27(2).

Steele, J. R. (1990). Biomechanical Factors Affecting Performance in Netball: Implications for Improving Performance and Injury Reduction. Sports Medicine, 10(2), 88-102. https://doi.org/10.2165/00007256-199010020-00003

Stoker, M., Maynard, I., Butt, J., Hays, K., Lindsay, P., \& Norenberg, D. A. (2017). The Effect of Manipulating Training Demands and Consequences on Experiences of Pressure in Elite Netball. Journal of Applied Sport Psychology, 29(4), 434-448. https://doi.org/10.1080/10413200.2017.1298166

Stuelcken, M. C., Mellifont, D. B., Gorman, A. D., \& Sayers, M. G. L. (2016). Mechanisms of anterior cruciate ligament injuries in elite women's netball: A systematic video analysis. 
Journal of Sports Sciences, 34(16), 1516-1522.

https://doi.org/10.1080/02640414.2015.1121285

Suchomel, T. J., Nimphius, S., \& Stone, M. H. (2016). The Importance of Muscular Strength in Athletic Performance. Sports Medicine, 46, 1419-1449. https://doi.org/10.1007/s40279016-0486-0

Sullivan, P. J., Ragogna, M., \& Dithurbide, L. (2018). An investigation into the Dunning-Kruger effect in sport coaching. International Journal of Sport and Exercise Psychology, 17(6), 591-599. https://doi.org/10.1080/1612197X.2018.1444079

Sykes, E. (2017). Transforming data into insight. Insights: The UKSG Journal, 30(2), 71-77. https://doi.org/10.1629/uksg.363

Theodoropoulos, J. S., Bettle, J., \& Kosy, J. D. (2020). The use of GPS and inertial devices for player monitoring in team sports: A review of current and future applications. Orthopedic Reviews, 12(1), 1-8. https://doi.org/10.4081/or.2020.7863

Thomas, C., Ismail, K. T., Simpson, R., Comfort, P., Jones, P. A., \& Dos'Santos, T. (2019). Physical Profiles of Female Academy Netball Players by Position. Journal of Strength and Conditioning Research, 33(6), 1601-1608.

Usta, Y. Y. (2012). Importance of social support in cancer patients. Asian Pacific Journal of Cancer Prevention, 13(8), 3569-3572. https://doi.org/10.7314/APJCP.2012.13.8.3569

Whitehead, S., Till, K., Weaving, D., \& Jones, B. (2018). The Use of Microtechnology to Quantify the Peak Match Demands of the Football Codes: A Systematic Review. Sports Medicine, 48(11), 2549-2575. https://doi.org/10.1007/s40279-018-0965-6

Wood, G., Jordet, G., \& Wilson, M. R. (2015). On winning the "lottery": psychological preparation for football penalty shoot-outs. Journal of Sports Sciences, 33(17), 17581765. https://doi.org/10.1080/02640414.2015.1012103

Yamada, M., \& Raisbeck, L. D. (2021). The Effects of Attentional Focus Instructions Specific to Body Movements on Movement Quality and Performance. Journal of Sport Rehabilitation, 30(3), 422-429. https://doi.org/10.1123/JSR.2019-0344

Young, C. M., Gastin, P. B., Sanders, N., Mackey, L., \& Dwyer, D. B. (2016). Player load in elite netball: Match, training, and positional comparisons. International Journal of Sports Physiology and Performance, 11(8), 1074-1079. https://doi.org/10.1123/ijspp.2015-0156

Zubac, D., Stella, A. B., \& Morrison, S. A. (2020). Up in the air: Evidence of dehydration risk and long-haul flight on athletic performance. Nutrients, 12(9), 1-15.

https://doi.org/10.3390/nu12092574 


\section{Appendices}

\section{Appendix A - Ethics Approval Letter}

19 March 2020

Names: Codi Ramsey

Hayden Croft

Dear Researchers

Re: Application for Ethics Consent

Reference Number: 850

Application Title: Athletes perceptions of performance

Thank you for your application for ethics approval for this research project.

Only one issue regarding the potential survey and interview questions was raised in the review process.

Accordingly, approval is granted for the project contingent on the Ethics committee being advised if there is a substantive change to potential interview questions provided on $\mathrm{p}$. 17, or to the survey or interview procedures employed within the project's approval time period (three years).

We wish you well with your work and remind you that at the conclusion of your research to send a brief report with findings and/or conclusions to the Ethics Committee.

All correspondence regarding this application should include the project title and reference number assigned to it.

Yours sincerely,

Professor Liz Ditzel (PhD)

Chair, Otago Polytechnic Research Ethics Committee

\begin{tabular}{llcc}
\hline Otago Polytechnic & Forth Street & Freephone 0800 762 786 & Email: info@op.ac.nz \\
& Private Bag 1910 & Phone +64 3 477 3014 & www.op.ac.nz \\
& Dunedin 9054 & &
\end{tabular}




\section{Appendix B - Player Information - Qualtrics Survey Flow}

IS Project title: Athletes perceptions of performance

General Introduction: It is well-understood that sport is a complex activity in which the team performance outcomes can be influenced by athlete perceptions and behaviours. Performance analysts provide the coaching staff and players with objective information about individual and team performances before, during and after a game or match. However, there is some speculation about the usefulness of statistics in improving individual player performance. There is currently little known about the athletes perceptions of performance without knowing their individual statistics and what influencing factors exist.

What is the aim of the project? This project aims to explore athlete's perceptions toward performance through two research questions:

1. How do athletes perceive their performance without feedback (I.e. game/match analytics)?

2. What factors influence athletes' perceptions/attitudes of individual performance?

How will potential participants be identified and accessed? Interested participants who are female, between the age of 18 and 40, and netball players within an ANZ Premiership franchise in 2020, can email for further information.

What will my participation involve? Should you agree to take part in this project, you will be asked to:

- Provide a rating (via questionnaire) of my performance for a variety of variables after a game

- Not view individual analytics prior to completing the rating questionnaire

- Provide consent for access to game/match performance data (video and/or statistical) if necessary.

- Participate in an interview (up to 60 minutes) or a focus group (up to 90 minutes) exploring factors influencing my perceptions of performance.

How will confidentiality and/or anonymity be protected? The Privacy Act of 1993 and the applicable codes of practice will be adhered to, ensuring the confidentiality and anonymity (when appropriate) of all participants and their data.

What data or information will be collected and how will it be used? Your perceptions of performance (via surveys) will be collected and compared with recorded performance data (statistical) to provide information about effective/ineffective performance practices. Results 
of this project may be published but any data included will in no way be linked to any specific participant without prior consent.

Data Storage: The data collected will be securely stored so that only named researchers will have access to it. This will be retained in secure storage for a period of seven years, after which it will be destroyed (unless agreed otherwise on the consent form).

Can participants change their minds and withdraw from the project? You can decline to participate without any disadvantage to yourself of any kind. If you choose to participate, you may withdraw from the project at any time, without giving reasons for your withdrawal. You can also withdraw any information that has already been supplied, until the stage agreed on the consent form. You have the right to refuse to undergo any related protocol. Shall you participate in interviews or focus groups, you can also refuse to answer any particular question, and/or ask for the audio/video to be turned off at any stage.

What if participants have any questions? If you have any questions about the project, either now or in the future, please feel free to contact either:

Any additional information given, or conditions agreed to will be noted on the consent form.

I have read and understand the above information, and am willing to participate in this study (1)

I am unwilling to participate in this study (2) 


\section{Start of Block: Block 7}

CF I have read the information sheet concerning this project and understand what it is about. All my questions have been answered to my satisfaction. I understand that I am free to request further information at any stage.

I know that:

- Data from this project will not be used to inform player selection (i.e. national teams) and/or playing time on my current team.

- My participation in the project is entirely voluntary and I am free to refuse to participate in any component of this research

- I am free to stop participating at any time

- I can choose to withdraw information provided without giving reasons and without any disadvantage

- Shall I participate in interviews or focus groups, I can refuse to answer any particular question, and/or ask for the audio/video to be turned off at any stage.

- My data will be destroyed at the conclusion of the project but any raw data on which the results of the project depend will be retained in secure storage for seven years after which it will be destroyed. If it is to be kept longer than seven years, my permission will be sought.

- The results of the project may be published and/or used at a presentation in an academic conference, but my anonymity / confidentiality will be preserved.

- I can ask to receive a copy of the research findings.

By signing below I agree to take part in this project under the conditions set out in the Information Sheet.

This project has been reviewed and approved by OPREC 
Q1 Please record your full name

Q2 Please select your date of birth

\begin{tabular}{c|cc} 
& & \\
Month (1) & $\boldsymbol{\nabla}$ January (1) ... & (150) \\
Day (2) & $\boldsymbol{\nabla}$ January (1) ... & (150) \\
Year (3) & $\boldsymbol{\nabla}$ January (1) ... & (150)
\end{tabular}

Q3 Please record your height in centimetres below

Q4 Please record your weight in kilograms below

Q5 How many years have you been a player in a high performance netball environment (ANZ Premiership or equivalent)?

\section{0-1 (1)}

1-3 (2)

3-5 (3)

5 or more (4) 
Q6 Please indicate your highest level of netball participation in the last year

National team (ie. Silver Ferns) (1)

National Age Group Squad (2)

National Development Squad (3)

ANZ Premiership (4)

Other (5)

Q7 Please indicate your highest ever level of netball participation

National Team (ie. Silver Ferns) (1)

National Age Group Squad (2)

National Development Squad (3)

ANZ Premiership (4)

Other (5)

Q8 What year was your highest level of netball participation? 
Q9 What positional group/s do you play within? (Select all relevant)

Shooting (1)

Mid-Court (2)

Defenders (3) 
Q10 Shooting - Please rate the level of difficulty for the performance tasks below

\begin{tabular}{|c|c|c|c|c|c|c|c|}
\hline & $\begin{array}{c}\text { Extremely } \\
\text { easy (1) }\end{array}$ & $\begin{array}{l}\text { Moderately } \\
\text { easy ( } 2 \text { ) }\end{array}$ & $\begin{array}{l}\text { Slightly } \\
\text { easy (3) }\end{array}$ & $\begin{array}{l}\text { Neither } \\
\text { easy } \\
\text { nor } \\
\text { difficult } \\
\text { (4) }\end{array}$ & $\begin{array}{l}\text { Slightly } \\
\text { difficult } \\
\text { (5) }\end{array}$ & $\begin{array}{l}\text { Moderately } \\
\text { difficult (6) }\end{array}$ & $\begin{array}{c}\text { Extremely } \\
\text { difficult } \\
\text { (7) }\end{array}$ \\
\hline $\begin{array}{l}\text { Shooting } \\
\text { (1) }\end{array}$ & 0 & & & & & ) & 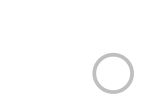 \\
\hline $\begin{array}{l}\text { Rebounding } \\
\text { (2) }\end{array}$ & O & $\mathcal{U}$ & 0 & $c$ & & 0 & 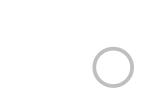 \\
\hline Feeding (3) & 0 & 0 & & $\cap$ & & & C \\
\hline $\begin{array}{l}\text { Ball } \\
\text { retention } \\
\text { (4) }\end{array}$ & & & & & & & \\
\hline
\end{tabular}


Q11 Mid-court - Please rate the level of difficulty for the performance tasks below

$\begin{array}{ccccccc}\text { Extremely } & \text { Moderately } & \text { Slightly } & \begin{array}{c}\text { Neither } \\ \text { easy nor }\end{array} & \begin{array}{c}\text { Slightly } \\ \text { difficult }\end{array} & \text { Moderately } & \text { Extremely } \\ \text { easy (1) } & \text { easy (2) } & \text { easy (3) } & \text { difficult } & \text { (ifficult (6) } & \text { (7) }\end{array}$

$\begin{gathered}\text { Feeding } \\ \text { (1) }\end{gathered}$
$\begin{gathered}\text { Centre } \\ \text { Pass } \\ \text { Receives } \\ \text { (2) }\end{gathered}$
$\begin{gathered}\text { Gains (3) } \\ \text { Intercepts } \\ \text { (4) }\end{gathered}$
$\begin{gathered}\text { Pickups } \\ \text { (5) }\end{gathered}$
$\begin{gathered}\text { Deflection } \\ \text { with Gain } \\ \text { (6) }\end{gathered}$


Q12 Defence - Please rate the level of difficulty for the performance tasks below

\begin{tabular}{ccccccc}
\multicolumn{9}{c}{ Neither } \\
Extremely & Moderately & Slightly & easy & Slightly & Moderately & Extremely \\
easy (1) & easy (2) & easy (3) & nor & difficult & difficult \\
& & & difficult & (5) & dicult (6) & (7)
\end{tabular}

(4)

\begin{abstract}
Rebounding
(1)

Intercepts

(3)

Pickups (4)

Deflections

with Gain

(5)

Deflections

no Gain (6)

Ball

Retention

(7)
\end{abstract}

\title{
End of Block: Block 6
}

\section{Start of Block: OSTRC}

Q13

Please answer all questions below, regardless of whether or not you have had any problems over the past week. Select the most appropriate response for you.

The term "problem" refers to any stiffness, aches, pains, swelling, instability, locking or any other complaints in relation to your body. 
Q14

Please label all areas you have experienced problems over the past week.

Off (1)

On (2)

Posterior Neck (1)

Head (2)

Abdominals/Digestion (3)

Shoulders (4)

Back (5)

Front Ankle (6)

Top of foot and toes (7)

Calves (8)

Hamstrings (9)

Glutes (10)

Quadriceps (11)

Knees (12)

Shins (13)

Wrist (14)

Wrist (15)

Arm (16)

Arm (17)

Chest (18)

Back of ankle (19)

Bottom of foot (20)

Hand/Fingers (21)

Hand/fingers (22)

Left Elbow (23)

Right Elbow (24)

Back of head (25) 

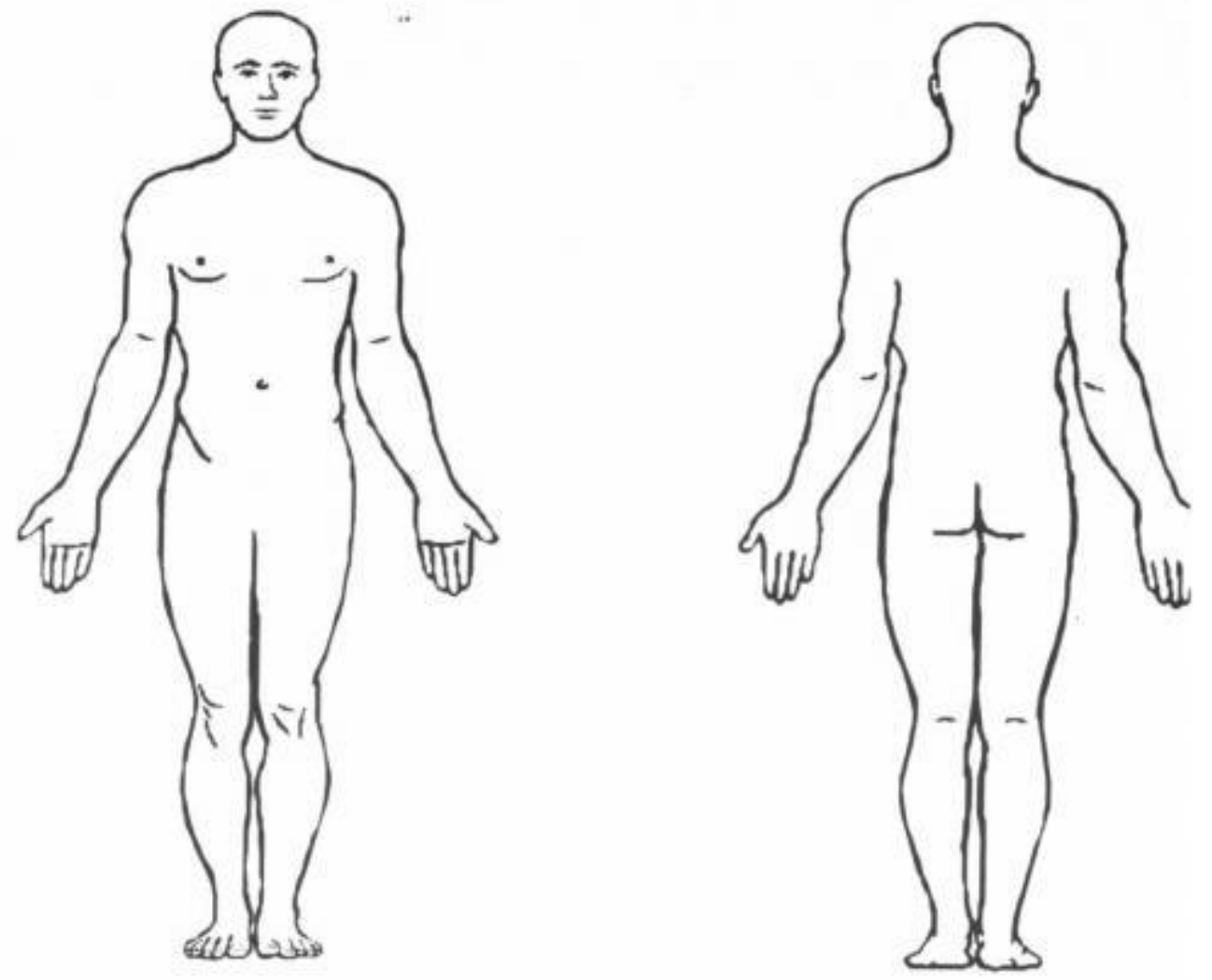

Q15 Choose the main problem from above to answer the below questions. 
Q16

Have you had any difficulties participating in normal training and competition due to the above problem during the past week?

Full participation with no issues (1)

Full participation but with issues (2)

Reduced participation due to issues (3)

Cannot participate due to issues (4)

Q17 To what extent have you reduced your training volume due to the above problem during the past week?

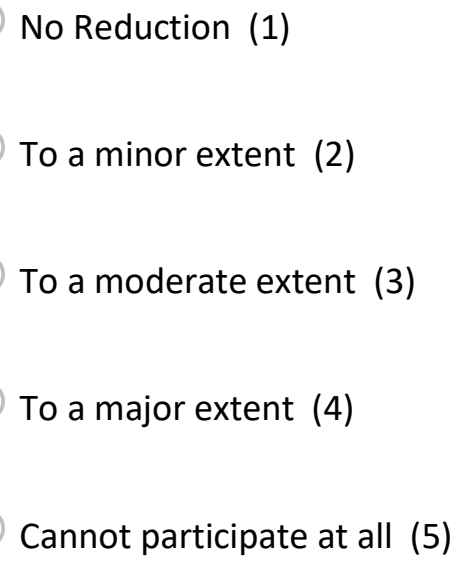


Q18 To what extent has the above problem affected your performance during the last week?

No affect (1)

To a minor extent (2)

To a moderate extent (3)

To a major extent (4)

Cannot participate at all (5)

Q19 To what extent have you experienced the above problem in relation to Netball this week?

No affect (1)

To a minor extent (2)

To a moderate extent (3)

To a major extent (4)

Cannot participate at all (5) 
Appendix C - Match Perceptions - Qualtrics Survey Flow

\section{Start of Block: Player Questions}

Q1 Please select your Participant ID from the drop down list below

$1106(24) \ldots 1132$ (34)

Q2 What position did you play for the longest period today (minimum 12 minutes)?
GS (1)
GA (2)
WA (3)
C (4)
WD (5)
GD (6)
GK (7)

Q3

Have you been made aware of any match statistics from this game (other than the score) before completing this survey?

Definitely yes (1)

Might or might not (2)

Definitely no (3) 
3.1 What individual statistics were you made aware of?

Shooting Statistics (1)

Turnover Statistics (2)

Centre Pass Statistics (3)

Passing Statistics (4)

Penalty Statistics (5)

Possession statistics (6)

Other (please specify) (7)

3.2 Who informed you of these statistics? (ie. analyst, interviewer, coach)

End of Block: Block 5

Start of Block: Block 9

Q27 Please answer the following questions based on your perception of your performance

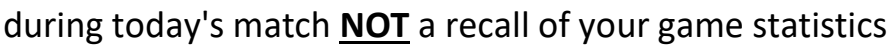


Q4 Shooting - Please indicate your perception of your performance of the following tasks during today's match?

Poor

Excellent

0

100

\begin{tabular}{r|r}
\hline Goals Scored () \\
\hline Goals Attempted () \\
\hline Rebounds () \\
Goal Assists () \\
\hline Possession Lost ()
\end{tabular}


Q4 Shooting - Please indicate your perception of your performance of the following tasks during today's match?

Poor

0
Excellent

100

\begin{tabular}{r|r|r|}
\hline Goals Scored () \\
\hline Goals Attempted () \\
Rebounds () \\
Feeds () \\
\hline Goal Assists () \\
\hline Centre Pass Receives () \\
\hline Possession Lost () \\
\hline
\end{tabular}


Q4 Mid-court - Please indicate your perception of your performance of the following tasks during today's match?

$$
\text { Poor }
$$

Excellent

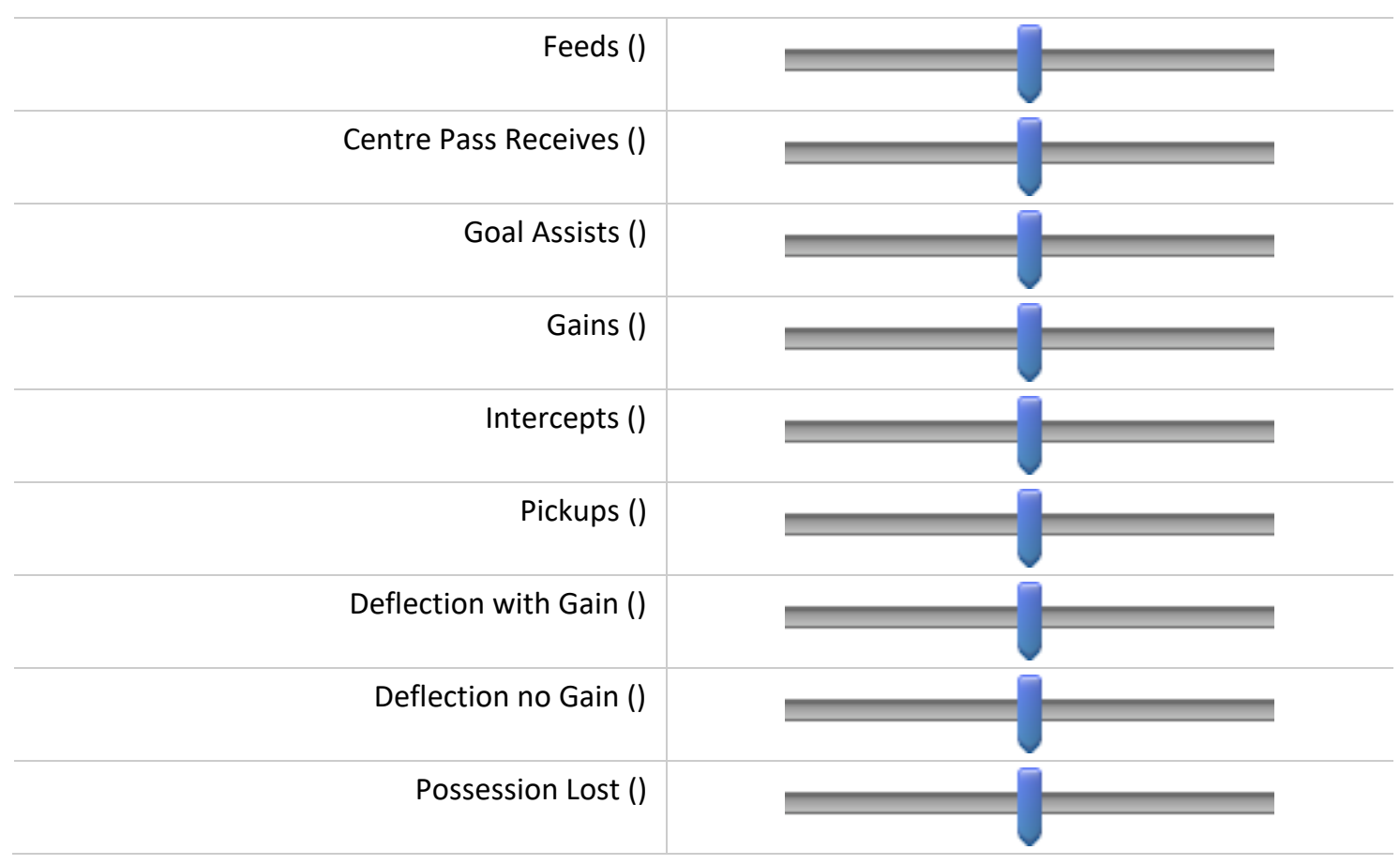


Q4 Mid-court - Please indicate your perception of your performance of the following tasks during today's match?

Poor

Excellent

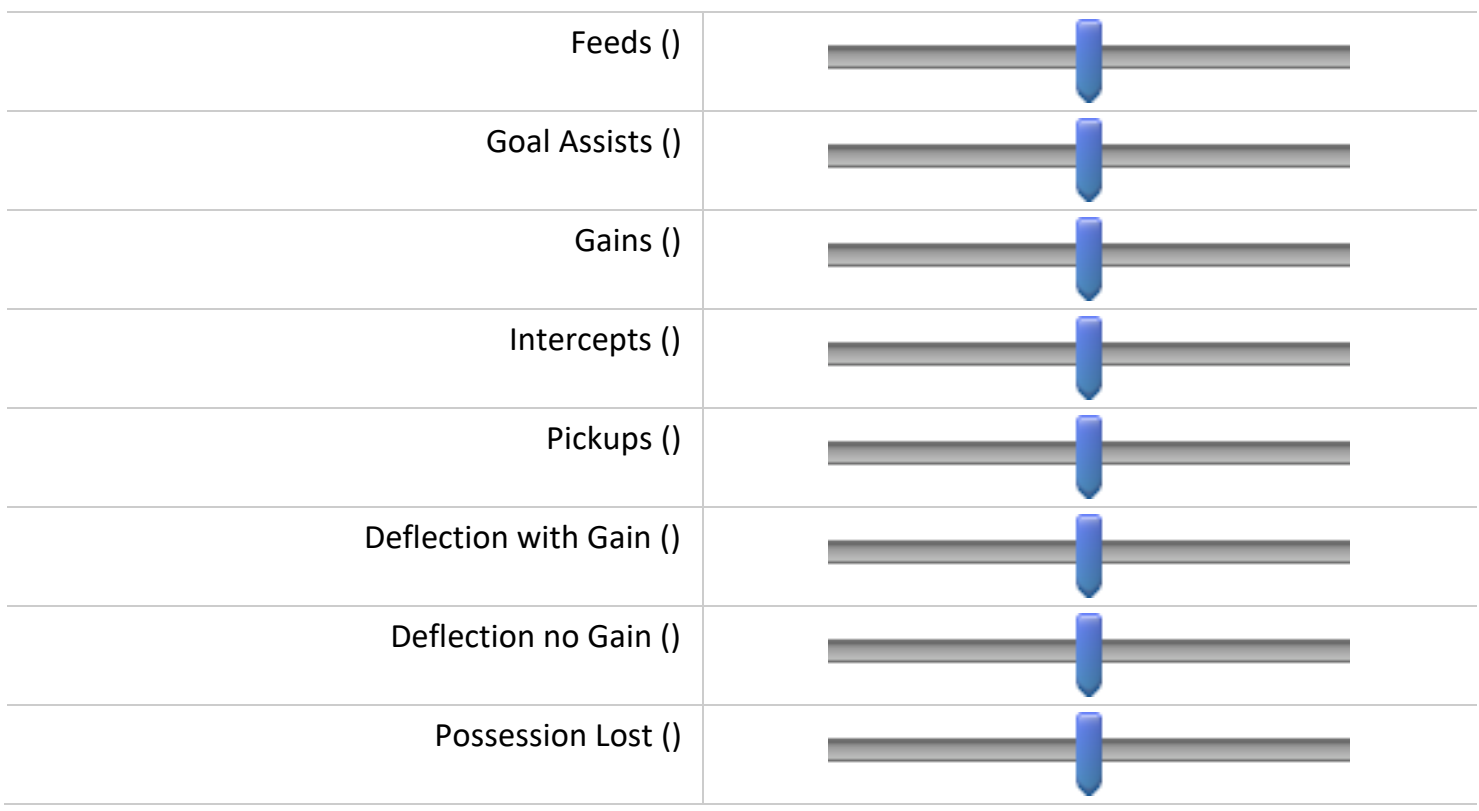


Q4 Defence - Please indicate your perception of your performance of the following tasks during today's match?

Poor

Excellent

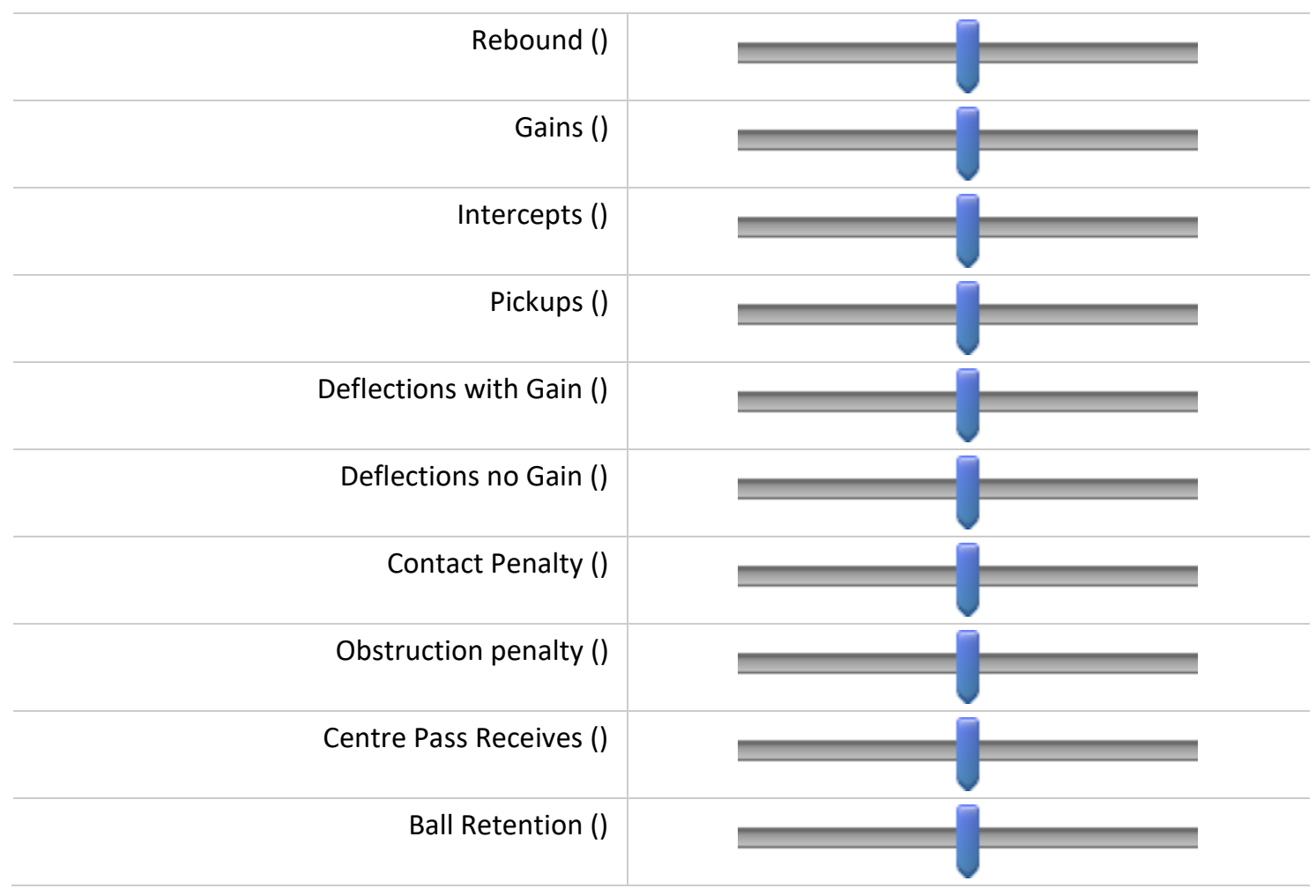


Q4 Defence - Please indicate your perception of your performance of the following tasks during today's match?

Poor

Excellent

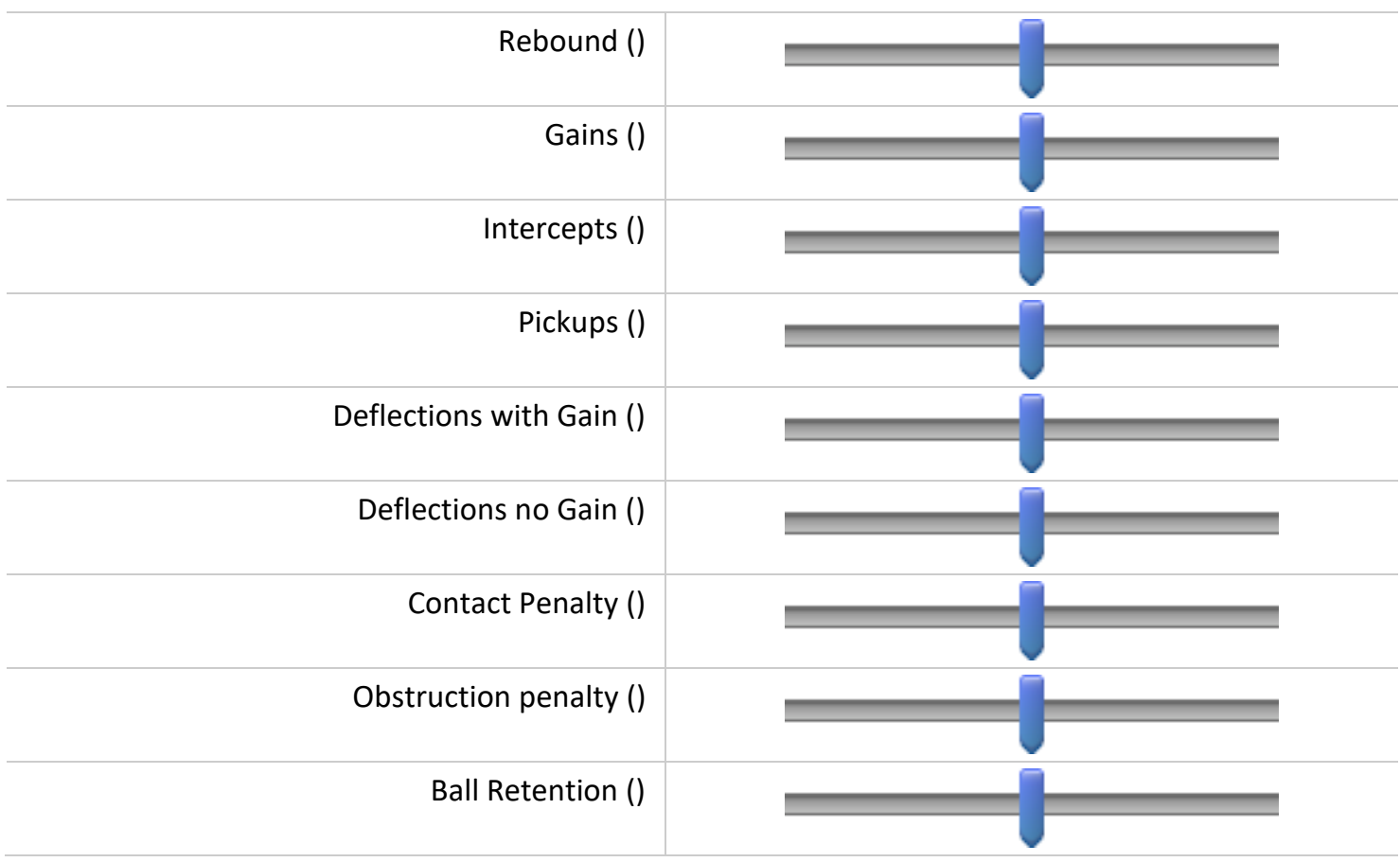

\section{Start of Block: Block 1}

Info

Please answer all questions below, regardless of whether or not you have had any problems over the past week. Select the most appropriate response for you. 
The term "problem" refers to any stiffness, aches, pains, swelling, instability, locking or any other complaints in relation to your body.

Q5

Please label all areas you have experienced problems over the past week.

Off (1) On (2)

\author{
Posterior Neck (1) \\ Head (2) \\ Abdominals/Digestion (3) \\ Shoulders (4) \\ Back (5) \\ Front Ankle (6) \\ Top of foot and toes (7) \\ Calves (8)
}

Hamstrings (9)

Glutes (10)

Quadriceps (11)

Knees (12)

Shins (13)

Wrist (14)

Wrist (15)

Arm (16)

Arm (17)

Chest (18)

Back of ankle (19)

Bottom of foot (20)

Hand/Fingers (21)

Hand/fingers (22)

Left Elbow (23)

Right Elbow (24)

Back of head (25) 

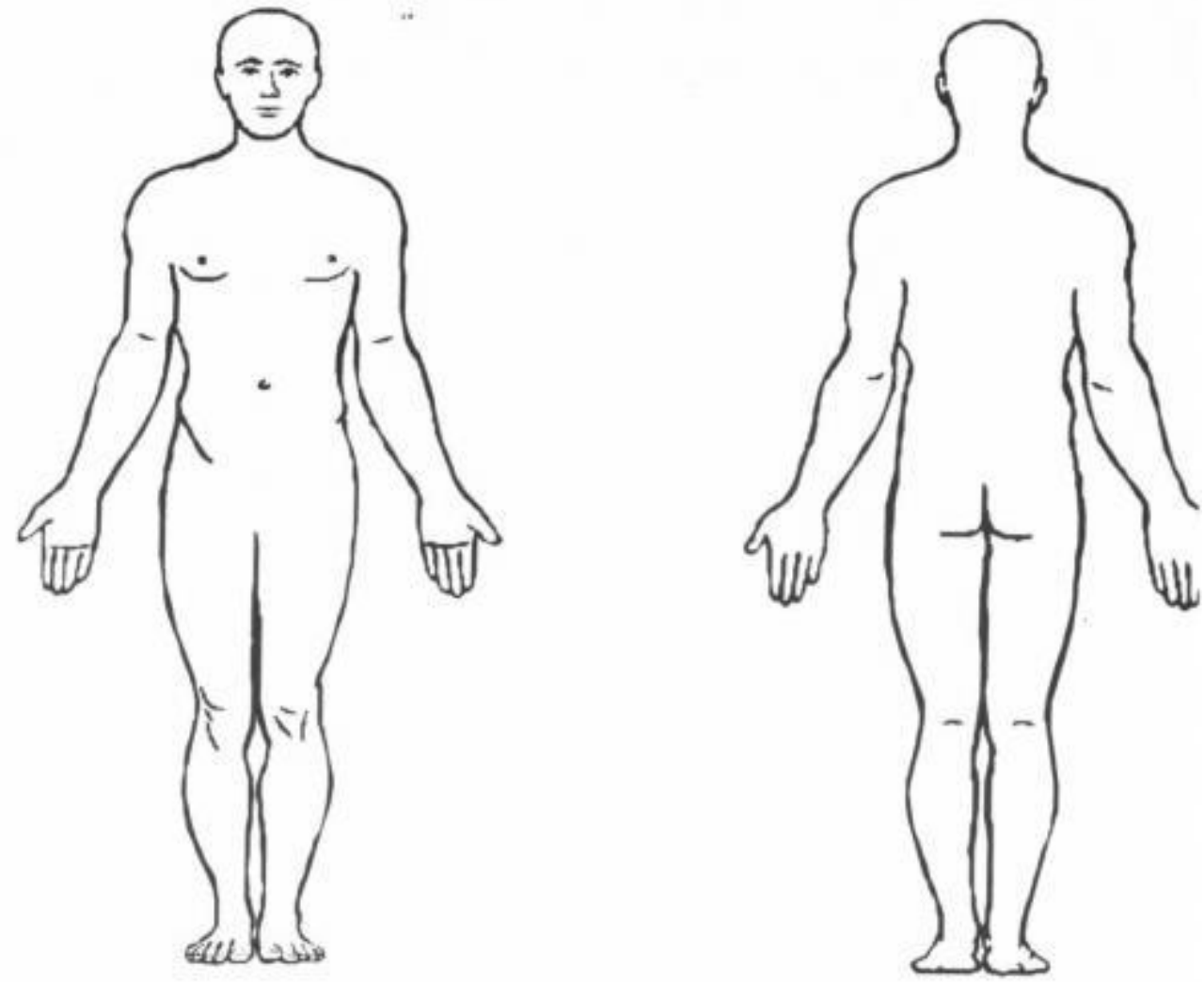

Info Choose the main problem from above to answer the below questions.

Q6

Have you had any difficulties participating in normal training and competition due to the above problem during the past week?

Full participation with no issues (1)

Full participation but with issues (2)

Reduced participation due to issues (3)

Cannot participate due to issues (4) 
Q7 To what extent have you reduced your training volume due to the above problem during the past week?

No Reduction (1)

To a minor extent (2)

To a moderate extent (3)

To a major extent (4)

Cannot participate at all (5)

Q8 To what extent has the above problem affected your performance during the last week?

No affect (1)

To a minor extent (2)

To a moderate extent (3)

To a major extent (4)

Cannot participate at all (5)

Q9 To what extent have you experienced the above problem in relation to Netball this week?

No affect (1)

To a minor extent (2)

To a moderate extent (3)

To a major extent (4) 


\begin{tabular}{|c|c|}
\hline Variable & Definition \\
\hline Goals Scored & This is when a Goal Attack or Goal Shooter scores a goal. \\
\hline Goals Attempted & $\begin{array}{l}\text { The total number of shots taken by the Goal Attack or Goal } \\
\text { Shooter }\end{array}$ \\
\hline Rebounds & $\begin{array}{l}\text { When a Goal Attack or Goal Shooter regathers the ball after an } \\
\text { unsuccessful attempt at goal by her or her team-mate } \\
\text { OR } \\
\text { When a Goal Defence or Goal Keeper regathers the ball after an } \\
\text { unsuccessful attempt at goal by the opposition }\end{array}$ \\
\hline Feeds & $\begin{array}{l}\text { This is the player who passes the ball from either outside or } \\
\text { inside the goal circle to a Goal Attack or Goal Shooter in the } \\
\text { goal circle in a goal scoring position }\end{array}$ \\
\hline Goal Assists & $\begin{array}{l}\text { This is the player that feeds the ball to the Goal Attack or Goal } \\
\text { Shooter prior to a goal being scored }\end{array}$ \\
\hline Centre Pass Receives & $\begin{array}{l}\text { This is the player (team in possession) who receives the ball } \\
\text { from the centre pass. }\end{array}$ \\
\hline Gains & $\begin{array}{l}\text { This is when an opposition player gets the ball through a great } \\
\text { individual effort. The player who originally had possession } \\
\text { before the gain was deemed to be not at fault. Gains are the } \\
\text { sum of 'Intercept', 'Deflection' then throw in by Opposition, } \\
\text { 'Deflection' then 'Pick up by Opposition', 'Toss Up Won' and } \\
\text { 'Defensive Rebound'. }\end{array}$ \\
\hline Intercepts & $\begin{array}{l}\text { When a player from the team without possession of the ball } \\
\text { creates the opportunity and takes possession via a catch or a } \\
\text { deliberate deflection and a pickup by themselves from an } \\
\text { opposition pass }\end{array}$ \\
\hline Pick Ups & $\begin{array}{l}\text { When a player from either team secures possession of a loose } \\
\text { ball }\end{array}$ \\
\hline Deflection & $\begin{array}{l}\text { When an opposition player touches the ball and changes the } \\
\text { course or motion or speed of the ball but does not initially gain } \\
\text { control of the ball. }\end{array}$ \\
\hline Deflection with Gain & $\begin{array}{l}\text { A deflection that results in a team gaining possession via a } \\
\text { subsequent 'Pickup' by their team which means a Gain is } \\
\text { recorded. }\end{array}$ \\
\hline Deflection no Gain & A deflection that does not result in a Gain for their team. \\
\hline Contact Penalty & $\begin{array}{l}\text { Taken from the umpire's whistle when they call a contact (a } \\
\text { player makes physical contact and disrupts play). }\end{array}$ \\
\hline Obstruction penalty & $\begin{array}{l}\text { Taken from the umpire's whistle when they call an obstruction } \\
\text { (a player obstructs play by standing within } 0.9 \mathrm{~m} / 3 \text { feet of the } \\
\text { opposing player). }\end{array}$ \\
\hline Possession Lost & $\begin{array}{l}\text { Possession changes teams within general play such as 'Bad } \\
\text { Catch/Hands', 'Bad Pass', 'Break', 'Held', 'Offside', 'Over a } \\
\text { Third', 'Intercept Pass Thrown', 'Replay', 'Short Pass', 'Step', } \\
\text { 'Turnovers via a deflection', 'Penalty while in possession' and } \\
\text { 'Turnover Other }\end{array}$ \\
\hline
\end{tabular}

Note. Reproduced with permission from Champion Data (Southbank Victoria, Aus. 2019) 
Appendix E - Email chain detailing permission from Champion Data for reproduction and use of definitions

\section{Hayden Croft}

to

Hi Sam and Christian

One of our students Brianna Ellis has been performing her masters using the same operational definitions for certain statistics as ChampionD. Are you happy for her to cite and quote these in her thesis?

Brie, cc'ed Sam (NZ) and Christian (Aus/head office) are your key contacts for this.

Warm regards Hayden

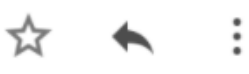

Wed, Oct 7, 2020, 11:18 PM 
to

Hi Brie,

At this stage, we don't need you to sign a formal research agreement. However we do ask that you obviously reference us where required and if we could get sent a copy of your thesis (or at the very least the parts that will appear in any journals).

If there is anything we can help you with, please let me know.

Good luck

Regards

Christian 